\title{
A Review of Concepts, Benefits, and Challenges for Future Electrical Propulsion-Based Aircraft
}

\author{
Smruti Sahoo * (D), Xin Zhao and Konstantinos Kyprianidis \\ Future Energy Center, School of Business, Society and Engineering, Mälardalen University, \\ SE72219 Västerås, Sweden; xin.zhao@chalmers.se (X.Z.); konstantinos.kyprianidis@mdh.se (K.K.) \\ * Correspondence: smruti.sahoo@mdh.se; Tel.: +46-736621602
}

Received: 28 January 2020; Accepted: 28 March 2020; Published: 13 April 2020

\begin{abstract}
Electrification of the propulsion system has opened the door to a new paradigm of propulsion system configurations and novel aircraft designs, which was never envisioned before. Despite lofty promises, the concept must overcome the design and sizing challenges to make it realizable. A suitable modeling framework is desired in order to explore the design space at the conceptual level. A greater investment in enabling technologies, and infrastructural developments, is expected to facilitate its successful application in the market. In this review paper, several scholarly articles were surveyed to get an insight into the current landscape of research endeavors and the formulated derivations related to electric aircraft developments. The barriers and the needed future technological development paths are discussed. The paper also includes detailed assessments of the implications and other needs pertaining to future technology, regulation, certification, and infrastructure developments, in order to make the next generation electric aircraft operation commercially worthy.
\end{abstract}

Keywords: electric aircraft; hybrid electric configuration; electric aircraft sizing; conceptual design; electrical powertrain; energy storage; multidisciplinary optimization; electrical machine; electrical grid architecture; distributed electric propulsion; boundary layer ingestion; thermal management system

\section{Introduction}

The aviation sector has evolved significantly with the improvements in propulsion system technology to deal with air-traffic demand growth and surges in fuel prices in an environmentally and economically sustainable manner. Despite being in existence for several decades, the sector has yet to achieve its full growth potential and market reach; as per the projections made by Airbus and Boeing, it is anticipated to grow at a rate of $4.8 \%$ annually in the coming years [1,2]. However, the prospective of efficiency improvement with evolutionary approaches are already reaching a plateau [3]. This implies that a radical change in technological lateral thinking is needed to address the environmental impacts.

To curb the impact worldwide, many regulations are set forth, outlining the emission reduction standards. In Europe, the guidelines are set by the European Commission in association with the Advisory Council of Aviation Research (ACARE), under Vision 2020, later through Flightpath 2050 and the corresponding strategic research and innovation agenda [4,5]. Environmentally Responsible Aviation N+ series programs sponsored by the National Aeronautics and Space Administration (NASA) lead the guidelines and performance goals for the civil aviation industry in the USA [6]. The key aspect of these goals is to make the fleet operation more energy-efficient, reliable, and to reduce the emission and community noise related impacts. Many technology paths are being explored for improvements in the airframe and structural designs, in the propulsion system, and of the air-traffic management system to achieve the espoused targets. However, it is believed that the improvements made from evolutionary development of conventional technology alone would fall short of meeting such targets $[3,7]$. This has 
steered the research towards transformative engine and aircraft design developments, beyond the current trend.

Contemporary thinking is aligned towards the use of more electric power in propulsion system. Electrification of the propulsion system offers promising avenues to make the operation more energy-efficient, less polluting, and quieter $[8,9]$. Supplementing with electrical energy sources gives the opportunity for optimizing the engine performance which is otherwise constrained in a thermo-aero-mechanical conventional design. The electrical technology is also endowed with many unique characteristics which could be leveraged to get the benefits from novel propulsion concepts such as distributed propulsion (DP), boundary layer ingestion (BLI), differential thrust control, blown wing, etc. It also enables many radical changes in the aircraft designs with improved aero-propulsion efficiency, stemming from the flexibility of placing the propulsors across the airframe. The afore-mentioned multi-faceted benefits make the electric propulsion (EP) concept-based designs a major cornerstone of future aviation development and generate interest among the researchers to explore the design space in the commercial sector.

The viability of an electric aircraft is associated with reduction potential in fuel/energy consumption, emission, noise, and operational costs. In several aircraft designs with novel airframe morphologies, disruptive propulsion concepts are established to reap the all-round benefits. While the concept is promising from many aspects, it entails inclusion of several additional components and losses in the existing system. The successful implementation the concept would be in achieving net level benefits overcoming all the odds of system losses, components' associated weight penalty, and design complexity.

The benefits are established based on anticipation of the technology matureness in future time horizon, which makes these concepts very futuristic. Conversely it can be stated that aircraft designs can be tailored to reap extended benefits from such concepts. To that end, significant efforts are underway in benchmarking the technology enablers and identifying the path to progress towards its commercial implementation. It is also equally complex and challenging to identify an efficient, viable design without compromising the safety and reliability criteria, under the aircraft top-level operational requirements. Moreover, introduction of these disruptive concepts impart impact on the aircraft designing and operational procedures. The modeling environment used to-date by the industry is not natively capable of capturing all the multidisciplinary aspects of the electrical propulsion system-based aircraft. Furthermore, the aviation sector lacks comprehensive knowledge for designing of such novel aircrafts.

Based on the available statistics on US commercial aviation operation, single-aisle aircraft operation contributes to $50 \%$ of fuel consumption which makes it intriguing to investigate the electric propulsion design application in that particular sector [10]. The inferior performance in the electrical energy storage technologies limits the current application of the electric propulsion system to the smaller aircraft segment. However, as the technology progresses, it is envisaged that it would scale-up to a larger passenger segment. With that in mind, a bigger research focus is diverted to the narrow-body segment; notable are NASA supported projects and projects under clean sky framework in Europe. While the future commercial operation of the electric aircraft is still up for debate on multiple fronts, preliminary assessment of the benefits showed sufficiently promising results for further exploration in this field. It is also envisioned that 15-20 years from now, there will be adequate market pull for electrical aircraft to fly in the short and medium range aircraft applications.

The industry knowledge-base is evolving with the gained insights from the ground-breaking progress in the research and prototype designs. The potential benefits and challenges of an electric aircraft concept has been a topic of discussion in much of the literature [8,9]. Jansen et al. [11] and Bowman et al. [12] presented an overview of the NASA supported conceptual designs. Gnadt et al. [13] presented a list of seventy fully electric aircraft designs, conceptualized in the past. Brelje et al. [14] offered a broad overview on the impacts of the electric propulsion system on the aircraft sizing process and emphasized on the need for a multidisciplinary optimization framework. Alongside, a survey on conceptual design system studies, and prototype designs were presented. Little attention has been paid, however, to the many developments 
that have taken place in Europe. A significant number of worthy articles have been published in the recent time that provide matured insight into electrical aircraft suitability and its market potential. This paper intends to generate a consolidated overview of hybrid electric propulsion concepts measured on fuel efficiency improvement, operating cost, noise, and emission reduction potential alongside the implementational challenges. In addition, technology development approaches, safety, reliability issues, fault-analysis strategies, ground infrastructure requirements, and regulatory and certification barriers are also mentioned to bring a completeness to the entire operation. The remainder of the paper is structured in four sections. In the Section 2, an overview of the electric propulsion concepts, their categorization, benefits, and the implementational challenges are briefed. Section 3 lists the conceptual and demonstrator designs system studies with a reflection on the potential opportunities for meeting the environmental goals. Section 4 summarizes the technology and research developments across industries and research institutions towards a future electrical aviation sector. The final section presents the authors' views towards future directions of electric aircraft developments.

\section{Electric Propulsion System: Concepts, Benefits, and Challenges}

The history of electric aircraft dates back to 1972, when a manned electric aircraft was flown, propelled by a nickel cadmium (Ni-Cd) battery on-board. Due to the dismal low energy density of the battery and performance in the electrical components, the concept could not take off then. Boosted by electrical component technology advancements in recent times and the enduring desire to make flight operations more reliable, safer, and efficient, the electrical technology was re-introduced in the aviation sector in the late 1980s. The concept dubbed "Fly by Wire", found in A320 and later in Boeing 777, was meant to replace part of the pneumatic and hydraulic system with electrical drives. Subsequently, the electric application was extended for use in the flight control, environmental control, engine starter/generator system, landing system, fuel pump, and for the avionics. Recognized under more electric aircraft (MEA) applications, some or all of these features can be found in Boeing 787, A380 [15]. This step-by-step growth under MEA has increased the electrical system installed capacity and the demand for advanced power electronic designs with a better heat management system. As a step further towards greener future aviation, and with an influence from the ongoing electrification revolution in the automotive industry, the current industry is on its way to electrifying the propulsion system. While both afore-mentioned trends are concurrent, the attributes and complexity from an electric powered propulsion system deviate quite a bit from the evolutionary MEA applications. The electrification of the propulsion system is expected to revolutionize propulsion system designs potentially with its merits and associated bottlenecks. The following subsections discusses on various propulsion concepts, their classifications, and the associated envisaged benefits and challenges.

\subsection{Electrical Propulsion System Concepts}

The idea of electrifying the propulsion system yielded to a realm of propulsion system configurations, falls into three primary domains: 1-fully electric, 2-turboelectric, and 3-hybrid electric. The configurations are characterized as per the extent of usage of the electrical energy source and based on the electrical powertrain arrangement. A fully electric system relies upon a battery or some other means of electrical energy source as a sole means to power the propulsion system. Such design features the advantages of a highly efficient conversion system and is the only configuration which has the potential for zero inflight emission and is much quieter in operation. A few publicized conceptualized designs in the fully electric category are: NASA's SCEPTOR X-57, in the general aviation sector, Bauhaus Luftfahrt's VoltAir [16], and Ce-Liner [17] designs in the regional and single-aisle segments, respectively. The majority of the aircrafts in this category are designed for smaller size, with a few exceptions. Gnadt et al. [13] study presented a survey on fixed wing airframe based fully-electric aircraft conceptualized designs.

Turboelectric configuration retains fuel as main source of energy and converts the chemical energy available in the fuel into electrical power either fully or partially to drive the propulsor. A turboelectric configuration features lower efficiency due to the additional losses in the electrical drive system for 
the conversion and transmission of mechanical power to electrical power and again from electrical to propulsive power. However, on the positive side, the concepts are well poised for implementing the novel concepts such as distributed propulsion arrangement with or without a boundary layer ingesting system. A further variant to the turboelectric is a partially turboelectric configuration, wherein the propulsive thrust is produced by both gas generator driven propulsors and the turbofans. Given a significant reliance on gas turbine technology, these configurations are deemed to be viable with modest beyond state of the art advancement in electrical component technology [18]. Moreover, it is established that successful application of the aircraft based on turboelectric/partially turboelectric configurations has a high reliance on superiority of the electrical drivetrain components' technologies [19-21]. The system level benefits and challenges of fully/partially turboelectric configurations were studied under NASA's N3-X [22-24], the single-aisle partially turboelectric aircraft with an aft boundary layer propulsor (STARC-ABL) design [25,26], Boeing's Subsonic Ultra Green Aircraft Research (SUGAR) Freeze design [27], and Empirical Systems Aerospace Inc. (ESAero)'s Environmentally Conscious 150 (ECO-150) design [28].

The term hybrid electric is coined for the options wherein the propulsion system utilizes more than one type of energy sources, such as fuel/chemical and battery/electrochemical system. The hybrid electric configuration further branches off to series and parallel types, which are characterized based on the nature of the node connecting the two constituent energy sources. In a parallel hybrid configuration, both the electrical system and gas turbine system are connected mechanically to drive the propulsors, either in conjunction or in-lieu. In this arrangement, the electrical motor is mounted on the low-spool shaft of the engine and backed up with an electrical energy source that can either be charged onboard or on the ground. With a benefit of requiring less numbers of components, the configuration enjoys advantages related to weight saving. Nonetheless, on the downside, it involves mechanical coupling which causes operational and control complexity. Another limiter for the parallel hybrid electric operation is the impact from the imposed operating conditions, that is not optimum for the performance of turbomachinery components. Hybridized condition entails reduced power demand from the engine core, under a fixed thrust requirement. In order to provide a lower shaft power output, the high-pressure shaft adopts to a reduced operating speed while the mass flow and the fan speed remain the same. This operational disruption causes flow mismatch between the two spools, eventually causing a reduced surge margin in the low-pressure components [29]. As proposed, a more strategic utilization of parallel hybrid electric configuration would be to use electrical power for boosting the engine operation during the take-off and climbing segments $[30,31]$ and/or to charge the battery under low thrust requirement conditions [32]. Under the scenario, it gives an opportunity for sizing the core for a lower thrust requirement condition and benefit from a more efficient cruise operation. The study performed by Sahoo et al. [33], highlights the beneficial aspect of a core resizing scenario on the surge margin, relative to a baseline design, when hybridized for same level of power. Furthermore, this concept benefits from requiring a reduced size conventional engine to meet operational requirement under one engine inoperative (OEI) condition [34]. Due to the simplicity of parallel hybrid electric configuration, the concept has been widely explored by multiple bodies in different projects: SUGAR Volt, United Technology Research Centre (UTRC)-Geared Turbofan design [31,35,36], Rolls-Royce North America (RRNA)-Electrically Variable Engine (EVE) [37-39], Bauhaus Luftfahrt (BHL) conceptualized designs [40], TRADE [41], etc. Such configurations inherently deprive the aero-propulsive synergistic benefits, if propulsors are not strategically placed close to the wing body surface of the aircraft. Nonetheless, such reformed concepts found application in Parallel Electric-Gas Architecture with Synergistic Utilization Scheme (PEGASUS) design, which adapts to a distributed architecture with two wing-tip propellers, two inboard propellers and one aft fuselage BLI fan to get additional aerodynamic benefits [42,43]. In addition to the fuel efficiency benefit, the design showed potential for operating cost improvements owing to the added redundancy in the system.

In a serial hybrid configuration, the propulsors are supplied electrically either from a gas turbine driven generator or from an electrical energy source. This arrangement enables decoupling of the gas turbine system from the propulsors by an electrical conversion and the transmission system. 
The inherent advantage of serial hybrid electric configuration is the flexibility to operate the gas turbine independent of the fan speed, thus making it feasible to operate at its maximum efficiency. Both serial and parallel hybrid electric architectures can store the electrical power in a battery to supplement the propulsive power in different operational segments. A serial/parallel hybrid electric configuration represents co-existence of both serial and parallel operation, meaning, it is arranged to drive the propulsors, both electrically, from power sources-a gas turbine driven generator or a battery and mechanically from the gas turbine. The decoupling of the propulsors from the power generation source in a serial/parallel hybrid electric configuration relieves the constraint of sizing or operating the engine to meet propulsor power requirement and thus, gives further opportunity for optimizing the engine performance in different operating segments [44,45]. A simplified pictorial representation of all the configuration arrangements is illustrated in Figure 1.

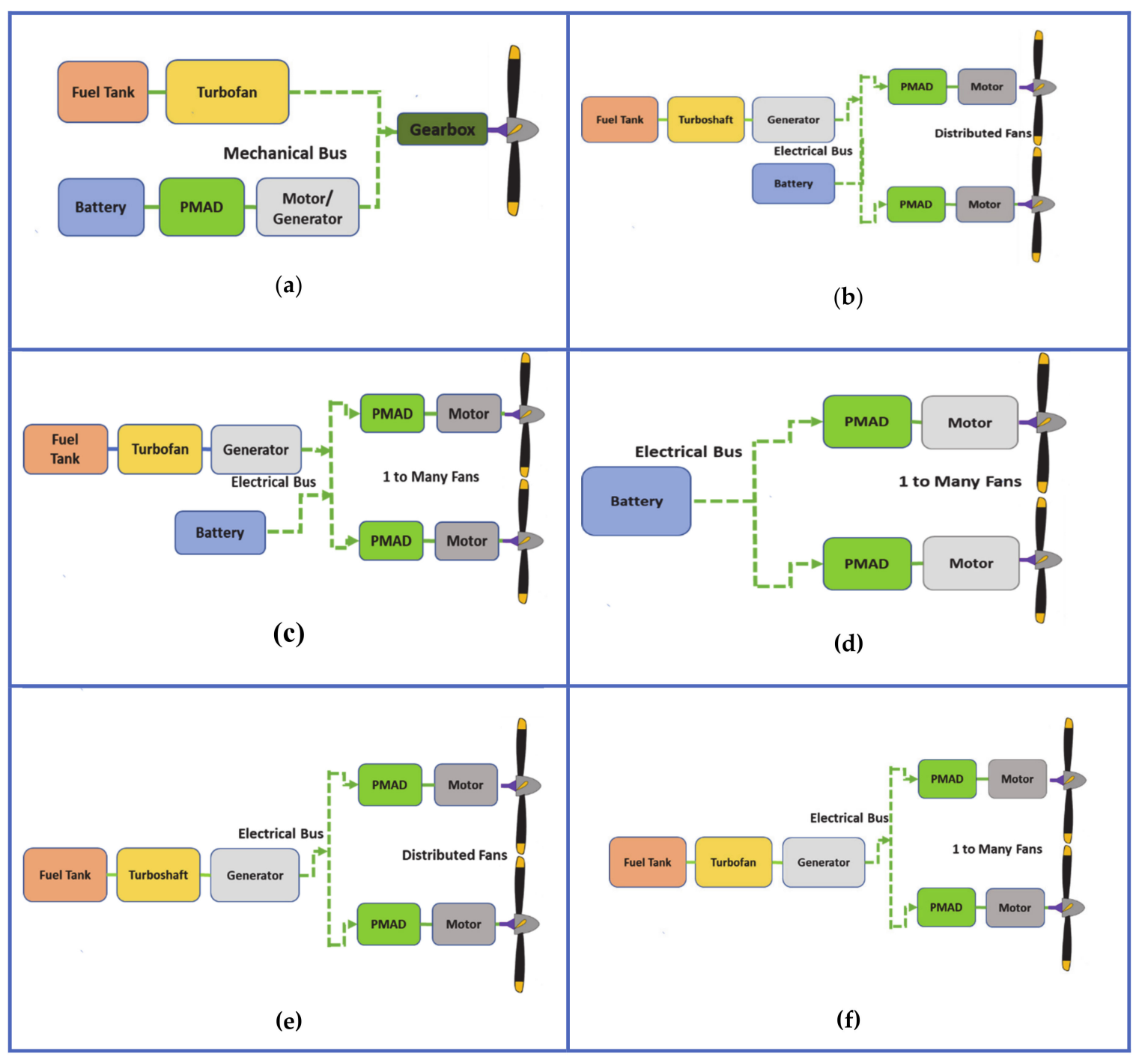

Figure 1. Illustration of various electric propulsion configurations adapted from Bowman et al. [12].
(a) parallel hybrid;
(b) serial hybrid;
(c) parallel/serial;
(d) fully electric;
(e) turboelectric;

(f) partially turboelectric.

While the ultimate objective is to aim for a fully electric aircraft, it is anticipated that even the most optimistic technology in the electrical components would not be adequate for these aircraft to achieve enough range in near or mid-time frames $[8,11,46]$. Using a lower specific energy (SE) in the battery makes a disadvantageous trade-off for an achievable range [46] and inadequate specific power (SP) in 
the components and would not meet the demand under in high-power applications. Hybrid electric /turboelectric systems reap the benefits of a higher efficiency electrical drive system yet build on the superior energy density of fuel to overcome the deficiency of a fully electrical aircraft in achieving a higher range. This makes the hybrid electric or turboelectric solution rather pragmatic to meet the environmental goals in the near term [19]. Although a hybrid electric/turboelectric configuration cannot match the efficiency of a fully electric, it could certainly be a stepping stone towards development of a fully electric aircraft.

\subsection{Electrical Propulsion System-Benefits and Challenges}

Electrification of the propulsion system enables many other novel propulsion system concepts and aircraft designs; if integrated together they give the opportunity for overall improvements in the aircraft performance. The following subsections enumerate the enabled performance benefits and implementational challenges of such concepts.

\subsubsection{Distributed Electric Propulsion System Design—Benefits and Challenges}

Distributed propulsion is termed for the approach in which the propulsors are distributed effectively across the aircraft body for enhancement of the aero-propulsion integration benefits $[47,48]$. By adopting such mechanism, the propulsors become an integral part in improving the overall vehicle efficiency. The benefits can be achieved for improved aerodynamic efficiency or in propulsion efficiency. A demonstrator aircraft from NASA, Cruise Efficient Short Take-off and Landing (CESTOL), employed a DP concept to get the benefit of a shorter take-off and landing distance [49]. The design employs twelve small engines that spread across the upper surface of the hybrid wing body. The Distributed Electric Propulsion (DEP) approach expands on the central idea of the DP concept, in which the electrically driven propulsors are connected to a centrally located energy source and transmitted through an electrical transmission system. The DEP enhances the benefits of a DP system leveraging primarily on two attributes of the electrical system. Firstly, due to the inherent flexibility and adaptive capabilities of the electric transmission system, which makes the distribution of the propulsors possible near to the aerodynamic surface of the airframe. Secondly, due to the scale invariance feature in electrical components that makes implementation feasible, for propulsors of any size, without compromising its performance. Aided further, the compactness of the electrical components offers flexibility of placing them y elsewhere in the aircraft body. While the DEP concept can possibly be implemented in conjunction with variety of propulsion configurations, it is believed that a turboelectric configuration with a DEP (TeDP) system holds the largest potential for efficiency improvement [50-52]. A large spectrum of aircraft designs has been conceptualized to this effect both on conventional and unconventional airframe designs. Ce-Liner utilizes a C-shape airframe [53], ECO-150 series designs are configured both for tube-and-wing and split-wing airframes s [28]. A blended wing body (BWB) airframe is considered in the N3-X design [23]. Though the common understanding is that a DEP system in serial or turboelectric configuration gives additional aerodynamic benefits, there are few studies made on hybrid electric configuration with a DP approach [54,55].

One of the early designs that established benefits of a DEP system configuration is N3-X aircraft in the 300-passenger capacity (PAX) segment. The design utilizes an array of 14 electrically powered ducted fans spanned across the airframe, supplied from two turboshaft driven generators located on the wingtips. The N3-X concept utilizes BLI distributed propulsion system across a BWB airframe to achieve $50 \%$ aerodynamic efficiency improvement. In addition, the turboelectric configuration enables a high effective BPR design, that further yields $4-8 \%$ improvement in the propulsion efficiency [23,24].

In the single-aisle narrow bodied segment, the ECO-150 regional airliner employs a TeDP configuration with eight electrically driven propulsors embedded between the upper and lower surface of a split-wing airframe. The split-wing DP system gives the benefit of achieving a high-lift coefficient through super-circulation of redirected jet flow from the exit nozzle. The proposed concept also merits from structural weight and aerodynamic drag reduction benefits with an overall gain in the 
fuel efficiency [49]. Another conceptual design from ESAero considers an aft-fuselage mounted BLI propulsor alongside the wing embedded distributed BLI propulsors, with a serial/parallel partial hybrid arrangement. The STARC-ABL demonstrator has implemented the simplest approach of DEP by employing a single aft propulsor. The propulsor is supplied with electrical power, generated and transmitted from the underwing mounted turbofan engines. [26]. Figure 2 illustrates few promising DEP designs from NASA under various projects.

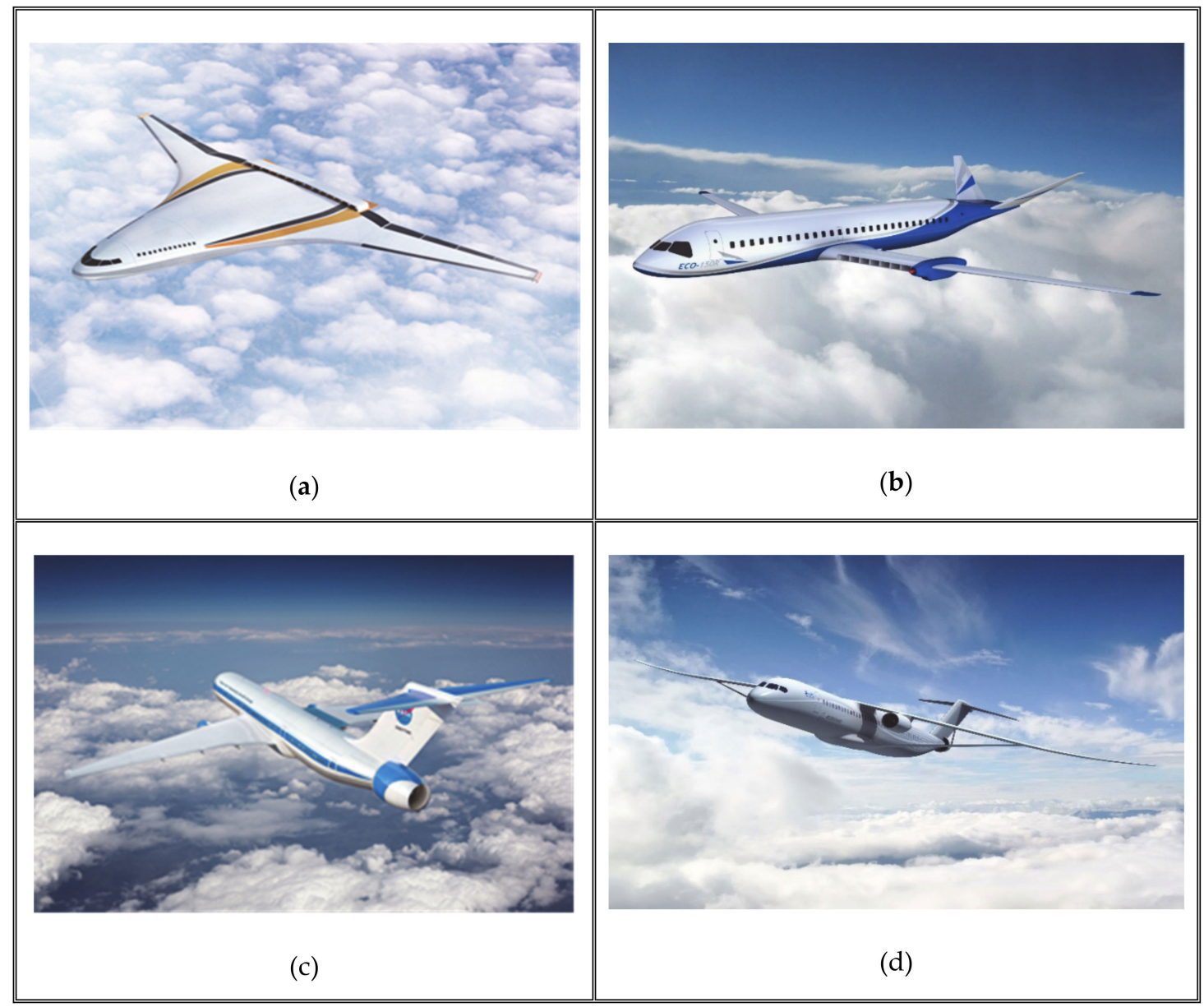

Figure 2. Distributed turboelectric and partially turboelectric configurations from NASA: (a) N3-X; (b) ECO-150; (c) STARC-ABL; (d) SUGAR Freeze.

A DEP system enables many radical design options in the airframe body; those are primarily tailored to make tight coupling of the propulsion system to the wing body surface to get the synergistic aero-propulsion integration benefits. The extent of the benefits out of such an arrangement is dependent on the type of propulsor, e.g., a ducted fan or a propeller and its proximity to the airframe body surfaces such as the wing, fuselage, or tail.

The propulsors can be spread in multiple fashions, such as in the leading edge of the wing [56,57], over-the-wing [58-60], under-the-wing [59,61], on the wing-tip [57,62], and on the fuselage-aft [26,53,63] to realize aero-propulsive synergistic integration benefits. Such benefits can be materialized in multiple ways: a lower size wing, better cruise performance, a shorter take-off and landing length etc.

In the case of a DEP system with propellers, the slipstream generated from the propeller interacts with the aerodynamic surface to produce blowing effect which enables an augmented lift coefficient during the cruise phase. If propulsors are placed ahead of the wing leading edge such as on wing-tip, interact favorably with the wing trailing vortex and reduces the induced drag in the system. 
Nonetheless, based on the location of the propeller, whether ahead of the wing leading edge or behind the wing trailing edge, propellers rotation direction would vary.

Besides, the distribution of propulsors along the wing surface increases the dynamic pressure over it and provides high lift during low speed operations such as during take-off and landing flight phases. The Leading Edge Asynchronous Propellers Technology (LEAPTech) 4 PAX aircraft adopts an effective approach of scattering the propulsors laterally along the wing to blow the wing in lower speed operation. The benefits are analyzed with extensive computational fluid dynamics (CFD) based Reynolds-number averaged Navier-Stokes aero-propulsive simulation analyses. These analyses were made for different propeller and wing designs in order to find the maximum gain in the lift coefficient. Contra-rotating propellers were considered as a means to raise maximum lift-coefficient by reducing swirl in the propeller downwash. This approach showed maximum lift coefficient improvement of the order of five times, compared to the baseline design [64]. In the project dubbed AMPERE by the French Aerospace Lab ONERA, a 4/6 seated aircraft deploys 40 small electrical ducted fans spreading across the leading edge of the upper wing to get a blowing effect during low speed operations. The electrical fans in this configuration are powered by combination of batteries and fuel cells [56]. A fully electric demonstrator is the X-57 Maxwell design which utilizes two wing-tip and 14 leading-edge propellers distributed across the airframe. The wing spread propellers increase the dynamic pressure over the wing surface, for enhancement of the lift-to-drag ratio during take-off and landing phases [65]. The wing-tip propellers which operate during the cruise phase interact with the wing tip vortex to enable a $10 \%$ reduction in the propulsive power requirement. This configuration enables a wing design with a lower wetted area-a $2.5 \times$ reduction, relative to the baseline aircraft and hence gives an opportunity for fuel burn savings over the whole mission [65]. An aircraft conceptual design with twin-turbo propeller in a regional 50 PAX segment showed a possible increase of $10 \%$ in the lift capability and subsequent impact on the wing sizing reduction and the opportunity for $2.5 \%$ of block fuel reduction [66]. The PEGASUS design implements two motor assisted wing-tip turboprops and two inboard electrically powered propellers. The inboard propellers are designed to be powered off and folded during high-speed operations in order to avoid swirl wind milling effects and the associated drag impacts. The wingtip propulsors utilize the advantage of vortex flow during the cruise operation to decrease the downwash effects, eventually to gain an $18 \%$ propulsion efficiency improvement [43].

A concept for a fully electric aircraft engine employing DEP system has shown potential in achieving $6 \%$ increase in the range when switched from two to four propulsors. The benefits were derived from lowering of OEI performance requirements [67]. DEP implementation also gives opportunity for using differential thrust/thrust vectoring for controlling the aircraft yaw moment in OEI condition. The fast-dynamic response in the electric system, facilitates generation of asymmetric thrust, thus, gives opportunity for either removing or reducing the size of conventional control surfaces such as the vertical tail, eleron surface, etc. A study to this effect was performed on a conceptualized design at the German Aerospace Centre (DLR) showcasing utilization of wing-tip propellers for directional control and yaw control, with areduced size vertical tail plane [45]. On a regional twin turboprop configuration without a tail plane, shows merit for 6\% fuel saving [66]; however, such implementation needs to be scrutinized for established flight-critical safety requirements. Furthermore, the concept was utilized in the ECO-150 design within the Federal Aviation Regulation (FAR) certification requirement and showed little to no improvement in the efficiency [68]. DEP also facilitates a steeper descent operation which gives opportunity for regeneration while descending by wind milling some of the propulsors [13].

Electrically enabled DP based aircraft can achieve a high effective BPR engine design without a requirement of increasing the fan speed. This reduces the overall noise from the propulsion system, especially reduced from the fan operation. Strategic placement of the propulsors enables noise-shielding effect in the wing body surface. Such implementation qualifies to bring forth the environmental benefits of a reduced community noise level $[69,70]$. The N3-X concept leverages such benefits by placing the wing-tip generator to the inboard of the airframe [52]. The ECO-150 design implements the 
wing embedded DEP approach to reduce the noise level. The DEP system in the commuter air vehicle also reduces the community noise during the take-off and landing phases [71]. The electrical machine operations are presumably quieter, and has lower acoustic impacts compared to the turbomachinery operation: the impact is quantified to be $8-20 \mathrm{~dB}$ and $17-29 \mathrm{~dB}$ lower than the fan noise for a regional jet, and a single-aisle transport class aircraft respectively [72].

Despite the advantages, the adoption of the DEP concept increases the sizing complexity by adding more components and entails an airframe body strikingly different from the conventional tube and wing. An assessment study used in a 150 PAX segment aircraft, shows huge impact of DEP on the operating empty weight, which makes this architecture unsuitable for implementation in near-term and pronounced a huge reliance on the vehicle efficiency gain and electrical technology advancement [54]. The benefits need to be weighed against the gained weight and structural complexity associated with them. Few review papers list the potential synergistical benefits and implementational challenges associated with DEP concept. Bijewitz et al. [73] highlighted the synergistic integration benefits from a fuselage based distributed propulsion architecture. Amir et al. [69] explored the applicability and technical challenges of DEP more specific to the fully electric 300 seat aircraft. Kim et al. [50] presented a comprehensive overview on beneficial attributes of DEP system, the design challenges and the technology requirements.

\subsubsection{Boundary Layer Ingested Electric Propulsion System Design—Benefits and Challenges}

BLI concept utilizes the thin, low-momentum air over the wetted surface of the wing, empennage, or fuselage for further re-acceleration and re-energization instead of passing undistributed into wake. The BLI propulsion system benefits are established by a plethora of analytical studies performed in the past $[48,74]$. The benefits are largely established for three reasons; The first one, the low momentum air demands lesser power from the propulsor to produce the same amount of thrust. The second one, it reduces the overall power dissipation in the flow-field due to filling-in of the aircraft wake with lesser kinetic energy propulsor outflow jets, ultimately giving the benefit of reduced drag and improvement in propulsion efficiency. The third one, when embedded inside the aircraft body, decreases the size of the nacelle and hence benefits from a reduced drag. All these synergistic integrations potentially provide improvement in the vehicle performance. Different means for ingesting the boundary layer are proposed for different conceptual designs; such range from an aft-mounted [16,26,27,63,73,75] propulsion fan to wing installed fans in a blended wing body airframe [23,76] and novel fuselage concepts as found for double-bubble fuselage design $[77,78]$.

Hall et al. study [77] illustrated two beneficial aspects of BLI: reduction in jet mixing loss and reduction in airframe wake mixing loss. Both the benefits can be attributed to the lower velocity boundary layer flow entrants in the propulsors. The benefits include $9 \%$ lesser propulsor mechanical power requirements when $40 \%$ of the fuselage boundary layer is ingested, established in relation to a non-BLI system. The study performed and tested on a reduced-scale wind tunnel on the D8 aircraft concept showed $5-7 \%$ propulsion efficiency improvement in fuselage based BLI on tube-and-wing style airframe [78]. The magnitude of benefits of BLI system is dependent on the amount of boundary layer captured and the sizing of the propulsors [26,77]. However, to able to capture more boundary layer (BL), requires more motor power in the aft fan. In the study performed on STARC-ABL conceptual design, the aft fan was sized to ingest $45 \%$ of the fuselage BL which corresponds to capturing of $70 \%$ of the momentum deficit [26]. With this arrangement, it showed potential for $7 \%$ fuel burn reduction in a mission range of $900 \mathrm{~nm}$, accounting for improvement from both in the propulsion efficiency and downscaling in size of the turbofans. The BHL's propulsive fuselage concept showed $10 \%$ fuel burn improvement compared to the baseline engine [73]. Plas et al. study [79] showed potential for $3.8 \%$ reduction in fuel burn from a BLI enabled propulsion system design. The study performed by Kawai et al. on a BLI propulsor aft fan on a BWB airframe showed potential for $10 \%$ fuel improvement [80]. Hardin et al. studied BWB airframe design with aft mounted fans, observing $10 \%$ fuel burn improvement over a pylon mounted ultra-high BPR turbofan baseline design [74]. 
All these benefits were assessed for a conventional engine with and without BLI implementation. The uniqueness of an electrically enabled BLI propulsion design is the flexibility to place the propulsors advantageously in the aircraft body surface such as on the wing-tip or on the tail cone for the possibility of capturing a higher fraction of the limited boundary layer. The distorted, non-uniform boundary layer is also expected to affect the performance of the core. The idea of utilizing the remotely arranged propulsors with a centralized power system merits from isolating the core performance from the propulsors. The electrical transmission system makes it conducive for such implementation by placing the turbo-generator and propulsor fan elsewhere in the vehicle, making it feasible to utilize the boundary layer even more effectively $[25,27]$.

In an environment enabled by the DEP system, there is further opportunity for an increased amount of BLI to give higher fuel burn benefits [23,25,48,81]. Many of the electric aircraft designs were conceptualized utilizing the benefits of BLI, under a highly or moderately DEP environment. NASA N+3 generation aircraft, N3-X design utilizes the thick boundary layer atop the planform to ingest to the electrically powered ducted fans embedded in a BWB airframe [39]. Such arrangement gives the opportunity for partial compensation of the wake created by the vehicle and thus, reduces the thrust requirement [23]. Boeing SUGAR Freeze, a partially turboelectric configuration, employs an electrically driven BLI aft-fan in the tail cone powered by a fuel cell topping cycle with superconducting electrical drivetrain technology [27]. Bijewitz et al. [82] surveyed a list of aircraft designs conceptualized based on reaping synergistic integration benefits of BLI in a DEP system and with an integration of novel airframe design.

However, the improvements achieved from the propulsion efficiency and drag reduction must compensate for the weight penalty of the electric drive system components, and the additional BLI propulsor fan, and inefficiency from the added components to achieve a net system level benefit. The study performed by Gray et al. [83] on STARC-ABL emphasizes the coupling effects of electrical drivetrain efficiency on the sizing and performance of the propulsion system. In a similar line, a partially distributed hybrid electric small regional 50 passenger aircraft showed high reliance on the transmission system efficiency parameter and on the specific power of the electrical system [84]. The design benefits from higher propulsion efficiency from the placement of two BLI ducted fans in the upper surface of the inboard wing section, powered from a tail located embedded gas turbine generator. In another system study performed by Thauvin et al. [66] on regional aircraft, a BLI system on the rear mounted propeller shows a meager propulsive efficiency improvement of $1 \%$ over the conventional design. These studies lead to the conclusion that there are many considerations to be accounted for, in order to realize the benefits of a BLI propulsion-based aircraft design.

Though promising, there are many difficulties in achieving such benefits in a conventional propulsion system design. The highly distorted BL flow makes the fan operation inefficient. To reap the benefits of BLI, a stronger distortion tolerant fan design with blades designed to straighten out the swirl flow is required [74]. UTRC and NASA Glenn Research Centre (GRC) made collaborative efforts in designing a fan aiming to limit the efficiency deterioration within 1-3\% [85]; Figure 3 displays the wind tunnel test for a distortion tolerant propulsor fan to observe the impact from varying wind speeds on the operability, structure, and performance of the fan.

Propulsion system designs featuring a DEP system approach with combined effect from BLI seem to be the best for achieving the aero-propulsive integration benefits. However, many technological and economical challenges still needs to be addressed for realization of any such benefits [50,69]. 


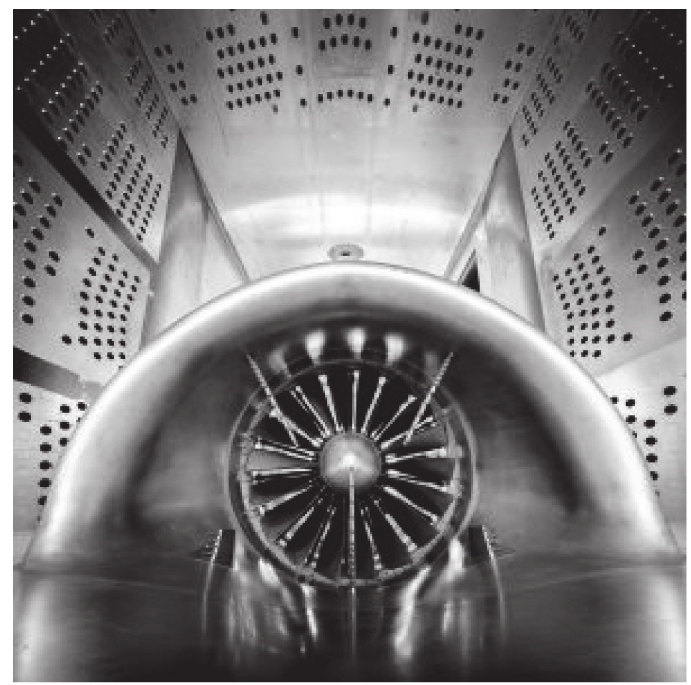

Figure 3. High-speed testing of the distortion tolerant fan propulsor at the NASA Glenn Research Center $8^{\prime} \times 6^{\prime}$ wind tunnel [86].

\subsubsection{Electrical Energy Boost Design-Benefits and Challenges}

Conventional engine performance is optimized for varying thrust requirement over different operating segments with optimized performance in the turbo components. The physical link between the gas turbine and fan limits for an obtainment of an optimum engine performance in certain segments. The decoupling of the thrust producing units from the power generating units, as is the case in a turboelectric and serial hybrid electric configuration, delimits such constraints. In a parallel hybrid configuration, the utilization of battery energy if used for boosting the propulsion system, alleviates the design requirement of the gas turbine for high power requirements. The concept was hypothesized for many conceptual designs for the assessment of the fuel and energy consumption reduction potentials. However, different operation strategies are implemented in different studies. The SUGAR Volt concept has been adapted to an operation strategy to electrify the cruise segment with a battery on-board. The said concept was proved to be no good from the energy saving perspective, though it had exhibited good potential in fuel saving and cruise NOx emission reduction [29].

The EVE design was conceptualized for parallel hybrid operation with a 1.9 megawatt (MW) electrical machine, embedded in a geared turbofan engine. The machine can be operated both as motor and generator as desired under different operating conditions. The engine is designed to meet the full thrust requirement, however, utilizes battery power to reduce fuel burn and overall emissions. In an optimized scenario, the design gives opportunity for $24 \%$ fuel and $7 \%$ energy savings over a $900 \mathrm{~nm}$ mission range [37,39]. UTRC conceptualized parallel hybrid electric design was built on the underlying concept of boosting the gas turbine operation with battery power during take-off and landing mission segments. With a core size optimized for the cruise operating condition, the concept provides potential for a $6 \%$ fuel burn reduction and $2.5 \%$ energy saving y for a $900 \mathrm{~nm}$ mission range [31]. A conceptual design from TU Delft, on A320 type aircraft, with a core resized to $90 \%$ of the original size and provisioning for $25 \%$ take-off hybridization and $14 \%$ climb hybridization, showed opportunity for $7.5 \%$ fuel burn reduction, when assessed over $1000 \mathrm{~km}$ mission range [87]. This energy boost operation also showed 3.7\% NOx emission reduction opportunity in the engine. Furthermore, it is assessed that, supplementing the gas turbine operation with battery energy could potentially reduce the energy consumption by $60 \%$ during the descent phase and $90 \%$ during taxiing phase [66].

A turboelectric configuration is particularly characterized by a design with an turbo shaft engine, power system components in the generation-side and load-side, and the fans requiring different levels of thrust across the flight envelope due to the altitude and airspeed caused power lapse. Sizing the engine for time to climb requirement, makes the design oversized for cruise condition, hence, makes it 
less efficient. In the aforementioned scenario, if battery power is used for boosting engine, theoretically, give the design benefits of a reduced engine size and reduced size in load-side electrical components and improved cruise engine performance $[84,88]$. However, on assessment of such a concept with technology for the year 2025, revealed that fuel saving benefits would be lopsided because of the added weight of the battery. It was concluded that such an operation can only be beneficial under stringent emission requirement conditions rather to be on fuel burn perspective, or if flown for a mission range, significantly lesser than the primary design mission [89]. Gladin et al. study [84] conceptualized for a partially distributed turboelectric system on a regional jet 50 PAX aircraft to partially boost the engine during the take-off segment with battery power. The study showed that the approach of boosting the engine in a turboelectric configuration is advantageous for achieving performance gain over a shorter mission range. Nonetheless, the viability of the configuration depends on high level of electrical drive system performance-efficiency and specific power. For a conventional fuel operated aircraft, sizing of the engine is made as per flight critical OEI climb-out condition. Facilitated with a rather reliable and flexible electrical transmission system, an electrical aircraft design could utilize alternate operating engine's power under the one engine failure scenario, and thus, provides scope for reducing the size of the engine.

A comprehensive understanding of the trends and impact on the propulsion system size and performance is needed to determine when to supplement with battery energy and how big the battery size should be [90]. This is considered as an optimization problem and covered in a few studies $[38,39,89]$. From the performance perspective, utilization of a battery in a stepped profile have less impact on the battery life than using it for ramping power during the take-off and climb, especially if the high current is drawn in a low state-of-charge [91].

\section{System Studies Assessment-A View towards the Current Research Portfolio}

The aviation industry over the last century has evolved from a propulsion system based on piston engine propelling wooden propellers to an ultra-high bypass ratio turbofan engine for achieving the market demand in range, speed, and capacity. The future developments in aviation are driven by the requirement of meeting the laid out environmental targets: some of those are presented in Table 1. The most ambitious goals are set forth for Flightpath 2050 Vision, targeting to reach a milestone of $65 \%$ reduction in the perceived noise emission, and $75 \% \mathrm{CO}_{2}$ emission reduction per passenger $\mathrm{km}$, and $90 \%$ reduction in oxides of nitrogen (NOx), in relation to the state-of-the-art (SOA) in the year 2000 [5]. The NASA N-plus series outlines strategic improvement goals for three advanced generation aircraft in the future timeframe: $\mathrm{N}+1, \mathrm{~N}+2$, and $\mathrm{N}+3$, where " $\mathrm{N}$ " refers to the current in-service airplanes. The most stringent requirements are outlined for $\mathrm{N}+3$ referenced timeframe aircraft; aims include an $80 \%$ reduction in the cruise NOx emissions from the 2005 level, $60 \%$ block fuel reduction relative to the 2005 SOA level, and 52 cumulative effective perceived noise in decibels (EPNdB) from the Federal Aviation Administration (FAA) defined stage 4 noise-level. The UN International Civil Aviation Organization (ICAO) made stringent calls for a cap on net aviation $\mathrm{CO}_{2}$ emissions as of 2020 and most recently for 2050 [6].

The visions are quite forward-looking. Electrical propulsion-based aircraft designs hold promises for making the aircraft operation suitable as desired for an environmentally sustainable world. A consistent research investment has been made to unlock the potential for it, with a prospect for meeting the environmental targets. The goodness of the electric aircraft is gauged based on the established metrics of reduction potential in fuel/energy consumption, emission, noise, and operating cost. The following section introduces the drivers and goals for the aviation sector as per various standards. Thereafter, a compendium of conceptual aircraft design assessment studies is presented to understand the potential of an electrical propulsion system in attaining those performance metrics. 
Table 1. Environmental Goals.

\begin{tabular}{|c|c|c|c|c|}
\hline \multirow[b]{2}{*}{ Target } & \multirow[b]{2}{*}{$\begin{array}{c}\text { Flightpath } \\
2050 \text { [5] }\end{array}$} & \multicolumn{3}{|c|}{ NASA N+Series [6] } \\
\hline & & $\begin{array}{c}\mathrm{N}+1 \\
\text { TRL } 6 \text { 2010-2015, } \\
\text { IOC: } 2015-2025\end{array}$ & $\begin{array}{c}\mathrm{N}+2 \\
\text { TRL } 6 \text { 2015-2020, } \\
\text { IOC: } 2025-2030\end{array}$ & $\begin{array}{c}\mathrm{N}+3 \\
\text { TRL } 6 \text { 2025-2030, } \\
\text { IOC: } 2030-2040\end{array}$ \\
\hline $\mathrm{CO}_{2}$ Emission & $-75 \%{ }^{1}$ & - & - & - \\
\hline Fuel Consumption & - & $-33 \%^{2}$ & $-50 \%^{2}$ & $-60 \%^{2}$ \\
\hline Cruise NOx Emissions & $-90 \%{ }^{1}$ & $-55 \%{ }^{2}$ & $-70 \%^{2}$ & $-80 \%^{2}$ \\
\hline LTO NOx Emissions & - & $-60 \%^{3}$ & $-70 \%^{3}$ & $-80 \%^{3}$ \\
\hline Noise & $-65 \%^{1}$ & $-32 \mathrm{~dB}^{4}$ & $-42 \mathrm{~dB}^{4}$ & $-71 \mathrm{~dB}^{4}$ \\
\hline
\end{tabular}

\subsection{Performance Metrics}

Aircraft NOx emission is the major source of the atmospheric pollution in the higher altitudes which is currently regulated by Committee on Aviation Environmental Protection (CAEP)-ICAO prescribed certification standards. These standards are defined as Landing and Take-off (LTO) cycles comprising four operating cycles, i.e., approach, LTO, and taxiing. In addition to the LTO cycle, the environmental standards also set forth reduction goals for the cruise NOx emission level, which is majorly established as a function of temperature and pressure at combustor inlet and the combustor mixing zone average temperature [52]. The burgeoning fuel efficiency improvement demand drove the advanced engine design for a higher overall pressure ratio design, which demands high temperature and pressure at the combustor inlet. In order to get a best design, a trade-off to be made between the cycle efficiency, NOx emission, and the material temperature constraints, in which, often a specific fuel consumption (SFC) gain was chosen over the NOx emission aspect [92]. However, a few technologies explored in the present time showed potential for improvement in NOx emission; those are: water/steam injection, rich burn quick quench-lean burn (RQL), lean premix pre-vaporized (LPP), lean direct injection (LDI), and advanced twin annular premixing swirler combustors [52,93]. The Graham et al. NOx emission prediction study [94] showcases that current and future engine designs well comply to the current time ICAO standards. Furthermore, the same study had reached a consensus that NOx emission reduction targets in the $\mathrm{N}+3$ timeframe are achievable with use of a lean-burn combustor technology. The prescribed technology enhances the NOx emission reduction potential, either by reducing the combustion temperature with the increase in the local air to fuel ratio or by adopting means for splitting the fuel flow into different streams to be directly ejected to different combustion locations.

The aviation sector jet fuel combustion contributes to $2.5 \%$ of the global anthropogenic emission [95] which is expected to grow further with the evolutionary growth from the fleet operation demand. In the wake of this anticipated growth and associated environmental concerns, global entities like the International Air Transport Association (IATA) aim for a carbon neutral growth starting from the year 2020 and $50 \%$ reduction in the net $\mathrm{CO}_{2}$ system by 2050 relative to 2005 levels [3]. IATA also outlined four strategic pillars to achieve this target, one of which prescribed improvement in the airframe and engine technologies. The committee opines that by 2035 , hybrid electric propulsion systems and novel airframe configurations will be a major cornerstone contributing to this goal, but their implementation would be subjected to their economic and business viability. Hassan et al. [96] proposed a study for assessing the feasibility of achieving the IATA environmental goals based on uncertainty based scenario analysis. The study considered three enablers: vehicle technologies in the form of improvements in structure, aerodynamic, propulsion, novel hybrid-electric, fully-electric enabled systems, operational improvements, and sustainable fuels. The study concluded that the hybrid-electric concepts would not be a major contributor in achieving $\mathrm{CO}_{2}$ emission reduction targets. This was attributed to three primary reasons: the first one-hybrid electric technology suitability is limited to only few vehicles classes, the second 
one - the technology is deemed to be only viable from year 2025, and the third one - even though it potentially reduces the fuel burn consumption, its contribution to $\mathrm{CO}_{2}$ emission reduction is minimal due to use of the grid based electrical energy. Along those lines, the study conducted by Epstein et al. [46] argued that though hybrid electric aircraft give the opportunity for fuel burn reduction and bring in gas turbine efficiency improvement, such benefits are highly dependent on the future battery and electrical drive system technology development. To claim any net $\mathrm{CO}_{2}$ emission benefit, the ground-based generation should be cleaner and renewable based.

Improvements in the direct operating cost are another vital factor in the short-haul regional segment. Current regional segment fleet operation is predominated by regional turboprop/jet airline operation in less than $500 \mathrm{~nm}$ range-accounting for about $91 \%$ of the global single-day operation [97]. Though a 50-seat regional turboprop aircraft outperforms in terms of a higher specific air range (SAR), operations dominate in a higher passenger seat capacity being benefitted from a better fuel burn per passenger economics. The demand growth in the less than $600 \mathrm{~nm}$ range and the availability of regional/commuter airports makes suitable market opportunity for electric aircraft operation in this segment [97]. While demand in this mission range did exist, the operational cost for the fleet operation was never suitable to make it competitive. It is anticipated that with introduction of an innovative pricing scheme and cutting-edge technology there could be potential reduction in the maintenance and energy cost, which would reduce the DOC in this segment. Based on the aforementioned philosophy, a thin-haul (4-9 PAX) aircraft design with distributed propulsion concepts is under development with collaborative effort from Joby Aviation NASA to achieve a $30 \%$ DOC reduction target [98]. A study carried out to that end showed potential for $20 \%$ DOC reduction in the year 2025. The study used Monte-Carlo simulations in order to account for the uncertainty in the electricity, fuel, battery technology price. However, there are many further considerations to be included and such are related to energy-replacement strategies in the aircraft, detailed scheduling of the flight, charging schedule, etc.

The efficiency in a fuel-based propulsion system is established by three efficiency parameters: the core efficiency, transmission efficiency-together termed as thermal efficiency, $\eta_{\text {ther }}$-and the propulsion efficiency, $\eta_{p r}$. The added electrical components in a hybrid electric/turboelectric configuration introduce new performance parameters in the propulsion system. Seitz et al. [99] formulated three unified parameters: energy conversion efficiency $\left(\eta_{e c}\right)$,transmission efficiency $\left(\eta_{t r}\right)$, and propulsion efficiency $\left(\eta_{p r}\right)$. The $\eta_{e c}$ parameter relates to the conversion of the onboard energy sources into available usable power in the propulsion system. The $\eta_{t r}$ parameter represents the translation of the usable power into actual propulsive jet and the $\eta_{p r}$ parameter accounts for the conversion of the actual propulsive jet to the propulsive power produced.

For a conventional fuel-based aircraft, the sizing and the performance of the aircraft is optimized for Specific Air Range (SAR), which is indicative of the unit distance flown for a given unit quantity of fuel. To relate the same metric for hybrid electric operation, it can be re-defined as Energy Specific Air Range (ESAR), quantified as change of aircraft range per unit change in energy in the system as proposed by [99] which is defined as the distance flown for each unit quantity of energy consumed. The applicability of ESAR as objective function for an aircraft with multiple energy sources would result in the minimization of the energy consumption and $\mathrm{CO}_{2}$ emission for the flight path, however, it would not be optimized for the minimum energy cost. Cost-Specific Air Range (COSAR) as an alternate figure-of-merit optimizes a flight profile for minimum energy cost, which accounts for the energy market price in the study in addition to the fuel cost [100].

In a conventional aircraft design, the range of the aircraft is computed with the Breguet range equation stating:

$$
R_{f}=\frac{L}{D} \eta_{p} \eta_{t r} \eta_{\text {ther }} \frac{S E_{\text {fuel }}}{g} \ln \left(\frac{1}{1-\frac{m_{f}}{m_{T O}}}\right)
$$


where, $\frac{L}{D}$ is lift-to-drag ratio, $\eta_{p}$, is the propulsion system efficiency, $\eta_{t r}$, is the efficiency accounted for the prolusion-integration losses and $\eta_{\text {ther }}$, is defined as the engine thermal efficiency. $S E_{\text {fuel }}$, represents the SE in the fuel and $\frac{m_{f u e l}}{m_{T O}}$ is the fraction of the fuel weight in the take-off gross weight.

For an electric powered aircraft, the modified version of the Breguet-range equation as derived in [8]:

$$
R_{\text {Electric }}=\frac{L}{D} \eta_{p} \eta_{t r} \eta_{e l} \frac{S E_{\text {battery }}}{g} \ln \left(\frac{m_{\text {battery }}}{m_{T O}}\right)
$$

where, $\eta_{e l}$ is the stack-up efficiency from the battery to the electrical motor driving the propulsor, $S E_{\text {battery }}$, represents the battery specific energy, and $m_{b}$ denotes the weight of it. Clearly, electric powered aircraft illustrated the range achieved has a correlation to the SE in the energy source, and therefore, the high specific energy yields a range which is much less compared to the conventional fuel-based sources. Furthermore, the decrease in the fuel weight over the mission improves with the drag reduction and makes the propulsion system more efficient in the process. For battery technology that gains mass over the range, the rate of mass gain is presented as [13]:

$$
\frac{d m_{\text {battery }}}{d t}=\frac{k z P_{\text {battery }}}{S E_{\text {battery }}}
$$

where, $k$ is the fraction of gained oxygen mass to active battery mass;

$\mathrm{z}$ is the fraction of active battery mass to total battery mass;

$P_{\text {battery }}$ is the power out of the battery.

The specific energy based on the final battery mass is presented:

$$
S E_{\text {batteryfinal }}=\frac{S E_{\text {battery }}}{1+k z}
$$

The range equation for the mass gaining aircraft with substitution of Equations (3) and (4) into Equation (2) results in [13]:

$$
R_{f}=\frac{L}{D} \eta_{p} \eta_{t r} \eta_{e l} \frac{S E_{\text {battery }}}{g} \frac{\ln (1+f k z)}{k z}
$$

where $f$ represents the ratio $\frac{m_{\text {battery }}}{m_{T O}}$.

On the component level, SE, measured as the energy per unit mass, and the SP available power per unit mass are arguably the most important technology parameters. Further, a degree of hybridization $(\mathrm{DoH})$ determines the desired performance-efficiency and SP from the electrical drivetrain system [18]. Two widely known descriptors are developed for defining the DoH: degree of hybridization for power $\left(H_{p}\right)$ and degree of hybridization for energy $\left(H_{E}\right) . H_{p}$ represents the share of maximum installed power in the propulsion system and $H_{E}$ defines the ratio of extent of energy storage in both the sources [101].

$$
\begin{aligned}
& H_{p}=\frac{P_{m}}{P_{t o t}} \\
& H_{E}=\frac{E_{b}}{E_{t o t}}
\end{aligned}
$$

The descriptors are further described with two non-dimensional parameters as elucidated by the authors in [102]: the supply power ratio, $\varphi$, represents the share of electrical power drawn in the total supplied power from both the energy sources (fuel $-P_{f}$ and electrical energy storage $-P_{\text {batt }}$ ) onboard, and the activation ratio, $\phi$, represents the time weighted average electrical power share drawn in the total propulsion system power.

$$
\varphi=\frac{P_{\text {batt }}}{P_{\text {batt }}+P_{f}}
$$




$$
\phi=\frac{\int_{0}^{T} \bar{\omega}_{b}}{\int_{0}^{T}\left(\bar{\omega}_{f}+\bar{\omega}_{b}\right)}
$$

$\bar{\omega}_{b}, \bar{\omega}_{f}$ represent the control parameter for the power supply from battery and fuel respectively, for a certain duration of use during the mission. The study utilizes these control parameters for exploring the design space in hybrid electric configuration, represented as onion charts for achieving the ACARE related goals [103].

Different studies use different control parameters to define the classification of the hybrid electric configurations. The study by Reynard et al. [55] used three control parameters: supply power ratio, $\varphi$ shaft power ratio, and gas turbine throttle ratio, to define the electric operation. Shaft power ratio defines the amount of shaft power produced by the electrical source and gas turbine throttle ratio represents the share of power produced by the gas turbine with respect to the maximum power it can produce.

Introduction of an electric drive system into the aircraft propulsion system would cause a penalty in terms of added weight and inefficiencies to the system. Successful implementation of the electric aircraft concept demands superior technology in those components to make the operation optimal. For a fully electric or a hybrid electric configuration, where battery is used as the energy source, successful application is largely attributed to a higher battery specific energy $[16,17,104]$. Furthermore, the inefficiencies in the electrical system components limits the amount of energy delivered to the propulsor and hence impacts the amount of fuel that the system can offset [33]. Understanding of the key performance parameters (KPPs) are essential in order to define the parameters necessary for operation and understand the likelihood of technology infusion. Jansen et al. [20] identified specific two KPPs in the electrical drivetrain system for a turboelectric configuration: specific power, $S P_{E D}$ and efficiency, $\eta_{E D}$. The study performed a break-even analysis with a modified Breguet range equation to identify the minimum allowable value that can preserve the operational empty weight, range, and the energy of the original aircraft. A break-even range for $S P_{E D}$ between 9 and $20 \mathrm{~kW} / \mathrm{kg}$ was found, for a range in $\eta_{E D}$ between $100 \%$ to $92 \%$, with representative numbers for propulsion and aerodynamic efficiency gain. The study was further extended to a partially turboelectric and parallel hybrid electric configuration with inclusion of a third KPP, i.e., electrical propulsion fraction $\xi[18,21]$. The studies showed that both high $S P_{E D}$ and high efficiency in $\eta_{E D}$ are paramount, for a high level of power integration in a larger aircraft. Saving weight in the drive system has a positive snowball impact whereas any improvement in the efficiency of the system would lead to the direct saving in fuel consumption or battery energy consumption [11,87]. Each \% efficiency improvement for the downstream components in the power drivetrain reduces the battery size and also merits reduction in amount of waste heat and weight related to thermal management system components [105].

\subsection{System Studies Portfolio}

The ambitious fuel burn and emission targets steered the research investment towards finding innovative aircraft designs well-suited to meet the objectives. A suite of conceptual-based designs aiming for entry into service at different time horizons was performed in a close alliance between researchers within academia and industries. These designs were further assessed through system studies for gauging their potential in meeting the targets in the emission. The following system study reviews highlight some of the promising designs performed to achieve the NASA N+3 series and Flightpath 2050 goals.

The NASA Subsonic Fixed Wing (SFW) had vested interest in the novel aircraft designs under the flagship SUGAR project, employing varied propulsion system concepts, namely the battery-Brayton, fuel cell-Brayton cycle, and fully electric [106]. The project conducted a comprehensive assessment on multiple advanced aircraft designs and propulsion configurations to meet the $60 \%$ fuel reduction target in the N+3 timeframe. Out of many designs, the most promising one was found in the SUGAR Volt design with a hybrid option of battery-Brayton, with the airframe morphology $n$ of the SUGAR 
High design. With the accrued aerodynamic and structural benefits from a high wing truss-braced airframe design, it showed potential for achieving fuel burn, however, it did not exhibit any energy saving opportunity. A fuel burn reduction potential between $10.9 \%$ to $21.7 \%$ is established for the battery-Brayton parallel hybrid configuration with varying degrees of electrification between $1 \mathrm{MW}$ and 5.2 MW, during cruise phase [12,29]. The parallel hybrid electric operation enables a lower operating temperature/pressure in the combustor inlet an thus benefits from lower NOx emission [29].The phase-II of the SUGAR project focused on employing advanced technologies appropriate to the aircraft expected to be in service in the N+4 (2040-2050) timeframe. The configurations were assessed under the flagship of SUGAR Freeze. The airframe design was developed on high speed aerodynamic build-up of laminar flow, and a composite structure strut braced wing. The hybrid concepts which were embarked upon were hydrogen $\left(\mathrm{H}_{2}\right)$ /liquified natural gas (LNG) fired fuel-cells or batteries electrical system in a partially turboelectric distributed propulsion system configuration. The electricity generated from the solid oxide fuel cell powers the aft tail cone located BLI fan which enables a reduced drag. The configuration was assessed for emission, fuel/energy, and noise metrics [27]. From the fuel saving perspective, an LNG fueled gas turbine with a fuel cell and cryogenic operating environment for the electrical system gives the benefit of reduced life cycle $\mathrm{CO}_{2}$, LTO NOx emissions. The concept of utilization of liquid hydrogen $\left(\mathrm{LH}_{2}\right)$ as fuel with fuel cell technology showed fuel burn reduction potential of $64.1 \%$.

In further pursuance, two more conceptualized designs were established under the NASA Research Announcement (NRA) project: UTRC and RRNA designs. These two designs explored the detailed design space based on different hybridization strategies [31,37]. The UTRC design employed a core design optimized for the cruise operation, being supplemented with battery power under the take-off and climbing segments. The design assumed 20 years of advanced technology in the electrical components, and showed a fuel saving potential of $7 \%-9 \%$ and energy reduction potential of $3 \%-5 \%$ [31]. The EVE design considering different degrees of electrification under taxiing, idle-descent, and take-off power augmentation showed potential for up to $28 \%$ fuel saving opportunity on a $900 \mathrm{~nm}$ mission and 10\% energy reduction on a $500 \mathrm{~nm}$ mission [39]. Furthermore, under a Small Business Innovation Research (SBIR) contract to ESAero, research investment was made to explore cryogenic and non-cryogenic technologies in the electrical power system [107]. The ECO-150, design assuming non-cryogenic SOA electrical technology, showed potential for 35\% reduction in SFC, because of the benefits from a DEP [28].

NASA-led Advanced Air Transport Technology (AATT) projects researched four electric aircraft concepts in different segments and entry-into-service (EIS) year: N3-X, STARC-ABL, PEGASUS, and MAXWELL X-57. The most technologically overwhelmed notional design from NASA in the subsonic segment, the N3-X design, was assessed for many N+3-time framed environmental performance targets such as for noise and NOx emission [52], fuel burn [22,23], and for economic viability [108]. The design is endowed with improved aerodynamic and propulsion efficiency benefits of a BWB airframe with electrically driven BLI fans and futuristic superconducting technology in the electrical components. The system study showed opportunity for 70\% fuel burn reduction: 33\% contributed from a TeDP with BLI system configuration, $14 \%$ from a hybrid wing airframe body, and the rest from advancement in the other technologies. Concerning NOx emission assessment in the LTO operating cycle, an empirical correlation based model developed under NASA's Ultra Efficient Engine Technology Project is used [52]. With the performance input parameters from Numerical Propulsion System Simulation (NPSS) engine model and the correlation derived for a higher overall pressure ratio (OPR) (59 at sea level) design, NOx emission is estimated. The study showed $85 \%$ lower level in NOx emission compared to the CAEP-6 standard, thus meeting the NASA N+3 target. However, since turboelectric operation does not relax the operating condition in a turboshaft engine, expected to run on high OPR for achieving a high thermal efficiency, it is important that it should be run on advanced combustion technology to meet the Flightpath, 2050 and NASA N+3 NOx emission reduction targets. In the single-aisle narrow bodied segment, STARC-ABL design showed an opportunity for fuel burn reduction by $7 \%$ over an economic mission range of $900 \mathrm{~nm}$ 
and by $12 \%$ over a design mission range of $3500 \mathrm{~nm}$, when compared to the baseline conventional configuration [25]. An upgraded system study established with a CFD based tail-cone flow field model showed modification to the previous published results. The design did not turn out to be beneficial for balancing out of the aft-propulsors weight against the size reduction in the underwing turbofan and the nacelle. The aft-propulsors weight turned out to be higher on operating empty weight (OEW) basis, due to the added electrical components. The fuel burn benefit was modified to $2.7 \%$ on economic mission range and $3.4 \%$ on design mission range [12].

In regional segment, the Parallel Electric-Gas Architecture with Synergistic Utilization Scheme (PEGASUS) concept was studied; with a particular focus on the operational cost aspect [42,43,97]. Suitable for a regional transport segment, a 50 PAX aircraft with a parallel hybrid architecture was assessed with varying degrees of electrification and in battery energy density on a $600 \mathrm{~nm}$ mission range. The study utilized the ModelCentre Framework for integrating Flight Optimization System (FLOPS) developed propulsion, geometric, aerodynamic, and weight data to the engine performance and battery energy weight files and to run the multidisciplinary optimization analysis. The economics of the parallel hybrid vehicles found to be attractive compared to baseline design for the assumed battery specific energy of more than $600 \mathrm{Wh} / \mathrm{kg}$ with a assumed value of fuel cost and electricity cost [42]. However, the study highlighted that the economics of a hybrid vehicle are dependent on prevalent electricity cost, fuel cost, and on the battery technology. In general, a lower mission range and higher batter energy density is favorable for hybrid electric economics.

In thin-haul segment, the program Scalable Convergent Electric Propulsion Technology Operations Research (SCEPTOR) invests the most extensive use of DEP, with the system studies and substantive demonstration work with developed ground test facilities $[65,109,110]$. X-57 Maxwell as part of the SCEPTOR program is based on the design improvements studied under Leading Edge Asynchronous Propellers Technology (LEAPTech).

In addition to the above-mentioned NASA supported designs, there are many conceptual design system studies that is currently underway under the Clean Sky Ecosystem and by various independent researchers in Europe. The earliest ones are the conceptual designs from BHL under the Integrated Aircraft Study Platform (IASP) in a short-range, medium capacity transport aircraft featuring Universally Electric Systems Architecture (UESA) [104].

The concept Ce-Liner uses a C-wing shaped airframe to achieve the aerodynamic efficiency benefit and high-temperature superconducting (HTS) technology in the machines and battery technology with energy density of $2000 \mathrm{Wh} / \mathrm{kg}$ [53,104]. Besides these, there are a few BHL conceptual designs that are perpetuated for electric aircraft potential assessment. A conceptual study of parallel hybrid electric design on a retrofit A320 aircraft was performed to show 20\% fuel burn reduction in the $900 \mathrm{~nm}$ range with assumed battery specific energy (SE) of $1500 \mathrm{Wh} / \mathrm{kg}$ [40]. Furthermore, Isikveren et al. 2014 [103] conceptualized a parallel hybrid electric configuration on tri-fan morphology (two under wing podded turbofans and an aft-fuselage mounted electrical driven fan) in 70 PAX and 180 PAX aircraft. The mission range was varied between 900 and $1300 \mathrm{~nm}$ to understand the sensitivity to different values in battery specific energy for block fuel reduction potential. The study pronounced a desirable battery specific energy of $900-950 \mathrm{Wh} / \mathrm{kg}$ for $15 \%$ fuel burn benefit in 70 PAX segment in a mission range of $900 \mathrm{~nm}$ and $180 \mathrm{PAX}$ in the $1100 \mathrm{~nm}$ range. A battery SE of $1300 \mathrm{Wh} / \mathrm{kg}$ could potentially give $20 \%$ fuel burn reduction. The BHL conceptualized quad-fan concept [44] considers two geared turbofans and two electrical ducted fans discrete parallel hybrid design on a of 180 PAX design payload aircraft. The mission range is varied between 900 and $1700 \mathrm{~nm}$ to check the sensitivity of battery SE with fuel burn reduction opportunity. The design requires at least $1500 \mathrm{Wh} / \mathrm{kg}$ of SE to claim any fuel burn benefit for mission range less than $1700 \mathrm{~nm}$. With a battery SE $1000 \mathrm{Wh} / \mathrm{kg}$ and mission range above $1100 \mathrm{~nm}$ there is no fuel burn benefit found.

The e-Thrust concept from Airbus and Rolls-Royce employs a series/parallel configuration arrangement with six distributed BLI fans. While the sizing of the turbine is made for the cruise conditions, the battery power is used to augment the engine power during the take-off and climb 
segments. The design has wing-mounted propulsors and a fuselage gas generator to power one of the four propulsors. It is provisioned for the battery to be recharged during the cruise and descent operations. In addition, the design benefits from a superior efficiency of cryogenically cooled superconducting technology and higher energy density of lithium-air (Li-air) battery. VoltAir is a fully electric aircraft design in the 70 PAX segment conceptualized based on the benefits of the BLI system, natural laminar wing, and lower slenderness fuselage structure. The system level studies projected an a minimum battery SE of $750 \mathrm{Wh} / \mathrm{kg}$ to make the concept viable [16] in the year 2035.

DLR performed a down-selection study for conceptualization of a suitable hybrid electric architecture and airframe morphology for a turboprop engine based aircraft [45]. At first, a total of forty-eight numbers of conceptual designs were generated, with different combinations of vehicle and propulsion concepts. Subsequently, a qualitative selection process was made to filter out the best four configurations with use of an expert-knowledge based compatibility matrix. In the final round of selection process, four of the designs were assessed with conceptual design-based approach for maximizing the airframe-propulsion synergies accrued benefits. A high aspect ratio wing airframe design with parallel hybrid electric propulsion system architecture, reduced size vertical tail plane, and electrically driven wing-tip propellers was found to be the optimum choices for the aircraft, with an estimated $4 \%$ fuel burn reduction opportunity. The project Advanced Engine and Aircraft configurations (ADEC) [111] compared three conceptual designs for assessing the benefits of hybrid electric configurations: boosted turbofan, BLI-annular fan with canard employing a serial/parallel configuration, and BLI wing-tip fans with serial/parallel partial hybrid configurations. The primary results of the study showed fuel burn improvement opportunity for all three designs. however, detailed analysis with coupled aero-propulsive design and structural implication study is desired further.

In the Energy System Transformation in Aviation (EWL) research project, various energy-based propulsion system technologies were explored with selected choices in the airframe morphology, advanced technology, and material in the structure together with benefits of utilizing laminar flow technology and a BLI propulsion system. The benefit assessment was made with an aircraft level suitable multidisciplinary optimized environment. The studies covered three types of aircrafts: regional/short range, medium, and long range with assumed new technologies for the year 2050; the BWB airframe design in the long range category was found promising in terms of achieving carbon emission and fuel efficiency goals as stipulated under Flightpath 2050 [112].

The Concept Validation Study For Fuselage Wake filling Propulsion Integration (CENTRELINE) project is aimed at demonstrating the benefits of aft-fuselage wake filling BLI system implemented on turboelectric configuration in 340 PAX aircraft [75]. In the NOVAIR project-a consortium of Delft University of Technology and Netherland Aerospace Center (NLR)_proposes a parallel hybrid design of an A320 type aircraft. The design considers electric taxiing alongside electrification of the non-propulsive system and downscaling of the turbofan engine in the fuel burn and emission reduction assessment studies [87,113-115]. Furthermore, the synergistic effects between the DEP system and the airframe are explored, establishing a suitable sizing methodology under the umbrella of this project [54]. Distributed fans research aircraft with electric generators by ONERA (DRAGON) conceptual design represents a DP architecture with ducted fans distributed along the wing span in a hybrid electric configuration aircraft carrying 150 PAX [61]. The study uses 2D aerodynamic analysis for locating the fans and utilizes propulsive flap concepts for high-lift requirement. Finite element code is used for carrying out the wing structure analysis. The study highlights the benefit of distribution of the mass across the span on the bending moment.

An aircraft conceptual design by TU-Delft made for the regional segment, for 70 PAX with parallel hybrid electric configuration with a design range of $1528 \mathrm{~km}$, based on Li-air batteries with a specific energy of $1000 \mathrm{Wh} / \mathrm{kg}$, providing 34\% of the shaft power throughout the mission, yields a reduction in emissions of $28 \%$ [116]. A 70-passenger aircraft design for the regional market, with a mission range of $1530 \mathrm{~km}$, was assessed with different variants in propulsion system configuration: parallel, serial, 
and parallel/serial for the fuel/energy consumption assessment. In these, parallel/serial showed the largest potential for fuel saving due to the added benefits from the aerodynamic improvements [117].

The project Turboelectric Aircraft Development Environment (TRADE) aims to establish a platform for integration of the multidisciplinary aircraft sizing tool EVA comprising engine performance and mission analysis model, integrated to the thermal model, electrical component model and structure model in OpenMDAO framework, with an objective of performing wide design space exploration and optimization work $[41,118]$.

Besides all these developments, many new entities have planned to enter the market with the fully electric and hybrid aircraft designs [3]. Wright Electric, has announced to build a 150-seat electrically-powered aircraft in the coming ten years period. Zunum Aero has been working on two variants of the regional series/parallel HE aircraft with PAX 15, $600 \mathrm{~nm}$ and PAX 50, $1000 \mathrm{~nm}$ with two fuselage-mounted electric propulsors powered by a combined system of a turboelectric generator and battery. The expected years of operation are 2023 and 2027, respectively. It is believed that the configuration is particularly suitable for a highly efficient and low-cost operation on a conventional airframe. The Eviation Alice is a fully electric nine-passenger aircraft that uses two BLI wing-tip propellers and one tail-cone propeller. Ampaire's Tailwind concept, features an aft mounted BLI propulsor employing either a fully electric or series hybrid electric architecture. The targeted range to be flown is for less than $350 \mathrm{~nm}$ with 9 PAX payload capacity.

A compendium of the electric propulsion application based conceptual design system studies is presented in Table 2. Some of these are demonstrators and some are conceptual and are not expected to fly in imminent future. Nonetheless, each of these studies contributes to the body of knowledge on the future of electric airplanes. 
Table 2. Summary of Key Findings of Electric Aircraft Studies.

\begin{tabular}{|c|c|c|c|c|c|}
\hline $\begin{array}{l}\text { Research Team/ } \\
\text { Conceptual Design }\end{array}$ & Category & $\begin{array}{l}\text { Propulsion System, } \\
\text { Aircraft Highlights }\end{array}$ & $\begin{array}{l}\text { Electrical Drivetrain Size, } \\
\text { Technology Parameters }\end{array}$ & Summary of Key Findings & References \\
\hline \multicolumn{6}{|l|}{$2035-2050$} \\
\hline NASA N3-X & $\begin{array}{l}\text { Single-aisle, } \\
\text { 300 PAX, } \\
\text { YEIS: 2040-2045 }\end{array}$ & $\begin{array}{l}\text { TeDP with } 14 \text { BLI fans } \\
\text { spanned on the trailing } \\
\text { edge of the wing body, } \\
\text { BWB design }\end{array}$ & $\begin{array}{l}\text { Superconducting technology, } \\
4 \text { MW motor }\end{array}$ & $\begin{array}{l}\text { Showed avenues for } 50 \% \\
\text { improvement in fuel burn from the } \\
\text { airframe improvement with } \\
\text { another } 20 \% \text { with turboelectric } \\
\text { enabled distributed electrical } \\
\text { system. ANOPP as noise prediction } \\
\text { tool is used, LTO NOx emissions } \\
\text { are calculated based on the existing } \\
\text { correlation-based methods. }\end{array}$ & {$[22,24,52,119]$} \\
\hline MIT & $\begin{array}{l}\text { A320 neo, } \\
\text { 180 PAX } \\
\text { YEIS: } 2050\end{array}$ & Fully electric & Battery SE: $800 \mathrm{Wh} / \mathrm{kg}$ & $\begin{array}{l}\text { A minimum battery SE } 800 \mathrm{Wh} / \mathrm{kg} \\
\text { is desired for } 500 \mathrm{~nm} \text { range. }\end{array}$ & [13] \\
\hline $\begin{array}{l}\text { E-Thrust, } \\
\text { EADS/Rolls-Royce }\end{array}$ & $\begin{array}{l}\text { Single-aisle, Regional, } \\
90 \text { PAX } \\
\text { YEIS: } 2050\end{array}$ & $\begin{array}{l}\text { Airframe: Tube and wing, } \\
\text { series/parallel hybrid } \\
\text { TeDP, wing-embedded BL } \\
\text { ingested electric fans, } \\
\text { system, six fans powered } \\
\text { from each gas turbine } \\
\text { generator and battery }\end{array}$ & $\begin{array}{l}\text { Battery SE: } 1000 \mathrm{Wh} / \mathrm{kg} \text {, } \\
\text { Lithium air, } 2 \mathrm{MW} \text {, } \\
\text { superconducting system }\end{array}$ & $\begin{array}{l}\text { It enables a high effective BPR } \\
\text { design: } 20 \text {. The core is sized for } \\
\text { cruise operation. Both onboard } \\
\text { charging, or ground-based } \\
\text { charging is possible. The battery } \\
\text { assists during take-off } \\
\text { and climb segments. }\end{array}$ & [120] \\
\hline TU-Delft & $\begin{array}{l}\text { TurboProp Regional, } \\
\text { YEIS: 2035-2040 }\end{array}$ & $\begin{array}{l}\text { Serial-parallel } \\
\text { tip-mounted }\end{array}$ & Battery SE: $750 \mathrm{Wh} / \mathrm{kg}$ & $\begin{array}{l}28 \% \text { fuel burn and } 14 \% \text { energy } \\
\text { reduction potential. }\end{array}$ & [117] \\
\hline \multicolumn{6}{|l|}{$2030-2035$} \\
\hline SUGAR Freeze & $\begin{array}{l}\text { Single-aisle, } \\
154 \text { PAX, } \\
900 \mathrm{~nm}, \\
\text { YEIS: } 2035\end{array}$ & $\begin{array}{l}\text { Airframe: Truss-braced, } \\
\text { natural gas-based fuel cell, } \\
\text { turboelectric DEP system } \\
\text { with BLI fans, } 2 \text { turbofans, } \\
1 \text { motor driven aft-fan }\end{array}$ & $\begin{array}{l}\text { SOFC fuel cell, } \\
\text { cryogenic power system }\end{array}$ & $\begin{array}{l}56 \% \text { fuel burn improvement, } \\
70 \% \mathrm{CO}_{2} \text { emission } \\
\text { reduction potential. }\end{array}$ & [27] \\
\hline SUGAR Volt & $\begin{array}{l}\text { Single-aisle, } \\
154 \text { PAX, } \\
900 \mathrm{~nm}, \\
\text { YEIS: } 2035\end{array}$ & $\begin{array}{l}\text { Airframe: Truss-brace, } \\
\text { parallel hybrid, electrified } \\
\text { cruise operation, } 2 \text { motor } \\
\text { assisted turbofans }\end{array}$ & $\begin{array}{l}\text { 1.3 MW or } 5.3 \mathrm{MW}, \\
\text { Battery SE: } 750 \mathrm{Wh} / \mathrm{kg} \text {, } \\
\text { EM SP: } 3-5 \mathrm{~kW} / \mathrm{kg}, \\
\text { EM Efficiency: } 93 \%\end{array}$ & $\begin{array}{l}\text { Potential for } 60 \% \text { reduction in fuel } \\
\text { burn and } 87 \% \text { reduction in } \\
\text { NOx emission. }\end{array}$ & [29] \\
\hline
\end{tabular}


Table 2. Cont.

\begin{tabular}{|c|c|c|c|c|c|}
\hline $\begin{array}{l}\text { Research Team/ } \\
\text { Conceptual Design }\end{array}$ & Category & $\begin{array}{l}\text { Propulsion System, } \\
\text { Aircraft Highlights }\end{array}$ & $\begin{array}{l}\text { Electrical Drivetrain Size, } \\
\text { Technology Parameters }\end{array}$ & Summary of Key Findings & References \\
\hline UTRC & $\begin{array}{l}\text { Single-aisle, } \\
154 \text { PAX, } \\
900 \mathrm{~nm}, \\
\text { YEIS: } 2035\end{array}$ & $\begin{array}{l}\text { Airframe: Tube and wing, } \\
\text { parallel hybrid, } \\
\text { power augmentation } \\
\text { during take-off and climb, } \\
2 \text { motor assisted turbofans }\end{array}$ & $\begin{array}{l}\text { System Voltage: } 1000 \mathrm{~V} \\
\text { Case 1: } 2.1 \mathrm{MW} \text {, } \\
\text { Battery SE: } 1000 \mathrm{Wh} / \mathrm{kg}, \\
\text { EM SP: } 13 \mathrm{~kW} / \mathrm{kg}, \\
\text { Powertrain Efficiency: } 95 \% \\
\text { Case 2: Battery SE: } 500 \mathrm{Wh} / \mathrm{kg} \text {, } \\
\text { EM SP: } 6.8 \mathrm{~kW} / \mathrm{kg} \text {, } \\
\text { Powertrain Efficiency: } 91 \%\end{array}$ & $\begin{array}{l}\text { Case 1: } \\
7 \%-9 \% \text { fuel, } 3 \%-5 \% \text { energy } \\
\text { reduction potential. } \\
\text { Case 2: } \\
3.4 \% \text { fuel, } 0.6 \% \text { energy increase. }\end{array}$ & {$[31,35]$} \\
\hline EVE, RRNA & $\begin{array}{l}\text { Single-aisle, } \\
154 \mathrm{PAX}, \\
900 \mathrm{~nm}, \\
\text { YEIS: } 2035\end{array}$ & $\begin{array}{l}\text { Airframe: Tube and wing, } \\
\text { parallel hybrid, } \\
\text { power augmentation } \\
\text { during take-off and climb, } \\
2 \text { motor assisted turbofans }\end{array}$ & $\begin{array}{l}\text { 1.9 MW, } \\
\text { Battery SE: } 750 \mathrm{Wh} / \mathrm{kg} \text {, } \\
\text { EM SP: } 13 \mathrm{~kW} / \mathrm{kg}, \\
\text { EM Efficiency: } 96 \%\end{array}$ & $\begin{array}{l}24 \% \text { fuel, } 7 \% \text { energy } \\
\text { reduction potential. }\end{array}$ & {$[37,39]$} \\
\hline STARC-ABL & $\begin{array}{l}\text { Single-aisle, } \\
154 \text { PAX, } \\
900 \mathrm{~nm}, \\
\text { YEIS: } 2035\end{array}$ & $\begin{array}{l}\text { Airframe: Tube and wing, } \\
\text { partially turboelectric } \\
\text { with electrically driven } \\
\text { aft-fan propulsor }\end{array}$ & $\begin{array}{l}\text { Two } 1.45 \mathrm{MW} \text { generators, } \\
\text { One } 2.6 \mathrm{MW}, \\
\text { EM SP:13kW/kg EM, } \\
90 \% \text { electrical } \\
\text { drivetrain efficiency }\end{array}$ & $\begin{array}{l}7 \% \text { fuel burn, } 12 \% \text { energy reduction } \\
\text { potential, in the later version } \\
\text { modified to } 2.7 \% \text { fuel burn } \\
\text { reduction potential. }\end{array}$ & {$[25,26,83]$} \\
\hline ECO-150 & $\begin{array}{l}\text { Single-aisle, } \\
150 \text { PAX, } \\
1650 \mathrm{~nm}, \\
\text { YEIS: } 2035\end{array}$ & $\begin{array}{l}\text { Airframe: Tube and } \\
\text { wing/split wing, TeDP, } \\
16 \text { wing motor driven fans }\end{array}$ & $\begin{array}{l}\text { Motor SP: } 4.5 \mathrm{~kW} / \mathrm{kg}, \\
\text { Generator SP: } 8 \mathrm{~kW} / \mathrm{kg} \\
\text { Battery SE: } 400 \mathrm{Wh} / \mathrm{kg},\end{array}$ & $\begin{array}{l}44 \% \text { and } 59 \% \text { fuel burn reduction } \\
\text { potential with conventional } \\
\text { technology and in superconducting } \\
\text { technology, respectively. }\end{array}$ & [28] \\
\hline $\begin{array}{l}\text { NOVAIR-Conceptual } \\
\text { Design }\end{array}$ & $\begin{array}{l}\text { A320 NEO aircraft, } \\
150 \text { PAX, } \\
800 \mathrm{~nm}, \\
\text { YEIS: } 2035\end{array}$ & $\begin{array}{l}\text { Parallel hybrid with } 10 \% \\
\text { downscaling engine }\end{array}$ & $\begin{array}{l}4 \text { MW EM, } 2020 \text { year, } \\
\text { Li-S Battery SE: } 500 \mathrm{Wh} / \mathrm{kg} \text {, } \\
\text { SP: } 300 \mathrm{~W} / \mathrm{kg}-Y e a r 2020 \\
\text { Li-S Battery SE: } 1000 \mathrm{Wh} / \mathrm{kg} \text {, } \\
\text { SP: } 600 \mathrm{~W} / \mathrm{kg} \text {-Year } 2040\end{array}$ & $\begin{array}{l}10 \% \text { and } 14 \% \text { block fuel reduction } \\
\text { potential in the year } 2020 \text { and } 2040 .\end{array}$ & [113] \\
\hline
\end{tabular}


Table 2. Cont.

\begin{tabular}{|c|c|c|c|c|c|}
\hline $\begin{array}{l}\text { Research Team/ } \\
\text { Conceptual Design }\end{array}$ & Category & $\begin{array}{l}\text { Propulsion System, } \\
\text { Aircraft Highlights }\end{array}$ & $\begin{array}{l}\text { Electrical Drivetrain Size, } \\
\text { Technology Parameters }\end{array}$ & Summary of Key Findings & References \\
\hline NOVAIR & $\begin{array}{l}\text { A320, } \\
\text { Single-aisle, } \\
\text { 150 PAX, } \\
\text { YEIS: } 2035\end{array}$ & $\begin{array}{l}\text { Airframe: Tube and wing, } \\
\text { parallel hybrid electric }\end{array}$ & $\begin{array}{l}\text { Battery SE: } 500 \mathrm{Wh} / \mathrm{kg} \text {, } \\
\text { EM SP: } 7.5 \mathrm{~kW} / \mathrm{kg}, \\
\text { Efficiency: } 95 \%, \\
\text { Inverter SP: } 7.5 \mathrm{~kW} / \mathrm{kg}, \\
\text { Efficiency: } 95 \%\end{array}$ & $\begin{array}{l}\text { Benefits from a } 5 \% \text {, and } 7 \% \text { in } \\
\text { energy and fuel reduction } \\
\text { opportunity with battery boosting, } \\
\text { electrical taxing, MEA and } \\
\text { downscaling of the engine. } \\
\text { An energy optimized scenario } \\
\text { found to be optimum for CO and } \\
\text { UHC emission, but not in } \\
\text { the NOx emission. } \\
\text { With a trade-off made, } \\
\text { a } 90 \% \text { downscaling of the engine } \\
\text { presented an optimum scenario } \\
\text { in all three options: } \\
2 \% \text { energy reduction, } 6 \% \text { fuel burn } \\
\text { reduction, and } 1.5 \% \text { NOx } \\
\text { emission reduction. }\end{array}$ & [114] \\
\hline CENTRELINE & $\begin{array}{l}\text { A330, Twin-aisle, } \\
300 \text { PAX, } \\
4800 \mathrm{~nm}, \\
\text { YEIS: } 2035\end{array}$ & $\begin{array}{l}\text { Turboelectrically driven } \\
\text { electrical fuselage aft fans }\end{array}$ & $\begin{array}{l}\text { Electrical generator: } 4.6 \mathrm{MW} \text {, } \\
\text { electrical motor: } 8 \mathrm{MW} \\
\text { machine efficiency: } 95 \%\end{array}$ & $\begin{array}{l}8 \% \text { block fuel reduction } \\
\text { opportunity is established. }\end{array}$ & [75] \\
\hline DRAGON & $\begin{array}{l}\text { Single-aisle, } \\
150 \text { PAX, } \\
1200 \mathrm{~nm}, \\
\text { YEIS: } 2040\end{array}$ & $\begin{array}{l}\text { Airframe: Tube and wing, } \\
\text { hybrid electric } \\
\text { distributed propulsion }\end{array}$ & $\begin{array}{l}2 \text { Turboshafts of } 15 \mathrm{MW} \text { each, } \\
\text { with } 20 \text { electrical motors, } \\
\text { SP: } 13.2-25 \mathrm{~kW} / \mathrm{kg} \text {, } \\
\text { Generator: } 13.5-19 \mathrm{~kW} / \mathrm{kg} \text {, } \\
\text { Voltage: } 2.16-5 \mathrm{kV}\end{array}$ & $\begin{array}{l}\text { A } 7 \% \text { fuel burn reduction potential } \\
\text { is established over conventional } \\
\text { advanced underwing } \\
\text { turbofan aircraft. }\end{array}$ & {$[61]$} \\
\hline TRADE & $\begin{array}{l}\text { Single-aisle, } 150 \text { PAX, } \\
925 \mathrm{~km} \text {, YEIS: } 2035\end{array}$ & Parallel hybrid electric & $\begin{array}{l}\text { Detailed Electrical machine } \\
\text { modeling, battery SE: } \\
1500 \mathrm{Wh} / \mathrm{kg} \text {, efficiency: } 90 \%\end{array}$ & $\begin{array}{l}3 \% \text { fuel burn reduction is plausible } \\
\text { with } 2 \mathrm{MW} \text { of electrical power } \\
\text { hybridization during the take-off. }\end{array}$ & [41] \\
\hline BHL & $\begin{array}{l}\text { Single-aisle, } \\
70 \text { PAX, } 900 \mathrm{~nm} / \\
180 \text { PAX, } 1100 \mathrm{~nm} \text {, } \\
\text { YEIS: } 2035\end{array}$ & $\begin{array}{l}\text { Airframe: fixed wing, } \\
\text { tri-fan morphology, } \\
\text { serial/parallel hybrid } \\
\text { electric }\end{array}$ & $\begin{array}{l}\text { 4.5 } \mathrm{MW} \text { in } 70 \mathrm{PAX} \\
\text { 8.5 } \mathrm{MW} \text { in } 180 \mathrm{PAX}\end{array}$ & $\begin{array}{l}\text { 15\% fuel burn reduction. } \\
\text { Battery SE } 900-950 \mathrm{Wh} / \mathrm{kg} \text { for } \\
70 \text { PAX design. } \\
\text { Battery SE: } 1300 \mathrm{Wh} / \mathrm{kg} \text { for } \\
180 \text { PAX design. }\end{array}$ & [103] \\
\hline
\end{tabular}


Table 2. Cont.

\begin{tabular}{|c|c|c|c|c|c|}
\hline $\begin{array}{l}\text { Research Team/ } \\
\text { Conceptual Design }\end{array}$ & Category & $\begin{array}{l}\text { Propulsion System, } \\
\text { Aircraft Highlights }\end{array}$ & $\begin{array}{l}\text { Electrical Drivetrain Size, } \\
\text { Technology Parameters }\end{array}$ & Summary of Key Findings & References \\
\hline BHL & $\begin{array}{l}\text { Single-aisle, } \\
180 \text { PAX, } \\
\text { 1100-1700 nm, } \\
\text { YEIS: } 2035\end{array}$ & $\begin{array}{l}\text { Airframe: Fixed wing, } \\
\text { quad-fan morphology, } \\
\text { discrete parallel } \\
\text { hybrid electric }\end{array}$ & $\begin{array}{l}\text { Battery SE: } 1000 \mathrm{Wh} / \mathrm{kg} \text {, } \\
1500 \mathrm{Wh} / \mathrm{kg}\end{array}$ & $\begin{array}{l}\text { No block fuel reduction potential } \\
\text { with battery SE. } 1000 \mathrm{Wh} / \mathrm{kg} \text { in a } \\
\text { range above } 1100 \mathrm{~nm} \text {. } \\
1500 \mathrm{Wh} / \mathrm{kg} \text { battery SE is desired to } \\
\text { have fuel burn for a range } \\
\text { less than } 1700 \mathrm{~nm} .\end{array}$ & [103] \\
\hline BHL & $\begin{array}{l}\text { Single-aisle, } \\
180 \text { PAX, } \\
900 \mathrm{~nm} \\
\text { YEIS: } 2035\end{array}$ & $\begin{array}{l}\text { Parallel hybrid, } \\
\text { hybridized for cruise and } \\
\text { climb operation }\end{array}$ & $\begin{array}{l}\text { 5.1 MW HTS Motor, } \\
\text { Cryogenic System } \\
\text { Battery SE: } 1500 \mathrm{Wh} / \mathrm{kg}\end{array}$ & $\begin{array}{l}16 \% \text { fuel burn reduction } \\
\text { using a mix of fuel. } \\
\text { Energy to electrical energy } \\
\text { of } 82 \%: 18 \% \text {. }\end{array}$ & [121] \\
\hline BHL & $\begin{array}{l}180 \mathrm{PAX}, \\
900 \mathrm{~nm}, \\
\text { YEIS: } 2035\end{array}$ & $\begin{array}{l}\text { Parallel hybrid, } \\
\text { hybridized for } \\
\text { cruise operation }\end{array}$ & Battery SE: 750-1000 Wh/kg & $\begin{array}{l}20 \% \text { fuel burn reduction potential } \\
\text { for battery SE of } 1500 \mathrm{Wh} / \mathrm{kg} \text {. }\end{array}$ & [40] \\
\hline BHL & $\begin{array}{l}180 \mathrm{PAX} \\
1300 \mathrm{~nm}, \\
\text { YEIS:2035 }\end{array}$ & $\begin{array}{l}\text { Discrete parallel hybrid } \\
\text { electric, hybridized for } \\
\text { take-off, climb, cruise and } \\
\text { diversion operation }\end{array}$ & $\begin{array}{l}\text { Superconducting technology, } \\
\text { Battery SE: } 1000 \mathrm{Wh} / \mathrm{kg}\end{array}$ & $\begin{array}{l}8.5 \% \text { fuel burn reduction potential } \\
\text { but a } 9.2 \% \text { increase in } \\
\text { the energy demand. }\end{array}$ & [122] \\
\hline VoltAir & $\begin{array}{l}68 \mathrm{PAX} \\
900 \mathrm{~nm} \\
\text { YEIS: } 2035\end{array}$ & $\begin{array}{l}\text { Fully electric, BLI fuselage } \\
\text { fan, laminar flow wing }\end{array}$ & $\begin{array}{l}\text { HTS Motor SP: } 8 \mathrm{~kW} / \mathrm{kg} \text {, } \\
\text { Superconducting wire, } 1 \mathrm{kV} \\
\text { DC transmission voltage, } \\
\text { Battery SE: } 750 \mathrm{Wh} / \mathrm{kg}\end{array}$ & $\begin{array}{l}5 \% \text { propulsion efficiency } \\
\text { improvement from BLI. In addition, } \\
\text { lesser induced drag and zero lift } \\
\text { drag is obtained from a laminar } \\
\text { flow wing design. Empty weight } \\
\text { saving because of low slenderness } \\
\text { fuselage design. }\end{array}$ & {$[16,67]$} \\
\hline $\begin{array}{l}\text { Georgia Institute of } \\
\text { Technology }\end{array}$ & $\begin{array}{l}\text { Regional jet, } \\
50 \text { PAX, } \\
\text { YEIS: } 2035\end{array}$ & $\begin{array}{l}\text { Partially electric } \\
\text { distributed system with } \\
\text { wing upper surface } \\
\text { boundary layer power } \\
\text { boosted during take-off } \\
\text { and climb }\end{array}$ & $\begin{array}{l}\text { Trade study showing } \\
\text { sensitivity with transmission } \\
\text { efficiency and the specific } \\
\text { power of the electrical } \\
\text { drivetrain and in the battery } \\
\text { specific energy for different } \\
\text { technology in 300-1950 nm } \\
\text { mission range }\end{array}$ & $\begin{array}{l}\text { The configuration is less sensitive } \\
\text { to the battery technology compared } \\
\text { to parallel hybrid system for } \\
\text { achieving a higher range. } \\
20 \% \text { assistance during take-off } \\
\text { gives significant opportunity for } \\
\text { fuel burn reduction. }\end{array}$ & [84] \\
\hline
\end{tabular}


Table 2. Cont.

\begin{tabular}{|c|c|c|c|c|c|}
\hline $\begin{array}{l}\text { Research Team/ } \\
\text { Conceptual Design }\end{array}$ & Category & $\begin{array}{l}\text { Propulsion System, } \\
\text { Aircraft Highlights }\end{array}$ & $\begin{array}{l}\text { Electrical Drivetrain Size, } \\
\text { Technology Parameters }\end{array}$ & Summary of Key Findings & References \\
\hline $\begin{array}{l}\text { Georgia Institute of } \\
\text { Technology }\end{array}$ & $\begin{array}{l}50 \text {-210 PAX, } \\
\text { YEIS: } 2035\end{array}$ & Parallel hybrid electric & $\begin{array}{l}\text { Trade study showing } \\
\text { sensitivity with electrical } \\
\text { drivetrain efficiency and the } \\
\text { specific power and in the } \\
\text { battery specific energy in } \\
500-1500 \mathrm{~nm} \text { range }\end{array}$ & $\begin{array}{l}\text { The } 50 \text { PAX regional jet segment, } \\
\text { increase in electrical drivetrain SP } \\
\text { can compensate for } \\
\text { the lower battery SE. } \\
\text { At lower battery SE, t trade-off } \\
\text { exists between drivetrain efficiency } \\
\text { and in specific power. }\end{array}$ & [123] \\
\hline UTRC & $\begin{array}{l}\text { TurboProp, } \\
30-50 \text { PAX, } \\
250 \mathrm{~nm}, \\
\text { YEIS: } 2035\end{array}$ & $\begin{array}{l}\text { Parallel hybrid electric } \\
\text { boosted configuration }\end{array}$ & $\begin{array}{l}\text { EM: } 13 \mathrm{~kW} / \mathrm{kg} \text {, efficiency: } \\
97 \% \text {, motor drive: } 98 \% \text {, } \\
1000 \text { V Battery SE: } 355 \mathrm{Wh} / \mathrm{kg}\end{array}$ & $\begin{array}{l}\text { A fuel burn reduction of } 30 \% \text { and } \\
\text { energy reduction of } \\
25 \% \text { is predicted. }\end{array}$ & [124] \\
\hline PHA2-TipProp, DLR & $\begin{array}{l}\text { Regional, } \\
\text { Turboprop, } \\
70 \text { PAX, } \\
800 \mathrm{~nm}, \\
\text { YEIS: } 2035 \\
\end{array}$ & $\begin{array}{l}\text { Airframe: Tube and wing. } \\
\text { parallel hybrid, } \\
\text { wingtip propellers }\end{array}$ & Battery SE: $500 \mathrm{Wh} / \mathrm{kg}$ & $\begin{array}{l}4 \% \text { fuel burn improvement } \\
\text { potential because of the } \\
\text { aero-prolusion } \\
\text { efficiency improvement. }\end{array}$ & {$[45]$} \\
\hline Ce-Liner, BHL & $\begin{array}{l}\text { Narrow-body, } \\
\text { 189 PAX, } \\
\text { YEIS: } 2035\end{array}$ & $\begin{array}{l}\text { Airframe: C-wing, } \\
\text { fully electric, } \\
\text { distributed } 4 \text { ducted } \\
\text { fan-2 aft mounted }\end{array}$ & $\begin{array}{l}\text { Cryogenic, } \\
\text { battery SE: } 2000 \mathrm{Wh} / \mathrm{kg}\end{array}$ & $\begin{array}{l}\text { DEP reduce the sizing of the } \\
\text { electrical ducted fan. } \\
\text { Improved aerodynamic } \\
\text { performance due to the } \\
\text { C-wing airframe. }\end{array}$ & [67] \\
\hline TU-Delft & $\begin{array}{l}\text { Regional, } \\
70 \text { PAX, } \\
1528 \mathrm{~km}, \\
\text { YEIS: } 2035\end{array}$ & $\begin{array}{l}\text { Parallel hybrid with } 34 \% \\
\text { shaft power } \\
\text { boosted from battery }\end{array}$ & Li-air battery SE: $1000 \mathrm{Wh} / \mathrm{kg}$ & $\begin{array}{l}28 \% \text { fuel burn reduction potential, } \\
\text { with } 14 \% \text { increase in MTOM and } \\
\text { wing area. }\end{array}$ & [116] \\
\hline TU Delft & $\begin{array}{l}200 \mathrm{PAX} \\
650 \mathrm{~nm} \\
\text { YEIS: } 2035\end{array}$ & Partially turboelectric & $\begin{array}{l}\text { Trade studies for different } \\
\text { technology levels in the } \\
\text { electric drivetrain specific } \\
\text { power and efficiency }\end{array}$ & $\begin{array}{l}11 \% \text { improvement in the } \\
\text { aero-propulsive efficiency is } \\
\text { achievable if } 20 \% \text { electric shaft } \\
\text { power is used, with potential for } \\
5 \% \text { energy saving. }\end{array}$ & [125] \\
\hline
\end{tabular}


Table 2. Cont.

\begin{tabular}{|c|c|c|c|c|c|}
\hline $\begin{array}{l}\text { Research Team/ } \\
\text { Conceptual Design }\end{array}$ & Category & $\begin{array}{l}\text { Propulsion System, } \\
\text { Aircraft Highlights }\end{array}$ & $\begin{array}{l}\text { Electrical Drivetrain Size, } \\
\text { Technology Parameters }\end{array}$ & Summary of Key Findings & References \\
\hline \multicolumn{6}{|l|}{$2025-2030$} \\
\hline PEGASUS & $\begin{array}{l}\text { Regional, } \\
48 \text { PAX, } \\
200 \mathrm{~nm} \text {-fully electric } \\
400 \mathrm{~nm} \text { - hybrid electric } \\
600 \mathrm{~nm} \text {-baselineYEIS: } \\
2030\end{array}$ & $\begin{array}{l}\text { Airframe: Tube and wing, } \\
\text { parallel hybrid/fully } \\
\text { electric fully distributed }\end{array}$ & $\begin{array}{l}1 \mathrm{MW} \text { EM SP: } 7.3 \mathrm{~kW} / \mathrm{kg} \text {, } \\
600 \mathrm{~V} \text { Battery SE: 500, 750, } \\
1000 \mathrm{Wh} / \mathrm{kg} \\
\text { Electrical drivetrain } \\
\text { efficiency: } 90 \%\end{array}$ & $\begin{array}{l}27 \% \text { and } 39 \% \text { energy reduction } \\
\text { potential shown for two different } \\
\text { operation strategies. }\end{array}$ & [43] \\
\hline $\begin{array}{l}\text { SAFRAN } \\
\text { Conceptual Design }\end{array}$ & $\begin{array}{l}19 \text { PAX, } \\
150 \mathrm{~nm}, 430 \mathrm{~nm}, 700 \mathrm{~nm}, \\
\text { YEIS: } 2030\end{array}$ & $\begin{array}{l}\text { Fixed Wing, a tri-prop } \\
\text { (two on wing podded } \\
\text { turbo-props and one } \\
\text { aft-fuselage mounted } \\
\text { electrical motor) }\end{array}$ & $\begin{array}{l}\text { Battery SE: } 500 \mathrm{Wh} / \mathrm{kg} \text {, } \\
1.1 \mathrm{MW} \text { shaft power electrical. } \\
\text { Powertrain drive efficiency: } \\
87 \% \text {, SP: } 10 \mathrm{~kW} / \mathrm{kg}\end{array}$ & $\begin{array}{l}\text { Block fuel reduction up to } 39 \% \text {, } \\
25 \%, 10 \% \text {, for } 150 \mathrm{~nm}, 430 \mathrm{~nm} \text {, } \\
\text { and } 700 \mathrm{~nm} \text { respectively. }\end{array}$ & [126] \\
\hline TU-Delft & $\begin{array}{l}\text { A-320 retrofit, } \\
1000 \mathrm{~km}, \\
\text { YEIS: } 2030\end{array}$ & $\begin{array}{l}\text { Parallel hybrid with } 90 \% \\
\text { downscaled core }(25 \%, \\
14 \% \text { boosted power } \\
\text { during take-off and climb) }\end{array}$ & Battery SE: $600 \mathrm{Wh} / \mathrm{kg}$ & $\begin{array}{l}7.5 \% \text { fuel burn and } 3.7 \% \text { NOx } \\
\text { reduction potential. }\end{array}$ & [87] \\
\hline \multicolumn{6}{|l|}{ 2020-2025 } \\
\hline DLR & $\begin{array}{l}\text { TurboProp, } \\
\text { Regional, } \\
72 \text { PAX, } \\
\text { YEIS: 2025, } \\
\text { Range } 1500 \mathrm{~km}\end{array}$ & $\begin{array}{l}\text { Serial/parallel hybrid } \\
\text { electric, turboelectric }\end{array}$ & $\begin{array}{l}\text { EM: 7.5-12 kW/kg, efficiency: } \\
\text { 97\%, Battery SE: } 750 \mathrm{Wh} / \mathrm{kg}\end{array}$ & $\begin{array}{l}\text { The serial hybrid and turboelectric } \\
\text { configurations show better fuel } \\
\text { saving potential than parallel } \\
\text { hybrid option. Four times } \\
\text { improvement in the battery SP and } \\
\text { SE is desired from the SOA to make } \\
\text { fully electric viable. }\end{array}$ & [127] \\
\hline
\end{tabular}


TeDP is the commonly used configuration if it is in the large passenger segment, e.g., N3-X, ECO-150, ECO-250. The researchers are also aiming for implementing superconducting technology in these designs [51,128]. The airframe morphology is evenly distributed between tube and wing [54] and other novel airframe technology such as BWB, strut-braced, split-wing, C-shape, etc. It is necessary that the conventional airframe be modified to get additional structural and aerodynamic improvements especially when targeted to get the benefit of the BLI and DEP system. SUGAR Volt is built on the improved aerodynamics of strut-braced wing of SUGAR High to get aerodynamic benefits. The N3-X concept utilizes the BWB airframe and the ECO-150 designs utilizes split-wings to get the aerodynamic benefits. The NOVAIR conceptual design considers a T and W airframe with DEP system.

The battery dependent configurations have significant limitations to the range given to the lower SE in present and future battery technology. This made a mission to choose the design for short-to-medium range. The commonality between these studies is that they are based on the assumed technology in the future time frame. However, there is no consensus found in these studies on the technology level assumption. The majority of the studies are focused for parametrically varying the battery SE for the range sensitivity. The challenges are scaled proportionally with the weight and inefficiency related drawbacks. There is also need for parametric study for calibrating the sensitivities of various other electrical performance parameters such as specific power in the components and electrical drivetrain efficiency for the performance of the aircraft. A electrical system sizing model with high level of accuracy and scaled for different levels of power is desired in order to predict the performance in the electrical system in a more realistic way. It is felt that the industry is missing an electrical system design, well suited for optimizing the performance of the electrical aircraft over a range of missions and suitable for different aircraft designs.

It is even a daunting task for the conceptual airline designer to estimate the weight of electric aircraft especially where there are many trade-offs and coupled interaction exists between different disciplines. It also has huge reliance on the assumed future technology level. The systems studying the assessment of the benefits of the electric aircraft are made for the sub-system level considering interaction between two or three disciplines in the existing multidisciplinary environment by integration of the electrical propulsion system with newly developed concepts. The system studies identified the technical and performance drivers for a specific electric aircraft, with trade studies and sensitivity analysis, however they can't make any generalized assumption on the technology level nor on the quantification of the benefits. It is desired that a modeling environment enables wide design space exploration with a modest running time and computational resources accounting for all the possible interactions amongst the various disciplines.

\section{Challenges \& Developments}

The motivation behind electrification of the prolusion system is to make it more efficient compared to conventional fueled propulsion systems. This is achievable with an efficient energy conversion and transmission system, and improvement in other attributes in vehicular efficiency parameters. Different philosophies in the propulsion system designs have been explored across various research organizations, academia, and industries. Though the outcome of the research is headed in the right direction, further developments are needed across the breadth of the enabling technologies to make many of the proposed concepts viable. Several of the studies focused on benchmarking the underlying technologies for successful implementation of electric aircraft concepts. This section summarizes the challenges in research portfolio of various research organizations and industries for key enabling technologies.

\subsection{Operational Challenges and Developments}

Research on electric aircraft conceptualization studies gave insights to its various unique characteristics and its limitations. One such operability issues is that it limits implementation of higher degrees of hybridization in a parallel hybrid configuration [29,30,32]. Hybrid operation also 
has adverse impact on the performance of the turbo-components. A variable area bypass nozzle or variable area core nozzle in the fan and operability bleed aft of the LPC are means to deal with the surge margin issues for the LPC components. The EVE design from RRNA includes a variable pitch fan design to deal with the higher degree of hybridization [37]. Furthermore, parallel hybrid electric design gives an opportunity for choosing the engine cycle for optimum performance benefits $[39,90]$. An engine design with a core sized accounting electric power addition, however, expands the surge margin limitation and allows for a higher degree of hybridization [33]. Along this line, a concept of discrete parallel hybrid electric operation was proposed in which both turbo fans and electric ducted fans (EDFs) are meant to operate independently without any serial or parallel connections [44]. This gives the full flexibility of optimizing the performance for both fans [44]. Different aircraft morphologies were suggested utilizing both turbo fans and EDFs, and the best benefits were found in a quad-fan serial/parallel arrangements.

The aircraft operation does not demand the same amount of thrust power during all segments of the mission. This gives the opportunity for harvesting some power during the low power demand for subsequent use during high power operation. Hybrid electric operation with battery and electric machines onboard makes this possible. One possible notional strategy- is to charge the battery in the cruise or descent segment with a regenerative process [32]. However, the SUGAR Volt phase-II study dismissed this option, on the grounds of causing a non-optimum descent operation.

\subsection{Electric Aircraft Sizing Challenges \& Developments}

The traditional aircraft sizing process is performed based on the premises of balancing the thrust to drag with the fuel flow within the set operational and performance constraints defined by the top-level requirements. It involves a multidisciplinary analysis comprising three major disciplines: aerodynamic, structure, and a fuel-based propulsion system largely based on established correlation-based scaling laws. The methodology involves a great deal of iterations between the engine performance module and the aircraft performance module. The novelty added in recent years for minimizing the iterations is using a multi-point design approach [129]. Hybrid electric configurations deviate from the conventional ones due to the presence of two energy sources with distinct characteristics-a fixed weight battery and variable weight fuel. The sizing of the components is determined based on the degree of hybridization and the operation strategy decides the fuel consumption rate. These characteristic features of hybrid electric propulsion make the performance mission time dependent. The conventional sizing methodology environment does not have the resiliency of capturing the characteristics of a hybrid electric system. Also, this concept entails inclusion of new electrical and thermal system components to the existing propulsion system. There are significant differences that must be accounted for sizing an electric aircraft and to explore the design space, hence, modification in the sizing method are entailed. In the wake of this demand, the existing aircraft sizing tools are being revamped in order to include the unique feature of electric propulsion concepts. The following sections introduce the challenges and requirements of developing an aircraft sizing methodology and modeling framework and ongoing development.

\subsubsection{Sizing Tool}

As an initial development, a sizing methodology for fully electric aircraft is proposed for general aviation applications [130-134], where the Breguet-range equation is modified for a battery sourced propulsion system. In further developments, Nam et al. [135] and Cinar et al. [136-138] proposed power-based sizing methods featuring multiple but generalized energy source paths. These are considered as very elementary design environments, with mere modifications in the existing propulsion system, and with added features of electrical energy source. Isikveren et al. [139] methodology considered a simplified graphical based method for sizing the electric aircraft with dual energy sources in the propulsion system, however, the energy sources do not feature the unique characteristics particular to the electrical energy storage. Riboldi et al. [134,140] presented 
a generalized sizing methodology based on predicting weight fractions using statistical regression methods, albeit applicable to smaller aircraft. The proposed method utilizes the sizing matrix plot which is a function of wing loading and power load, and imposed certification and regulation constraints on top of it for finding the viable design space. These methodologies do not include the sizing and operational impact from inclusion of the newly added propulsion system components and, thus, lack the design versatility stemming from a hybrid electric system.

Two research teams are in the frontier of proposing hybrid electric aircraft sizing methodology with distributed electric propulsion systems. Finger et al. [141,142] proposed a preliminary sizing methodology for a light aircraft for vertical take-off and landing (VTOL) based on the point performance (constraint diagrams) and mission performance. The top-level aircraft performance requirements (TLAR), the aerodynamics, propulsion system architecture, and efficiencies are set as input parameters. With the imposed constraints such as for the rate of climb, take-off field length, or cruise point airspeed, the point performance tool determines the constraint diagrams. The mission performance tool is based on the iterative process; however, it considers the non-consumable mass part of the battery into account. Instead of using mass fraction, classical endurance, and range equations, the method discretizes the mission segment into a number of steps with a mission explicitly defined for each step. Using an energy-based approach, the fuel mass and battery mass are determined for each step and through use of degree of hybridization convert the energy requirement to thrust power with a distinction made between consumable and non-consumable energy sources. The sizing algorithm is implemented in many conventional take-off and landing (CTOL) aircraft sizing studies as well [143].

Reynard et al. [55] formulated sizing methodology where the design space is created with a point performance matching scheme in a power-to-weight ratio and wing-loading domain at first, on which various aircraft top-level driven constraints are imposed in order to segregate between the viable/unviable design spaces. A random point located on this design space represents the degree of hybridization to be optimized for the power-to-weight value for a given wing-loading (W/S). The mission performance tool determines the maximum take-off weight (MTOW) and the size of the components in the aircraft with an iterative process. The mission segments are discretized by an energy-based approach and the whole mission is simulated for each iteration step. The sizing methodology also accounts for the propulsion-aerodynamic coupling effects. The performance equations are modified to account for aero-propulsive interaction. Thrust-lift-drag decomposition was modified considering the impact from multiple thrust producing source on the wing and from the hybrid electric architecture. The proposed methodology is used in several of the system and sensitivity studies $[54,59,125,144-146]$. This is proposed for finding the optimal power schedule for a hybrid electric distributed propulsion (HEDP) system configuration but based on the low-fidelity aerodynamics tool. Finger et al. [147] presented a comparison of the sizing methodology on a 19 PAX aircraft to check for the potential and validity in both sizing methodologies.

Hybrid electric configurations are endowed with a design freedom of choosing between a low energy density and high efficiency electrical drivetrain system and high energy density but low thermal efficiency fuel system. An operational strategy determines the split of the power between the two sources, based on which the sizing of the components is made. As the aircraft performance is weight and volume critical, the particular types of designs are challenged with a requirement for formulation of optimized degree of hybridization. This introduces new design variables for optimizing the size in the propulsion components and the flight performance. The classical sizing tool and the disciplines are not well versed for formulation of an optimization problem with all the characteristics of the electrical components. A suitable fidelity level model in other electrical and thermal model developments is desired in order to make a sensible design space exploration work to analyze the optimized usage of a hybrid electric. Pornet et al. [121] sizing methodology simplified the optimization process by considering a fixed split power ratio between the energy sources for a given mission segment. Zamboni et al. [117] make use of the three computational modules: constraint analysis, the point mass analysis, and the component sizing module. The input control parameters and TLAR, are given as input 
to the constraint module to determine the minimum power-to-weight ratio within the boundary set by the point performance and regulatory requirements. Once determined, the power split propagates through the component sizing module to determine the propulsion component size with the established performance map and the mission energy requirement. With power and energy estimated, the aircraft sizing is performed that is fed back to the mission tool and the relative shaft power to the constraint module. The process is repeated until the convergence is reached. The optimization technique utilizes a monolithic architecture using a single optimization problem. These studies are based on isolated engine and aircraft analysis models that in turn need manual iteration between the disciplines to finalize the sizing of the configuration. This makes the sizing methodology inefficient and leaves room for further optimization.

Trawick's study [90] proposed a methodology termed as Systematic Hybrid Aircraft Power Schedule Optimizer (SHAPSO) for finding an optimum power schedule for parallel hybrid designs. The sizing process uses global optimization techniques based on dynamic programming and optimal control methods for establishing optimized power schedule. The methodology showed that an ideal power schedule optimizes the performance of a hybrid system. The study performed by Gladin et al. [84,123] used an integrated modeling framework Georgia Tech Hybrid Electric Analysis Tool (GT-HEAT) to conduct the parametric study interlinking the electrical and engine performance at the mission level for identifying the viable design space in a parallel hybrid electric and partially electric distributed configurations. The GT-HEAT tool, which is an extension of the NPSS tool, is developed further to include the electrical component performance in an integrated modeling environment with the existing engine performance and mission performance analysis tools [148]. HYBRID Aircraft Propulsion System Synthesis (HAPSS) was developed by ESAero and written in MATLAB and designs and analyzes turboelectric propulsion system aircraft. ESAero developed design framework take-off gross weight (TOGW) suitable for studying the hybrid electric sizing and performance study. The tool can optimize a design with consideration from the coupled interaction between the thermal and propulsion system disciplines [28]. The framework has further grown, to be known as Propulsion Airframe Integration for Hybrid Electric Research (PANTHER). It also needs incorporation of the high-fidelity analysis software to address new aerodynamic concepts, propulsion systems, thermal management systems, propulsion-airframe-thermal integration (PATI), and the overall integration into the empirical and physics-based component sizing and performance analysis subroutine sizing and synthesis of the propulsion system and thermal management system.

\subsubsection{Multidisciplinary Optimization Framework}

Besides the introduced design variable for optimizing the energy schedule in a hybrid electric configuration, the attributed aerodynamic benefits of the propulsion concepts like BLI or DEP have to be established based on strong coupled interactions between the propulsion and aerodynamic performance tools. The analysis needs to be done for change in the operational behavior and physical design characteristics of the aircraft. This concept introduces a significantly higher number of operational variables to be considered for the optimization study. Furthermore, the electrical system performance features the coupled interaction with the thermal management system. Other aspects include re-orientation of the propulsion system lay-out for the radial aircraft design associated structural implication. The possible interactions between the different subsystems were considered when estimating the benefits at the global level. A fully-coupled propulsion-aerodynamic model in a multidisciplinary optimization environment is necessary to assess the benefits with more accuracy. In the study presented by Schnell et al. [149], a coupled integration was established between streamline curvature method based BLI aft-fan design and the gas turbine performance tool EVA [150] for a partially turboelectric configuration. Though physics-based models are used, the study lacks an optimization study for the design.

Perullo et al. [151] defined the electric aircraft sizing process with three distinct steps: determining the fidelity level in the system-modeling, selecting the energy management approach, and the 
optimization technique. A low-fidelity linearized modeling and simulation tool is necessary for the weight and size estimation for the components for the design space exploration, whereas high-fidelity models are necessary for the assessment of the closed coupled interaction between different disciplines such as aerodynamics and propulsion. Martin et al. [152] divided the optimization technique in to two broad categories: monolithic and distributed architecture based. The monolithic architecture considers a single optimization problem. Monolithic architectures become computationally expensive in an environment when the coupling variables between the disciplines grow larger. Most of the optimization studies performed to date are made for single objective monolithic architecture. The distributed approach breaks the optimization problem into a set of sub-problems with subsets of variables and constraints and generally proves to be computationally efficient [153]. The monolithic approach becomes computationally expensive when it involves many disciplines with higher fidelity tools and multiple design variables. Perullo et al. [151] proposed a pre-sizing methodology using the elements from model predictive control (MPC) and concurrent optimization to formulate a new structure for the aircraft sizing. In this, the design problem is classified to two sub-level problems; the high-level optimization problem uses design parameters for the coupled propulsion system-airframe and the low-level optimizer uses the MPC algorithm to optimize the mission adaptive design variables such as the power split. The optimization architecture reduces the number of coupling variables between different disciplines, and thus makes the sizing and optimization procedure efficient and less computationally expensive.

The PEGASUS design analysis uses a low-order multidisciplinary optimization environment created by extending the features of the NPSS and FLOPS tools. The performance of the gas turbine and propeller and the electrical system were built with use of NPSS, whereas the aircraft aerodynamics, sizing, weight, and performance were developed utilizing the FLOPS tool. The split between the electric and mechanical shaft power is discretized and the vehicle performance model outputs the battery sizing. The performance of the propulsion system was imported to the ModelCentre based optimization framework to minimize the MTOW. The optimization environment uses wing area and maximum take-off thrust as the two design variables; however, it lacks the coupled interaction between the aerodynamics and structural disciplines [42,43]. Applicable to thin-haul aircraft, a sizing method with an optimization study for the fuel consumption/take-off thrust is proposed by authors Silva et al. [154] The sizing methodology duly accounts for the aero-propulsive interaction and the impact of power scheduling on the sizing of the energy source.

Trajectory analysis is an important part of the aircraft optimization study, traditionally made for fuel burn or range, but could be utilized for noise prediction and propulsion system sizing and mission performance. The time-varying operational behavior of a hybrid electric aircraft and the imparted impact on the physical design of the aircraft motivates a tighter integration of the trajectory analysis with other disciplines such aerodynamics, propulsion system performance, and weight. This transforms the aircraft optimization problem into an even more complex problem, dealing with significantly larger numbers of design variables along multiple disciplines. The optimization environment tools developed in the past lack any methodology for full mission energy optimization with physics-based models in different disciplines. While many studies claimed the benefits of using BLI on the cruise performance, they are subjected to many simplifications. They largely focus on estimating the BLI profile and its imposed impact on the inlet of the propulsion system [26,74,155]. A fully coupled aero-propulsive analysis enables such study. The work simplified the assumption for electrical system components for the performance assessment study and does not include the optimization study.

OpenMDAO is an open-source multidisciplinary optimization framework developed by NASA GRC which has been explored by many researchers due to its versatile application. This platform enables coupled integration of different discipline models coded in several programming languages with various levels of fidelity into a single analysis tool. The framework uses a gradient based approach with analytic derivatives and uses in-house solvers and optimization methods to address the optimization problem $[83,156]$. Gray et al. [83] used this platform for coupled aero-propulsive interactions to examine 
an optimized split ratio in the shaft power for different powertrain drive transmission efficiency values. The platform uses ADFlow computational fluid dynamics (CFD) solver to solve the Reynolds-averaged Navier Stokes (RANS) equations and the PyCycle-1-D propulsion analysis tool for generating the adjoint analytic derivative. The framework enables multidisciplinary optimization based on the Sequential Quadratic Programming (SQP) gradient-based optimization method. Falck et al. [157] used the OpenMDAO with moderate fidelity propulsion and aerodynamic discipline tools to conduct the mission analysis for observing the thermal state in the electrical components.

PyMission, as mission analysis tool, produces analytic derivative for the trajectory analysis when integrated with other disciplines and enables an adjoint-based optimization in the aircraft mission analysis [158]. Hendricks et al. [159] assessed the aircraft concepts with a view towards coupled interaction in the aero-propulsion system, with a negotiation with the flown trajectory. In the proposed environment, the PyCycle tool [160] is used to generate the thermodynamic cycle and the trajectory analysis is implemented using the Pointer tool. The OpenMDAO is utilized to generate the analytic derivative for the optimization work. A tightly coupled modeling environment is built between the propulsion system and the trajectory analysis with a simplified approximated aerodynamic model. A multidisciplinary (MDO) technique was implemented with the integration of the Fixed Aircraft Sizing Tool (FAST) sizing tool to OpenMDAO framework to conduct design optimization in a distributed hybrid electric system [161]. pyOptSparse is a similar optimization framework with Sparse Nonlinear Optimizer (SNOPT) utilized in association with the SUAVE aircraft sizing tool for the design study of 19 PAX aircraft, with BLI and DEP effects [162]. A list of modified multidisciplinary aircraft design analysis tools including attributes of electric propulsion system changes is presented in the Table 3.

Table 3. Aircraft sizing tools used for electric aircraft applications.

\begin{tabular}{ll}
\hline \multicolumn{1}{c}{$\begin{array}{c}\text { Framework/ } \\
\text { SizingTool }\end{array}$} & Reference \\
\hline STARC-ABL Design & $\begin{array}{l}\text { The study utilizes PyCycle tool built in OpenMDAO to } \\
\text { generate 1-D thermodynamic cycle engine performance data, } \\
\text { that is being integrated with ADFlow finite volume CFD } \\
\text { solver for aerodynamic analysis for carrying out the } \\
\text { optimization study in OpenMDAO environment. }\end{array}$ \\
\hline & $\begin{array}{l}\text { GT-HEAT is a sizing and synthesis platform run in integrated } \\
\text { environment with extension of the NPSS tool for hybrid } \\
\text { electric components, aero analysis, TMS models and mission } \\
\text { analysis. A suite of electrical components is added to the } \\
\text { existing NPSS tool to represent the electrical drivetrain system. } \\
\text { Parametric based models are used to predict the performance } \\
\text { of the electrical components. The modeling environment does } \\
\text { not account for aero-propulsive interaction. }\end{array}$ \\
\hline GT-HEAT Tool & $\begin{array}{l}\text { An aircraft conceptual sizing and optimization tool, } \\
\text { written in Python, with low-fidelity libraries in hybrid electric } \\
\text { disciplines, aircraft sizing algorithm, and aircraft models. } \\
\text { The tool runs atop the OpenMDAO framework and utilizes } \\
\text { the analytic derivative of the models to perform } \\
\text { gradient based optimization. }\end{array}$ \\
\hline OpenConcept Tool & A low-order multidisciplinary optimization environment is \\
used for sizing the aircraft. The FLOPS tool is used for \\
computing the aerodynamics, propulsion weight, \\
performance and geometry data. The ModelCentre platform is \\
used to connect FLOPS to the generated excel on engine \\
performance, battery sizing and weight parameters. \\
WATE++ is used for the engine weight estimation while NPSS \\
is used for modelling the hybrid electric \\
propulsion system components.
\end{tabular}


Table 3. Cont.

\begin{tabular}{|c|c|c|}
\hline $\begin{array}{c}\text { Framework/ } \\
\text { SizingTool }\end{array}$ & Features & Reference \\
\hline $\begin{array}{l}\text { Hybrid Electric Aircraft } \\
\text { TOGW Development Tool }\end{array}$ & $\begin{array}{l}\text { A multidisciplinary aircraft design tool builds on } \\
\text { empirically-based airframe design and physics-based hybrid/ } \\
\text { turboelectric propulsion system component designs. The tool } \\
\text { enables sizing and weight estimation of the components in } \\
\text { propulsion system and with due structural consideration } \\
\text { revised TOGW estimated. The tool is used in ESAero's } \\
\text { ECO-Series conceptual design studies. }\end{array}$ & [28] \\
\hline PACIFYC Tool & $\begin{array}{l}\text { PACE suite of tools, Pacelab APDTM for aircraft conceptual } \\
\text { design and performance analysis, Pacelab SysArcTM to } \\
\text { perform multi-layered integrated system sizing, } \\
\text { uses OpenVSP for aircraft geometry. }\end{array}$ & [126] \\
\hline RCE Framework & $\begin{array}{l}\text { Multi-disciplinary aircraft sizing with semi-empirical and } \\
\text { low-level physic-based model. Includes novel airframe } \\
\text { configuration, BLI fan designs and electrical components. }\end{array}$ & [111] \\
\hline MYSTIC & $\begin{array}{l}\text { Multidisciplinary Sizing Tool for Integrated Concepts, used in } \\
\text { DRAGON notional design sizing, with a turboshaft } \\
\text { performance model, 3D aerodynamic assessment, and finite } \\
\text { element method based wing structure analysis associated with } \\
\text { below the wing ducted fan installations. }\end{array}$ & {$[61]$} \\
\hline FAST Tool & $\begin{array}{l}\text { A multidisciplinary design analysis tool with python-based } \\
\text { code for disciplines comprising airframe, structure/weight, } \\
\text { and propulsion system. The code is modified for adding } \\
\text { hybrid architecture sizing with new electrical components. } \\
\text { The sizing tool is based on empirical equations and } \\
\text { low-fidelity tools. The FAST tool is implemented } \\
\text { within the OpenMDAO platform. }\end{array}$ & {$[161,164]$} \\
\hline SUAVE & $\begin{array}{l}\text { A multi-fidelity electric aircraft design environment, with tools } \\
\text { for optimizing the wing size, flight path, and electrical } \\
\text { propulsion system. It uses the sizing correlations of the } \\
\text { Program for Aircraft Synthesis Studies (PASS) tool. } \\
\text { The pyOptSparse constrained non-linear optimization } \\
\text { framework is utilized for the optimization study. Capable of } \\
\text { performing aerodynamic impact analysis of BWB airframe } \\
\text { design with BLI and DEP systems. }\end{array}$ & {$[162,165]$} \\
\hline $\begin{array}{l}\text { Multidisciplinary } \\
\text { Conceptual Design } \\
\text { Optimization (MCDRO) } \\
\text { Framework FRIDA }\end{array}$ & $\begin{array}{l}\text { A sizing methodology proposed for hybrid electric } \\
\text { configurations with BWB airframes includes a semi-empirical } \\
\text { turbofan model, added aeroelastic analysis for computing } \\
\text { aerodynamic forces, and an aeroacoustics model } \\
\text { used for prediction in the noise. }\end{array}$ & [166] \\
\hline HERMiT & $\begin{array}{l}\text { Hybrid Electric Regional Multi-Propeller Integrated Transport, } \\
\text { uses Pacelab Aircraft Preliminary Design (APD) } \\
\text { multidisciplinary design framework with WASPE } \\
\text { (Wing Aerodynamic Simulation with Propeller Effects) for } \\
\text { wing-propeller aerodynamics, and FLOPS tool. }\end{array}$ & [167] \\
\hline EWL Tool & $\begin{array}{l}\text { A flexible physics-based aircraft design process with } \\
\text { technology tools for aerodynamics, structure, and the engine. }\end{array}$ & [112] \\
\hline TASOPT/TASOPTe & $\begin{array}{l}\text { A multidisciplinary optimization program with first } \\
\text { principle-based methods for simultaneous integration of } \\
\text { airframe, propulsion system and mission operation. } \\
\text { Added unconventional features of BLI, strut-braced wing, } \\
\text { double-bubble fuselages, etc. }\end{array}$ & {$[13,168]$} \\
\hline Aircraft Design Initiator & $\begin{array}{l}\text { A sizing method suitable for HEDP architecture and to } \\
\text { account for the synergistic airframe-distributed propulsion } \\
\text { system integration effects. A vortex lattice method is } \\
\text { used for computing the aerodynamics. }\end{array}$ & [54] \\
\hline
\end{tabular}


Considerable efforts have been undertaken for building the aircraft sizing methods with inclusion of the hybrid propulsion system configuration and accounting for the associated structural and aero-propulsion effects. Also, such tools are integrated to a multidisciplinary optimization framework for optimizing the aircraft sizing. The complexity of performing a study for optimized usage of the electrical propulsion system over a wide array of mission ranges and aircraft design has limited the performance assessment system studies to fewer variations. This leaves more opportunity for efficient management in battery power utilization, optimum operation of the gas turbine, and propulsion system sizing trade-offs.

\subsection{Propulsion System Component Sizing Challenges and Developments}

Newly introduced propulsion system designs demand for significant addition of components in the existing design. This is a multi-collaborative approach with involvement from both industries and research labs. The technological development is also inspired from the adjacent fields of interest applicable to marine propulsion, automotive industries, etc., that are deemed suitable for aerospace applications. Following subsections consolidate the research efforts made in hybrid electric propulsion system architectural lay-out and associated components, namely-electric machines, circuit breakers, cables, power converters, energy storage, thermal management systems, etc.

The Hybrid Gas Electric Subproject (HGEP) under NASA's Advanced Air Transportation Technology (AATT) project, aims to finding configurations in hybrid electric system for achieving the NASA N+3 goals, and endorsing investment in the key-pole technologies in for a 150-PAX single-aisle transport plane segment. The Research and Technology for Aerospace Propulsion (RTAPS) study is dedicated to illustrating and evaluating the design tradeoffs for different architectural concepts from safety and critical dynamic operational issue perspectives, for a superconducting TeDP system [128]. A superconducting distributed propulsion grid is explored extensively under the SBIR contract for N3-X architecture [169]. Although these developments are made toward meeting the N+3 targets, the certainty of achieving these targets is questionable. The National Academies for Sciences Medicine and Engineering (NAE) report consolidated researched works in conceptual studies and technology development both from North American and European aviation research. The committee has specific suggestions for high priority research areas and also in achievable component performance 20 years into the future [19]. Dever et al. [105] presented a technology assessment work in a non-cryogenic system. Based on which the key performance parameters in a 15- or 30- year timeframe are projected in the electrical system components. Jansen et al. [11] presented a collection of the prototype/research development designs that target to meet NASA's targeted key performance goals for the components.

\subsubsection{Electrical Power System}

Superconducting materials or normal conductors operated in liquid hydrogen temperature offer zero resistance (electrical resistance for pure aluminum or copper can be 1/100th or less of that at the room temperature) to the conduction of electricity and hence stand out in terms of conductivity and ampacity. Use of the superconducting wires in DC transmission systems exhibits very low loss. For machine applications, the superconductors can produce higher magnetic field strengths and can be enabled for higher power density and torque density machines [170]. Power generation is also a big issue for the turboelectric/hybrid or even fully electric configurations. These utilize either fuel onboard or a battery charged from the grid, and do not give emission saving benefits as desired [96]. A possible and promising alternative is to fuel the aircraft with liquid hydrogen $\left(\mathrm{LH}_{2}\right)$ and possible use of a cryogenic enabled electrical system. The current underlying technology level for the machine power electronics lags substantially from the desired level in the aircraft application. The development and future technology prediction in the non-cryogenic system is equally compelling and competitive [107]. Suitability of the high temperature superconducting (HTS) material for use in airborne applications is large, as they can carry huge amounts of current with negligible loss. These features enable high power density and high torque density machines. However, there is need for a cryo-cooler to cool this 
machine and a possible candidate in this regard is liquid hydrogen $\left(\mathrm{LH}_{2}\right)$ superconductivity, an obvious choice for higher power density and torque requirements. A cryogenic cooled propulsion system is highly efficient but there is unlikeliness of reaching sufficient maturity over the next 20 to 25 year [171].

High Voltage Architecture and Protection

Propulsion power sized electrical system necessitates lightweight components and a flexible architecture design with components as per the reliability and fail-safe operation standards. That entails boosting the system voltage level and defining appropriate voltage regulation standards for it. Historically, the commercial adoption of electrical system for aircraft application was initiated with the advent of the 'Fly by Wire' concept. The operating voltage was chosen for $115 \mathrm{~V}$ AC with a constant frequency at $400 \mathrm{~Hz}$ in high power applications and $28 \mathrm{~V}$ DC in low power applications [172,173]. The increased demand under more electric aircraft (MEA) applications drove the initial evolution in the electrical power system architecture, transiting to a variable frequency $(360-800 \mathrm{~Hz}) 230 \mathrm{~V} \mathrm{AC}$ or \pm 270 V DC system $[153,174,175]$. Further boost in the voltage level from the current standard of $540 \mathrm{~V}$ would potentially lower the cable weight in a propulsion power sized transmission system.

Nonetheless, adapting to a higher voltage level system would require thicker insulation material in the machines and cables and corona protection mechanisms for power converters and circuit breakers which altogether would impact the system mass. A preliminary power system sizing study conducted on STARC-ABL design, for 2.6 MW power application, showed a potential for cable weight reduction of $1400 \mathrm{~kg}$ when increased the voltage level from $540 \mathrm{~V}$ to $4800 \mathrm{~V}$. However, the impact from insulation material mass increase was not accounted in the study [176]. Sadey et al. study considers $2 \mathrm{kV}$ as the threshold voltage in the trade study. It is based on the reasoning that adapting to a voltage level above $2 \mathrm{kV}$ outweigh any cable weight saving benefit, with the current technology in insulation material i.e., not matured for high voltage aviation application [177]. NASA's N3-X design study suggested adoption of a minimum voltage level of $6 \mathrm{kV}$ in order to capture the system level weight reduction benefits [51,128]. In further pursuance, for a cryogenically cooled DC system, a voltage level of $4.5 \mathrm{kV}$ is recommended when optimized for the system mass accounting detailed component mass, efficiency estimations in the system [178]. The SUGAR team design has made a selection for a $10 \mathrm{kV}$ system architecture for the system studies $[29,179]$. Vratny et al. study presented an impact analysis for selection between a constant system voltage (CSV) and a variable system voltage (VSV) architecture for a battery powered $6000 \mathrm{~kW}$ electrical drive system [180]. In the CSV design, the decreasing output voltage from the battery is compensated with a converter, whereas in VSV design, the voltage output from battery was directly fed to the motor inverter. The VSV design shows a higher efficiency: $4.6 \%$ higher than in a CSV system. Furthermore, the optimum voltage level in VSV system was found to be the motor operating voltage whereas for the CSV system it was found to be between the range of $3000-4000 \mathrm{~V}$.

The primary limitation of adopting a higher voltage level is linked to the Paschen's law, which recommends a minimum breakdown voltage of $327 \mathrm{Vdc}$, below which the probability of arcing at high altitude is negligible [181,182]. An electric grid operated with cryogenic temperature relieves this limitation to a certain level because of less sensitivity of the breakdown voltage to the increased air gap strength, but it could not be completely ignored [169].

The selection between a DC and AC distribution architecture is a subject of discussion by many authors. Lack of suitable superconducting AC conductor technology has made a DC distribution system as a primary choice in many of the conceptual designs $[29,51,128]$. Furthermore, a DC architecture allows decoupling of the fan and engine operation, becoming an enabler for a high-pressure ratio, high BPR designs. It also eliminates the need for synchronizing the AC generator to the AC distribution system. However, on the downside, it requires addition conversion units on both generator and motor ends in turboelectric application [183]. In a study performed on a non-cryogenic turboelectric configuration [107], three different microgrid type electrical system architectures, namely DC distribution, AC synchronous distribution, and hybrid of both AC and DC, 
were considered to evaluate mass and efficiency performance metrics. The parametric sweep of the system voltage and frequency led to three primary conclusions:

I The efficiency and weight can be traded on the system level.

II The AC system at the $6 \mathrm{KV}$ voltage level and operation frequency of $1 \mathrm{kHz}$ is optimum for the weight; however, a DC system above $3 \mathrm{kV}$ is favorable while accounting for the thermal management system (TMS) weight.

III Even though a DC system is potentially lighter, it is $2 \%-3 \%$ more inefficient than the AC system.

The paper further highlights that the power electronics and circuit protection components development in the DC system at $3 \mathrm{kV}$ voltage level and above will face certification related challenges due to the low technology readiness level (TRL) of it. In similar line, the sensitivity study performed on STARC-ABL design [177] for a 2.61 MW sized powertrain, AC transmission system was found more efficient than the DC counterpart, with $13 \%$ reduction potential for the thermal loss. Moreover, there is also subtle impact from the operating frequency on the system loss that makes an ideal choice of $800 \mathrm{~Hz}$ for this design. In a quantitative assessment study by Jones et al. [183] on a cryogenically cooled TeDP configuration AC system showed better performance over DC and AC-DC hybrid systems for weight and efficiency parameters. However, controllability is a major issue for an AC system architecture. It is believed that suitable power electronics with efficient cryo-cooler designs would help bridging the gap between the AC vs. DC architecture.

Despite the implicit benefits of a high voltage system, the industry has not advanced much in developing the insulation material with a high dielectric strength, defying the Paschen's law under high altitude condition. A pragmatic voltage level was rather considered in many of the studies s, appearing in the range of $700-1000 \mathrm{~V}[31,176,184,185]$.

The voltage level selection also impacts the size and loss at the component level. While there is a major influence on the converter losses [153], the battery mass is indifferent to the voltage selection. Also, another thought is that a MW-scale power converter with a high conversion ratio could undermine the benefits of a high voltage efficient transmission system. Alternatively, a high voltage with a widely varying frequency range for the transmission system, using both $\mathrm{AC}$ and $\mathrm{DC}$ architecture, is proposed. Such a design has potential for 10-15\% power electronics size reduction over DC system, as shown by NASA convergent aeronautics solutions (CAS) study [177]. A DC power transmission system was considered in the CENTRELINE project to assess the weight and efficiency sensitivity in the electrical system both at the component level and system level with ae voltage variation between a range from $1000 \mathrm{~V}$ over to $5000 \mathrm{~V}$ [186]. The study illustrated that a high voltage level could be beneficial from overall mass and efficiency point of view. The study promoted that even with an increase in mass and a lowering of efficiency in the electrical machine and converter components, there are still other considerations which could limit the applicability of the high voltage, namely: the semiconductor blocking voltage and associated control complexity.

While the machine performance can be optimized, independent of the voltage level, a coordination is still desired between the generator voltage and the propulsor motor voltage. The converter topology selection and its performance is dependent on the desired voltage gain of power converters, which is driven by the voltage ratio of generator voltage over bus voltage or the ratio of bus voltage over propulsor voltage. This has further impact on the weight and efficiency. Also, the selection and sizing of the protection and fault isolation equipment, machine control, and insulation material are dependent on the operating voltage, thus impacting the overall system performance. An accurate prediction of electrical system weight and volume can be made if the voltage standards are defined. At the same time, an optimum selection of voltage level can be made with a holistic approach, accounting for all the performances of individual components [180]. Additionally, the optimum design should be adopted through an advanced algorithm based approach, considering the thermal stability and power quality in balance with system mass and efficiency [175]. 
Circuit breakers/fault current limiters electrically isolate the components under the fault operation with a quick response time. DC circuit breakers (CBs) for microgrid applications are available in three categories: classical mechanical base, solid-state circuit breakers (SSCBs), and hybrid circuit-breakers (HCBs). Mechanical CBs are actuated mechanically and have the advantage of zero on-state loss; however, they are slow in their operation. SSCBs use semiconductors for isolating the fault incredibly quickly, in the order $15 \mu \mathrm{s}$, but desires a blocking voltage in the semiconductors which is usually $1.5 \times-2 \times$ DC voltage [187]. The main disadvantages of the SSCBs were found to be power loss and additional weight in the associated cooling system. A SSCB design, with bidirectional insulated-gate bipolar transistor (IGBT) switch is capable of withstanding voltage levels up to $18 \mathrm{kV}$ with a current capability of $800 \mathrm{~A}$, is used for the ECO-150 architecture [107]. The current technology in metal-oxide-semiconductor field-effect transistor (MOSFET) switches limits its application up to a $4 \mathrm{kV}$ DC voltage. The HCB device conducts with the mechanical contact under normal operations, but while interrupted with a fault current, the current passes through a solid-state interrupter, thus, combines goodness of both classical mechanical system and SSCBs. The SOA in HCB shows capability to operate at $325 \mathrm{~V}$ voltage level and $2 \mathrm{kA}$ current capacity with a breaking capability of $10 \mathrm{kA}$. More potential protection options are hybrid relays developed by Merson with breaking capability of $2 \mathrm{kA}, 2 \mathrm{kV}$ and rated for $300 \mathrm{~A}$, $1200 \mathrm{~V}$. SSCB sizing made for the ECO-150 design at $6 \mathrm{kV}$ showed an efficiency parameter of $99.9 \%$ and SP of $200 \mathrm{~kW} / \mathrm{kg}$ [107]. A higher SP is assumed for CBs on an AC bus than desired for a DC bus in the sensitivity study by Armstrong et al. [188].

Limited literature was found dedicated to the weight and efficiency influences of power circuit protection schema and quantitative tradeoff analysis between the vertical tail sizing and power transmission distribution architecture. Noteworthy mentions are studies performed on N3-X and ECO-150 configurations. Under N3-X concept, a down selection work is performed between four candidate architectures with different interconnectivities and distribution approaches. The architectures are assessed under reliability, redundancy, and capacity criteria. The components' are sized for flight-safe operation under critical failure scenarios [188,189]. All architectures follow a unique power management strategy for assigning power to the propulsors: distribution is made symmetrically through the distribution buses to eliminate asymmetric thrust failure cases in critical off-nominal thrust requirement conditions. A design optimized for failsafe operation showed potential for $40 \%$ propulsor size reduction, but at the expense of a complex and heavy weight distribution system. The study also highlights that the use of a battery improves the thrust response ability and the thrust lapse from the component failure $[51,169,190]$. It is worth considering whether the weight added by routing power cables from one wing to the other pays for the improvements in vertical tail weight and drag. ECO-150R design implemented electric microgrid with a dual inner bus tie power distribution architecture. The design allows for symmetric thrust distribution between the propulsors in the event of an engine or fan failure scenario. The architecture allows full power distribution from the alternate engine to all the fans under one engine failure condition. Each of the four DC buses powers four propulsion units which are arranged to negate the yaw impact of a bus failure. This practice can diminish the design impact of off-nominal conditions on power transmission components and on the vertical tail size.

The high power and relatively low voltage for the system requires that the power cables exhibit high ampacity insulation requirements with high-altitude low-pressure effects [185]. Future research on this topic should include weight and efficiency influences of power circuit protection schema and quantitative tradeoff analysis between vertical tail sizing and power management and distribution lay-out design. For example, it is worth considering whether the weight added by routing the power cables from one wing to the other pays off for the improvements in vertical tail weight and drag reduction. Powered yaw control through asymmetric thrust distribution amongst the propulsors gives the opportunity for reducing the size of the propulsor but causes more demand on the generator capacity and associated components. A DC grid gives better flexibility for yaw control over a AC synchronous distribution system [177]. Despite the decades of historical precedent, the electrical 
system has not reached the tipping point of being considered fully reliable and safe, though it is on the right track of technological prowess.

\section{Electrical Machine}

An electrical machine design for aircraft operation is characterized by several requirements, such as low-weight, low-volume, high-reliability, high-efficiency, and low-cost. Out of these, high specific power and superior efficiency are the two most important parameters to be investigated [191-193]. In order to suit these requirements, NASA Research Announcement (NRA) set a goal of demonstrating technologies in MW-class machines with a power density greater than $13.2 \mathrm{~kW} / \mathrm{kg}$ and efficiency greater than $96 \%$ in the next 10 years in the non-cryogenic segment [176]. Along similar lines, the NAE committee recommends a minimum specific power of $6.5 \mathrm{~kW} / \mathrm{kg}$ in machines for regional and single-aisle segments and $10 \mathrm{~kW} / \mathrm{Kg}$ for twin-aisle segment [19].

The current machine technologies for aviation applications are only available in a few hundreds of kilowatts. With the current technology level, if the machine were to be scaled up for higher sizes, it would not yield a SP as desired. In order to get a high SP in the MW-scale machine, new technologies with improved material and design has to be introduced.

The superconducting machine has the potential of achieving efficiency close to unity and a SP of higher order in magnitude relative to a normal temperature operating one. The superior conductivity improves the current carrying capability in the winding, enhancing the field strength drastically over a reduced volume and physical footprint and thus, hold the avenues for reduction in the machine size and weight $[170,191,194,195]$.The SOA in superconducting machines, exhibits a SP of 3-8 kW/kg; however, is not enough for commercial electric aircraft application [196].

Early adoption of superconductors in the electrical machine was established with the advent of the material niobium-titanium (NbTi). $\mathrm{NbTi}$ as superconductor was only suitable to replace the DC field winding in the machine. However, the low operating temperature of the material (4.5-5.5 K) and operational issues related to the harmonics resulted in a very uneconomical cryogenic system [191]. Hence any further development ceased to continue beyond the mid-1980s. In the later part of the 21st century, the development of high temperature superconductors (HTS) with an operating temperature range $25 \mathrm{~K}-77 \mathrm{~K}$ gave an impetus to further the technology. A fully superconducting machine uses superconductors both in stator and rotor and gives opportunity of reducing the losses both in field and armature windings. The SOA for a fully superconducting machine design is impeded by the lack of technology development in the AC (armature) winding conductor for high current density, low-loss, and compactness [197]. Both partially and fully superconducting machines can be advanced further with improved performance for high magnetic field and high temperature withstanding capacity and technology matureness. Cryogenic technology improvement is an essential part of such development. The industrial applications based superconducting material for machine use are yttrium barium copper oxide $(\mathrm{YBaCuO})$ compounds and magnesium diboride $\left(\mathrm{MgB}_{2}\right), \mathrm{Bi}-2223$, which correspondingly require operating temperatures of liquid nitrogen $\left(\mathrm{N}_{2}\right)-77 \mathrm{~K}$ and liquid hydrogen $\left(\mathrm{H}_{2}\right)-30 \mathrm{~K}$, respectively [198]. In the study performed by Luongo et al., the roadmap for HTS technology improvements is outlined for achieving a SP in the range of $25-40 \mathrm{~kW} / \mathrm{kg}$ for the motors and $40-80 \mathrm{~kW} / \mathrm{kg}$ in the generators [196]. In addition, the development is expected for the cryocoolers requiring a Carnot efficiency of $30 \%$, and weighing less than $3 \mathrm{~kW} / \mathrm{kg}$ [196]. A partially superconducting wound field synchronous machine (WFSM) design developed under NASA showed a potential for achieving $98 \%$ efficiency and SP of $16 \mathrm{~kW} / \mathrm{kg}[194,199]$. Despite the promising perspective of superconducting technology, the low technology readiness level (TRL) in the flightworthy cryogenic system and the associated design complexity is likely to postpone the developments into aircraft application to 20-30 years future time horizon [191].

Achieving a SP in normal temperature operating machine is a matter of key concern, as it requires high current densities in the conductor which cause the cooling system design to be rather challenging. Furthermore, electrical machines are limited by an achievable torque. However, a higher power output 
can be achieved with a higher speed. Also, for a given speed use of high number poles would increase the SP of the machine. In both the cases, the resulted increase in electrical frequency would increase the AC losses in the core. Under the above backdrop, an air-gap winding enabled machine design well suits for high-pole and high frequency machine designs, with provision for reduced iron loss. Besides, if topped up with Halbach arrays to eliminate part of rotor yoke, it improves SP further [200].

A high SP machine gets advantages from high numbers of pole counts, rotational speed, and shear stress. Nonetheless, the SP in machine exhibits a declining trend with the increase in machine power, due to the design limitations [201-203]. Several machine types have been investigated while considering their design suitability for the aircraft operational environment. The permanent magnet synchronous machines (PMSM) [105,184,203-205], WFSM [11], synchronous reluctance machines (SRM), brushless doubly-fed machines (BDFM) [204], and induction machines (IM) [184,202] are some of the machine types which are separately suited for specific requirements. The suitability and unsuitability of different motors are summarized in Table 4. The studies, however, concluded that PMSM is the clear frontliner in achieving multiple desirability in aerospace application.

Table 4. Summary of electrical machines for aircraft applications.

\begin{tabular}{|c|c|c|}
\hline Motor Type & Suitability & Unsuitability \\
\hline \multirow{2}{*}{ SRM } & $\begin{array}{l}\text { Simple, rugged construction, applicable for } \\
\text { high temperature and speed operations. }\end{array}$ & $\begin{array}{l}\text { Higher losses, poor power factor, relatively } \\
\text { low torque density. }\end{array}$ \\
\hline & Inherent fault tolerant capability. & $\begin{array}{l}\text { High torque ripple, design limitation of } \\
\text { maintaining fewer slots. }\end{array}$ \\
\hline \multirow[t]{2}{*}{$\mathrm{IM}$} & \multirow[t]{2}{*}{ Robustness, high reliability of operation. } & $\begin{array}{l}\text { Poor performance due to the additional } \\
\text { magnetizing component for } \\
\text { the stator current. }\end{array}$ \\
\hline & & $\begin{array}{l}\text { Performance worsens further in the case of } \\
\text { high pole count and air gap winding. }\end{array}$ \\
\hline \multirow{5}{*}{ PMSM } & $\begin{array}{l}\text { High-pole number and short-pole-pitch } \\
\text { designs potentially saves the yoke iron } \\
\text { material, potentially give high specific } \\
\text { power, and lower loss. }\end{array}$ & $\begin{array}{l}\text { Lower magnetizing inductance makes it } \\
\text { vulnerable for the short } \\
\text { circuit fault conditions. }\end{array}$ \\
\hline & $\begin{array}{l}\text { Surface mounted PMs are more suitable } \\
\text { for high speed applications. }\end{array}$ & $\begin{array}{l}\text { Limited with tip-speed constraints due to } \\
\text { the mechanical tip-speed challenges } \\
\text { at high speed. }\end{array}$ \\
\hline & $\begin{array}{l}\text { An air gap winding in a PMSM design } \\
\text { facilitates more space for conductors. }\end{array}$ & \\
\hline & $\begin{array}{l}\text { In conjunction with the use of Litz wire, } \\
\text { potentially saves the high-frequency } \\
\text { copper loss. }\end{array}$ & \\
\hline & $\begin{array}{l}\text { Halbach arrangement improves } \\
\text { magnetizing effectiveness improving the SP } \\
\text { and achieves higher efficiency }[200,202] \text {. }\end{array}$ & \\
\hline
\end{tabular}

Lighter materials and material with better conductivity and methods to optimize the machine size were to be used for achieving the performance targets. Carbon nanotubes (CNTs) fabricated nanoconductors, possess properties of improved conductivity and lower density an order of magnitude compared to the copper [105]. In a study conducted at GRC for assessment of the material improvements in the machine technology in the coming 15 to 30 years. based on which the performance parameters for the components were predicted. In the machine segment, $1 \mathrm{MW}$ sized radial flux standard/tip drive motor designs were considered. Graphene and CNT based conductors for the winding, composite material incorporating hard and soft magnetic material for the lamination, and higher remanence flux nanocomposite magnetic materials were proposed for the future improvements. With incorporation of 
the improved materials, out of many designs, the surface-mounted PM machines exhibited the largest potential for performance improvements: predicted to be $97.4 \%$ and $14.5 \mathrm{~kW} / \mathrm{kg}$ for the efficiency and SP, respectively [184]. Other significant research developments related to machine design proposes a design for a 1.4 MW size of WFSM type, with achievable SP of $16 \mathrm{~kW} / \mathrm{kg}$ and efficiency $>98 \%$ [11]. The motor is built on the technology of a self-cooled, superconducting rotor with a slot-less stator which enables a design of exceptionally high specific power and efficient design. The E-Fan X introduces a breakthrough technology in electrical systems with a projected electrical machine SP $7.7 \mathrm{~kW} / \mathrm{kg}$ in a 2 MW size machine with technology levels in the year 2020 [206]. A compilation on the machine prototypes conceived for different designs are presented in Table 5.

Table 5. Projection in electrical machines.

\begin{tabular}{|c|c|c|c|}
\hline Machine Type & $\begin{array}{l}\text { Research } \\
\text { Project/Organization }\end{array}$ & Performance & Reference \\
\hline SRM & SUGAR Volt & $\begin{array}{l}\text { Efficiency: 93\%, } \\
\text { SP: 3-5 kW/kg }\end{array}$ & [29] \\
\hline HTS, Bi-2223 HTS wire & & $\begin{array}{l}1 \mathrm{MW}, 3600 \mathrm{rpm}, \\
\text { Bi-223 HTS field coil, } \\
\text { Armature Terminal Voltage: } 3300 \mathrm{~V}\end{array}$ & [207] \\
\hline $\begin{array}{l}\text { Partially } \\
\text { Superconducting WFSM }\end{array}$ & NASA GRC & $\begin{array}{l}1.4 \mathrm{MW}, \\
\text { SP: } 16 \mathrm{~kW} / \mathrm{kg} \\
\text { Efficiency: } 98 \%\end{array}$ & {$[194,208]$} \\
\hline $\begin{array}{l}\text { IM Variable } \\
\text { Cross-Section Wet Coil } \\
\text { (VCSWC) }\end{array}$ & Ohio State University & $\begin{array}{l}2.7 \mathrm{MW} \\
\mathrm{SP}: 13 \mathrm{~kW} / \mathrm{kg} \\
\text { Efficiency: }>96 \%\end{array}$ & [11] \\
\hline WFSM & & $\begin{array}{l}2.5 \mathrm{MW}, \\
14 \mathrm{~kW} / \mathrm{kg}, \\
\text { oil cooling }\end{array}$ & [209] \\
\hline WFSM & & $1 \mathrm{MW}, 4.7 \mathrm{~kW} / \mathrm{kg}$ & [209] \\
\hline Air Core PMSM & University of Illinois & $\begin{array}{l}\text { 1MW, } \\
\text { Efficiency: >96\%, } \\
\text { SP: } 13 \mathrm{~kW} / \mathrm{kg}\end{array}$ & [200] \\
\hline Radial Flux PMSM & & $1 \mathrm{MW}, 10 \mathrm{~kW} / \mathrm{kg}$ & [210] \\
\hline Solid Rotor IM & & $8 \mathrm{MW}, 6.6 \mathrm{kV}, 12 \mathrm{krpm}, \mathrm{SP}: 2-3 \mathrm{~kW} / \mathrm{kg}$ & {$[211,212]$} \\
\hline $\begin{array}{l}\text { Direct Drive Permanent } \\
\text { Magnet, SP260D }\end{array}$ & Siemens/Rolls-Royce & $\begin{array}{l}260 \mathrm{~kW}, 2500 \mathrm{rpm}, \\
\text { oil cooled, } 580 \mathrm{~V} \text {, } \\
\text { SP: } 5.9 \mathrm{~kW} / \mathrm{kg} \text {, Efficiency: } 95 \%\end{array}$ & [206] \\
\hline $\begin{array}{l}\text { Permanent Magnet, } \\
\text { SP2000D }\end{array}$ & $\begin{array}{l}\text { Siemens/Rolls-Royce } \\
\text { E-Fan X }\end{array}$ & $\begin{array}{l}2000 \mathrm{~kW}, 6500 \mathrm{rpm}, \\
\text { direct liquid cooling, 3000V, } \\
\text { SP: } 7.7 \mathrm{~kW} / \mathrm{kg}\end{array}$ & [206] \\
\hline
\end{tabular}

Power Converter

Power converters are needed for variable speed operation of electrical machines and also to adapt to different voltage levels in the generation and transmission systems. The NRA set a goal for achieving specific power 16-19 kW/kg and efficiency greater than $98 \%$ in the next 10 years in MW-sized power converters. The MEA applications (have made considerable improvements in the performance of the airborne power electronics with mutual advancements in the underlying technology. Further improvement is desired for the operability in high temperature environments, increases in the efficiency, and reduction in the weight and volume.

The SOA for SP and efficiency in the power electronics are limited to $8 \mathrm{~kW} / \mathrm{kg}, 93 \%$ to $95 \%$ respectively [197]. Improvement in filter components, advanced switching topologies, adaptive multilevel topology, and use of improved materials are the key areas of development to achieve further gain in 
the performance. Use of silicon carbide $(\mathrm{SiC})$ material in the power electronic components show the potential to make it efficient, lighter weight, high-temperature compliant, more reliable, and thermally more conducting designs [213]. Some of the commercially available devices based on the technology are Schottky Diodes and field-effect transistors (FETs). SiC metal oxide semiconductor field effect transistor (SiC-MOSFET) switches, in addition to having characteristics of lower conduction and switching loss compared to Si insulated gate bipolar transistors (IGBTs), have high switching capability that make these switches appropriate for high speeds and high frequency motor drive systems $[214,215]$. The recent $\mathrm{SiC}$ MOSFET devices are rated for $1200 \mathrm{~V}$ and $1700 \mathrm{~V}$ [216]. The technological development assessment in these areas suggests that in 15 to 30 years there is a possibility to achieve efficiency and SP in the range of $98 \%-99 \%, 16.5-25 \mathrm{~kW} / \mathrm{kg}$ respectively in a non-cryogenic system [105]. The SBIR study sourced from NASA made a prediction of achievable specific power and efficiency of $16.5 \mathrm{~kW} / \mathrm{kg}$ (including the cooler weight) and $99.3 \%$ in cryogenically cooled inverter/converter [197]. Another type of wide band device gallium nitride $(\mathrm{GaN})$ also promises a better performance, however it is not developed for high voltage and high current application yet [217]. GaN based FET switches are proven to be better suited in cryogenic applications.

The MW-class propulsion system will need adaptation to higher voltages in order to get benefits from a lower weight and higher efficiency transmission system. Furthermore, the high SP machine for high-speed application requires a higher fundamental frequency drive. These considerations need future developments in power electronics to be made on high DC link voltage levels and for higher switching frequency components. There are few potential topologies which are considered by the researcher to find the most suited in these applications. The study by Krug et al. considered five topologies for $2.3 \mathrm{kV}, 2.39 \mathrm{MVA}$ converter design [209]: two-level/three-level neutral-point-clamped (NPC), three-level/four-level flying capacitor (FC), and five-level series connected H-bridge (SCHB) voltage source converter (VSC) using IGBT switches with different blocking voltage ratings. The topologies were assessed based on the numbers of components requirement and for the efficiency parameter. Two-level NPC designs are found not suitable in this application due to the high magnitude of losses in the switches. In lower to medium switching frequency applications ( $<1000 \mathrm{~Hz}$ ), a 3-level NPC topology is recommended. The selection between 2-level or 3-level topology makes a trade-off between weight, reliability, and efficiency parameters [218]. The FC converters are preferred for a higher switching frequency. The 5-level SCHB was found to be a versatile option in any of the situations. A design study performed by Zhang et al. [219] considering 3-level active neutral-point clamped conveter (ANPC), showed promises for achieving a SP of $12 \mathrm{~kW} / \mathrm{kg}$ and $99 \%$ efficiency, designed for $2.4 \mathrm{kV}$ DC voltage and $1.4 \mathrm{kHz}$ fundamental output frequency with use of SiC MOSFET switches. In a prototype design performed by Loder et al. [107], a flying capacitor multilevel converter (FCMC) was considered to drive an air-core PM machine. The said topology has the advantage of achieving ultra-low levels of total harmonic distortion (THD) in the output voltage by increase in the number of levels. The NASA NRA program aims to demonstrate a power converter with an efficiency of $99 \%-99.3 \%$ and specific power of $19-26 \mathrm{~kW} / \mathrm{kg}$. A list on future prototype developments in power converters are presented in Table 6. 
Table 6. Projections in power converters.

\begin{tabular}{|c|c|c|c|c|}
\hline $\begin{array}{l}\text { Converter Type } \\
\text { and Topology }\end{array}$ & $\begin{array}{l}\text { Research Project/ } \\
\text { Organization }\end{array}$ & Performance & $\begin{array}{l}\text { Switches and } \\
\text { Components, Topology }\end{array}$ & Reference \\
\hline $\begin{array}{l}1 \mathrm{MW} \text {, three-level } \\
\text { active neutral point } \\
\text { clamped (ANPC), } \\
\text { non-cryogenic }\end{array}$ & General Electric & $\begin{array}{l}\text { Efficiency: } 99 \% \text {, } \\
\text { SP: } 19 \mathrm{~kW} / \mathrm{kg}, \\
\text { input voltage: } 2.4 \mathrm{kV} \text {, } \\
\text { output frequency: } \\
1-3 \mathrm{kHz}\end{array}$ & $\begin{array}{l}\text { SiC-MOSFET switches, } \\
1.7 \mathrm{~kW}, 500 \mathrm{~A}, 1.7 \mathrm{kV}, \\
\text { input DC voltage: } 2.4 \mathrm{kV}\end{array}$ & [219] \\
\hline $\begin{array}{l}200 \mathrm{~kW}, 7 \text {-level } \\
\text { flying capacitor, } \\
\text { non-cryogenic }\end{array}$ & $\begin{array}{l}\text { University of } \\
\text { Illinois }\end{array}$ & $\begin{array}{l}\text { Efficiency: } 99 \% \text {, } \\
\text { SP:19 kW/kg, } \\
\text { input voltage: } 2.4 \mathrm{kV}\end{array}$ & $\begin{array}{l}\text { GaN based FET switches, } \\
\text { input voltage: } 1000 \mathrm{~V}\end{array}$ & [11] \\
\hline $\begin{array}{l}1 \mathrm{MW}, \\
\text { three-level ANPC, } \\
\text { Si switches, } \\
\text { Cryogenic }\end{array}$ & Boeing & $\begin{array}{l}\text { Efficiency: } 99.3 \% \text {, } \\
\text { SP: } 26 \mathrm{~kW} / \mathrm{kg}, \\
\text { input voltage: } 2.4 \mathrm{kV}\end{array}$ & $\begin{array}{l}\text { Input voltage: } 1000 \mathrm{~V} \text {, } \\
\text { output frequency: } \\
200-3000 \mathrm{~Hz}\end{array}$ & [11] \\
\hline
\end{tabular}

\subsubsection{Energy Storage}

Energy storage is a critical component for fully/hybrid electric aircraft application due to its dominancy in determining the aircraft's range and number of passengers. Further to add, electric aircraft operation benefits from a light, compact, and improved cycle life energy storage option. Based on that, five parameters are majorly identified for defining the suitability of it: specific energy or gravimetric energy density ( nominal battery energy per unit mass, $\mathrm{Wh} / \mathrm{kg}$ ), volumetric energy density (nominal battery energy per unit volume, $\mathrm{Wh} / \mathrm{L}$ ), specific power (maximum available power per unit mass, $\mathrm{W} / \mathrm{kg}$ ), and number of cycles (number of charge/discharge cycles the battery can experience) [220]. Among $t$ several energy storage options for future electric aircraft application, the research predominates for four options: fuel cells, supercapacitors, flywheels, and batteries.

A fuel-cell system stores the chemical energy in liquid or gaseous form and converts it to electrical energy by chemical reaction. Fuel-cells give the opportunity of improving the thermal efficiency of the combustion system which could be based on either high energy density hydrocarbon fuel LNG (methane) or low energy density fuel- hydrogen $\left(\mathrm{H}_{2}\right)$ [221]. A hydrocarbon powered fuel cell still produces $\mathrm{CO}_{2}$ but does not have $\mathrm{NOx}$ or other particulate emissions. If fueled from $\mathrm{H}_{2}$, it becomes a carbon and hydrocarbon emission free source of generation, but on the downside, it generates contrails in the atmosphere. In addition, the storage of $\mathrm{H}_{2}$ both in forms of liquid or gas and its operation in aircraft operating environment imposes further safety challenges. Besides, fueling the aircraft with $\mathrm{H}_{2}$ also needs a huge infrastructural requirement.

Among various technology-based fuel cells, proton exchange membranes (PEM) purely fueled with $\mathrm{H}_{2}$ and Solid Oxide Fuel Cells (SOFC) are the two most common ones explored for aviation applications. PEM requires pure hydrogen without any form of $\mathrm{CO}$ as the fuel and operates in a temperature range between $80^{\circ} \mathrm{C}$ and $120^{\circ} \mathrm{C}$. The SE in SOA PEM cell is in the range between 600-800 Wh/kg that makes it attractive to use for aerospace application. A SOFC operates with different types of fuel sources but requires an operating temperature between $750{ }^{\circ} \mathrm{C}$ and $1000{ }^{\circ} \mathrm{C}$. Fuel cell technology is also limited by a lower SP. A study concerning fuel cell applications in auxiliary power unit (APU) in the Boeing Dreamliner concluded that the technology needs boosting in the SP parameter if it has to compete with the fuel technology and beyond to achieve the benefit of any savings in fuel burn [19]. Hybrid designs such as combining $\mathrm{H}_{2}$ fueled SOFC combined with gas turbine in the bottoming cycle improves the thermal efficiency and gives opportunity for core noise reduction. Boeing has developed various propulsion concepts based on combination of energy sources: fuel-cell/battery and fuel-cell/gas turbine, as means for reduction in the fuel burn and generated emission [29]. Future works in the fuel cell technology are to improve SP beyond $500 \mathrm{~W} / \mathrm{kg}$ and improve the storage technology for the $\mathrm{H}_{2}$ fuel. In SOFC technology, efficiency improvement in hot recycle blower and steam reformer is desired to achieve the full potential in it. There is a plenty of 
research investment exploring this technology. NASA led Fostering Ultra Efficient Low Emitting Aviation Power (FUELEAP) program focuses on development of stack technology for a $120 \mathrm{~kW}$ SOFC system and processing of hydrocarbon fuel [222,223]. Bauhaus Luftfahrt led AdVanced Aircraft CONcepts (AVACON) project researches on $\mathrm{H}_{2}$ fueled PEM cell for APU application [224]. DLR is developing a purely hydrogen fueled PEM technology based four-seater aircraft, HY4, with $80 \mathrm{~kW}$ capacity. Despite these efforts, there remain many barriers to overcome before they become part of the propulsion technology. Presumably, the technology is not likely to advance sufficiently to achieve a SP level competitive enough to be beneficial for future medium to long range aircraft operations, neither in the short term, nor in the long term. Such predictions are also echoed in the NAE report $[19,27]$.

Supercapacitors/ultracapacitors are suitable to achieve high SP and discharge rate and therefore, considered to be a suitable for boosting power application, such as during take-off condition. It has a very long cycle life and shows good performance for wide temperature range. Such technology also exhibits low toxicity and high efficiency. The technology is also apposite to boost the specific power in a hybrid energy storage system, e.g., combination of batteries and supercapacitors [221]. The current application of the supercapacitor for A380 is for powering the electrochemical actuators and for use as backup power for emergency exits. It is anticipated that the improvement in the electrode material can enable to achieve a SE level in the range of 100-150 Wh/kg and 200-300 Wh/kg in 15 and 30 years' time ahead, respectively. Similarly, the SP is expected to improve in the range of $2-3 \mathrm{~kW} / \mathrm{kg}$ and $4-6 \mathrm{~kW} / \mathrm{kg}$ in the aforementioned timeframe [105].

Flywheels store the energy mechanically in the spinning rotor through an integrated motor/generator and charges and discharges through speeding up and slowing down respectively. The current technology for flywheels represents a SE in the range on $100 \mathrm{Wh} / \mathrm{kg}$. However, the technology has the potential for exhibiting a higher SP and discharge rate, and is low toxic, and lesser temperature sensitivity in relation to the battery technology. however, has been forecasted to achieve $860 \mathrm{Wh} / \mathrm{kg}$ and $3430 \mathrm{Wh} / \mathrm{kg}$ in 15 and 30 years, respectively, from the improvement in the weight in the motor, bearings, and housing [105]. The packaging of the flywheel remains a challenge to be overcome [221].

However, the application until now is limited to the battery technology for two reasons: high level of technical maturity and successful application in the automotive industry. In that pre-context, SE is majorly referred to when defining the technological pre-conditions for viability of an electric aircraft. A higher SE in the battery has a positive snowball impact, and thus, is conducive for achieving a higher range. BHL conceptualized studies have pronounced a desirable SE in the range of 1000-1500 Wh/kg for HE applications in single-aisle segments [40,121]. The desired level varies based on the type of propulsion system configuration, airframe morphology, size of the aircraft, degree of hybridization, and the flown mission range [225]. The NAEreport made a consensus effort in defining the least desired SE in three different segments of aircrafts: $1.250 \mathrm{Wh} / \mathrm{kg}$ in a fully electric general aviation aircraft, 2. $800 \mathrm{Wh} / \mathrm{kg}$ in a HE regional aircraft, and 3. $1800 \mathrm{Wh} / \mathrm{kg}$ for a fully electric regional aircraft [19].

Another important feature of the battery is the SP. Batteries do not allow independent design of the installed power and energy due to its integral electrochemical structure. The battery design trades for high SE and high SP [220,221]. The Ragone diagram, as an indicator shows the relation between the achievable SP/ power density for a given SE/energy density [226]. A more suitable metric, power-to-energy ratio (P/E-ratio), is proposed by the authors under reference [34], defined as the ratio of SP to SE. Another important metric, though majorly neglected in system studies, is the "C-rate". It defines the coulometric capacity, i.e., the total Amp-hours available when the battery is discharged at a certain discharge current. In an application where battery energy is used to boost the gas turbine operation for high power requirements, a high C-rate is paramount. The battery life cycle also has major impact on its usage: ramping, or step-change. Hence, the technology selection is dependent on it [91]. The summary report on the assessment of advanced energy storage technologies released by NASA GRC [227] emphasized on SE and SP as the most desired parameters in the battery. The extract 
from the report on the recommended desired cell-level specific energy for fully electric and hybrid electric applications are as follows:

Fully Electric:

- $250 \mathrm{Wh} / \mathrm{kg}$ in $2-3$ PAX,

- $400 \mathrm{Wh} / \mathrm{kg}$ in 4-10 PAX,

- $600 \mathrm{Wh} / \mathrm{kg}$ in 50-70 PAX,

Hybrid Electric:

- $600 \mathrm{Wh} / \mathrm{kg}$ in 100-150 PAX,

- $750 \mathrm{Wh} / \mathrm{kg}$ in $180 \mathrm{PAX}$.

The report has also pronounced desired minimum SP level of $1 \mathrm{~kW} / \mathrm{kg}(2-3 \mathrm{~kW} / \mathrm{Kg}$ for some applications), and a cycle life between 1000 and 2000 in order to make the battery powered electrical aircraft plausible.

High SE batteries for aircraft applications are based on light weight lithium materials. Of them, lithium-Ion ( $\mathrm{Li}-\mathrm{Ion}$ ) batteries are the most matured one; the SOA exhibits a cell level SE of $300 \mathrm{Wh} / \mathrm{kg}$ [228]. The Li-ion types are defined based on the used cathode and anode material, those are used differently for achieving different performance parameters. SOA in Li-Ion type is Li-Ion polymer batteries which feature a semisolid polymer electrolyte. Future advancement is to transition to a solid-state Li-Ion battery for high SE, improved volume and increased safety. Technology considerations, such as replacement of the anode graphite with silicon, cathode materials with higher Li-Ion storage capacity, and stability at higher voltages have beneficial impacts on the cell-level performance and show potential for an improved SE approximately up to $400 \mathrm{Wh} / \mathrm{kg}-450 \mathrm{Wh} / \mathrm{kg}$ in 2022-2025 timeframe [229].

The SOA in the lithium-sulfur (Li-S) battery shows a SE of over $350 \mathrm{Wh} / \mathrm{kg}[19,105]$. Li-S as battery technology has the potential to achieve a high theoretical SE-greater than $2000 \mathrm{Wh} / \mathrm{kg}$. However, the added weight of the current collectors, electrolytes, battery cases, separators, terminals, etc. limits the achievable SE to a low level. Low cost and abundant availability of the sulfur material has shown a large promise in this technology. It is envisioned that Li-S battery technology, with improvement in the electrolytes, anode, and cathode materials, would be enabled as a commercial product and achieve a cell-level specific energy of approximately $500-650 \mathrm{Wh} / \mathrm{kg}$ within 15 years and 800-950 Wh/kg in 30 years [105]. The current developments in the technology demonstrates $500 \mathrm{Wh} / \mathrm{kg}$ specific energy and 1500 cycles in the laboratory environment [230].

The SOA in the lithium-air/oxygen $\left(\mathrm{Li}-\mathrm{air} / \mathrm{O}_{2}\right)$ battery technology exhibits a specific energy of 250-300 Wh/kg. The technology has potential for achieving a very promising theoretical cell-level SE for 3000-3500 Wh/kg [231]. The Li-air battery SE level is anticipated to surpass both Li-Ion and $\mathrm{Li}-\mathrm{S}$ technology during a time horizon of 2030. The energy density of Li-air systems (discharged, including oxygen) is predicted to reach values between 750 and $2000 \mathrm{Wh} / \mathrm{kg}$ on a cell level based on studies conducted at different laboratories. The technology progress study by GRC predicts the achievable value to be $600-750 \mathrm{Wh} / \mathrm{kg}$ within 15 years and $1200-1400 \mathrm{Wh} / \mathrm{kg}$ within 30 years [105]. The specific power is expected to improve from special coating of the electrodes. The projection in achievable specific power varies in the range between $0.4 \mathrm{~kW} / \mathrm{kg}$ and $1 \mathrm{~kW} / \mathrm{kg}[232,233]$. Johnson predicts the power density in the $\mathrm{Li}$-air to be in the range of $0.4-0.64 \mathrm{~kW} / \mathrm{kg}$ [234]. Though it seems promising, it is only expected to be commercially available by the year 2030 due to the developmental challenges [165]. Furthermore, the technology has major bottlenecks as the battery discharges the oxygen particle that deposits over the cathode for potential weight gain. The current technology shows a limited number of charging/discharging cycles[46]. Lithium polymer batteries exhibit attractive volumetric energy density as well as high specific power [221]. Developments of the electrodes based on nanostructure is promising in achieving higher SE; it is expected to be in the range of $1500 \mathrm{Wh} / \mathrm{kg}$ in 2035 [19].

The other promising non-Li battery technology which could potentially find a place in aerospace applications are aluminum-air (Al-air), magnesium-air (Mg-air), zinc-air ( $\mathrm{Zn}$-air), and Flow batteries. 
Battery technology is the only promising energy storage technology which potentially could be used as an energy storage means for airborne applications in the near term. It is believed that achieving a SE beyond $700 \mathrm{Wh} / \mathrm{kg}$ need break-through developments in cell chemistry, materials and packaging, and integration techniques [227]. Current battery technology is not only limited in achieving high SE/SP but also suffers from inadequate cycle life. Both impart a high operational cost as highlighted by Epstein et al. [46]. Optimum performance of batteries demands a narrow temperature range between 20 and $60{ }^{\circ} \mathrm{C}$, which makes the TMS for batteries very challenging. It is equally pertinent to assess the application of these devices in terrestrial applications from the safety and the reliability perspectives. Predictions for battery technology in the future from various resources are compiled and presented in Table 7.

Table 7. Performance projections.

\begin{tabular}{|c|c|c|c|c|c|c|}
\hline \multirow[b]{2}{*}{ Technology } & \multicolumn{2}{|c|}{ Specific Energy (Wh/Kg) } & \multicolumn{2}{|c|}{ Specific Power (kW/kg) } & \multicolumn{2}{|c|}{ Cycle Life (Numbers) } \\
\hline & SOA & $\begin{array}{l}\text { Future } \\
\text { Projection }\end{array}$ & SOA & $\begin{array}{l}\text { Future } \\
\text { Projection }\end{array}$ & SOA & $\begin{array}{l}\text { Future } \\
\text { Projection }\end{array}$ \\
\hline Li-Ion & $80-200$ [105] & $\begin{array}{l}400^{1}, 450^{2} \text { [105], } \\
300^{3}[227], \\
250^{4}[8]\end{array}$ & 0.3 & & $>300$ & $400-450$ \\
\hline $\mathrm{Li}-\mathrm{S}$ & $\begin{array}{l}250-300 \\
{[105],} \\
160-350 \\
{[19,235]}\end{array}$ & $\begin{array}{l}500-650^{1}, \\
800-950^{2}[105], \\
600-700^{3}[227] \\
500-1250^{4}[8]\end{array}$ & & $1[233]$ & & $1000[230]$ \\
\hline $\mathrm{Li}$-air/ $\mathrm{O}_{2}$ & $\begin{array}{l}300-350 \\
{[105]}\end{array}$ & $\begin{array}{l}600-750^{1}, \\
1200-1400^{2} \text { [105], } \\
900-1000^{3}[227], \\
800-1750^{4}[8]\end{array}$ & & $\begin{array}{l}0.4-0.64 \\
{[234]}\end{array}$ & $>50[236]$ & $500[234]$ \\
\hline $\begin{array}{l}\text { Flywheels } \\
\text { (rim) }\end{array}$ & 100 [105] & $\begin{array}{l}860^{1}, \\
3430^{2} \text { [105] }\end{array}$ & & & & \\
\hline $\begin{array}{l}\text { Super } \\
\text { capacitors }\end{array}$ & 5-15 [105] & $\begin{array}{l}100-150^{1}, \\
200-300^{2}[105]\end{array}$ & $0.1-0.3$ & $\begin{array}{l}2-3^{1} \\
4-6^{2}\end{array}$ & $10^{6}$ & \\
\hline Fuel Cell & & & $0.1[19]$ & 0.5 [19] & & \\
\hline
\end{tabular}

\subsubsection{Thermal Management System Challenges \& Developments}

Thermal management systems (TMS) are necessary to pull away the heat in the propulsion system components due to the system inefficiencies. Maintaining the right operating temperature in the electrical components (battery, converter, motor/generator, etc.) ensures optimized performance of it and negates the runaway heat problems. On the downside, the inclusion of TMS components impacts the aircraft weight and causes parasitic drag, affecting the aircraft overall performance for the worse. A study performed on designing the TMS for electric propulsion system application indicates that the TMS weight could be even $5 \%$ of the weight of the total electrical system weight even for a low electric power level and could impose an efficiency penalty in the range of $3 \%$ thrust loss $[28,176]$. TMS designs for a conventional aircraft exhausts the waste-heat to the free stream air or to the fan by-pass duct air through a liquid coolant loop [237]. Given a higher order of magnitude of the heat load emanating from the electrification of the propulsion system, it is envisioned that both the conventional approach and existing onboard heat sinks would not be adequate for exhausting the heat load of an electric aircraft. Some novel approaches for dissipating the heat should be worked through $[237,238]$.

Typical components desired in TMS are the heat exchanger, coolant pump, a coolant reservoir, and the piping system. The heat sinks appropriate for the TMS are fuel, fan bypass/ ram air, and coolants, and heat exchanger designs vary as a fuel oil cooler and air oil cooler. The architectural lay out can 
be made as centralized/decentralized [180], parallel/serial [31] systems, etc., optimized based on the placement and sizing of the head load components. Coolants are typically single phase or two-phase; some of the suitable coolants are listed in the literature [180]. Advanced heat exchanger designs are microchannel based multi-pass tube-fin designs [239] and surface coolers [240].

Thermal constraints concerning the electrical components are time-varying in nature and mission path dependent [157]. TMS also inherently exhibits a coupled interaction with other propulsion system components, making the sizing optimization rather a challenging task [241]. Therefore, a strategic design of a TMS requires a modeling environment suitable to capture the TMS associated performance trade-offs at the aircraft level. A few conceptual design studies focused on sizing of thermal system components, performed in an integrated environment. Notable amongst them are studies performed on UTRC's parallel hybrid electric design [31,35,36], and ESAero's ECO-150 TeDP [28], and Maxwell X-57 design [110]. Vratny et al. study used analytical equations for sizing of the TMS [180]. Another conceptual design, which considered TMS aspects, is the EVE design [37]. The study utilizes the multidisciplinary optimization tool GT-HEAT for sizing of the TMS. The OpenConcept tool provisions thermal constraints aspects in the aircraft sizing optimization study $[163,242]$. The ESAero developed propriety tool, PANTHER, incorporates the TMS module as part of the propulsion system and aircraft sizing process with due consideration in the performance trade-off for the TMS and the electrical system components [28]. Heerdeen et al. [243] proposed a novel thermal architecture of utilizing the wing surface area as means to exhaust the heat with use of fuel and atmospheric air as the potential heat sinks. The study performed a thermal analysis with a compartment-based wing thermal model for a future ultra-high bypass ratio turbofan engine and established a strong relationship between the engine heat sink temperatures in sizing of the thermal system. An advanced battery heat acquisition system is proposed by the authors Annapragada et al. [244] showing potential for $60 \%$ weight reduction. An effective heat transfer management system needs CFD based heat transfer analysis to ensure that electrical components do not operate beyond thermal limits. Schunlo et al. [110] conducted a flow-through analysis to optimize the heat sink design in the electrical system components. The heatsinks are proposed to be embedded in the wing-tip propulsor in proximity to the heat source. Liu et al. conducted a steady state RANS based method for assessing the benefit in a surface cooler. A ducted radiator design potentially reduces the cooling drag with the Meredith benefit by utilizing the heated air to generate extra thrust to offset the drag impact [28]. The heat exhaust can be also strategically utilized, as suggested by Freeman et al., for other purposes such as anti-icing, cabin heating, cooking in galleys, or pre-heating the fuel, etc. [241].

TMS for superconducting components requires an operating temperature of $-20 \mathrm{~K}$ to $60 \mathrm{~K}$ that needs to be addressed using a cryo-cooler system. The current cryo-cooler design exhibits a SP of $3 \mathrm{~kW} / \mathrm{kg}$ and efficiency of 30\% [197] which adds significant weight penalty in the system. Both N3-X and SUGAR Volt designs are explored for a reverse Brayton cycle cryo-cooler, in which the mechanical power is used to cool the working liquid to make it suitable for superconducting temperatures [29]. A novel thermal conversion approach is proposed by the author Dyson [245] for an electric aircraft application with tighter integration of the propulsion, thermal, and airframe systems. The design proposes a Strayton based engine with an embedded cryo-cooling system for the electrical machine and an integration approach for benefiting from the effective implementation of BLI system.

Special consideration is needed for designing light weight radiators and surface coolers. Strategic utilization of the waste heat, such as with radiator design to benefit from Meredith effect, surface cooler, use of different cooling mediums such as fuel, and use of the waste heat for environmental control system (ECS), are proposed as some of the means. This needs further detailed investigation.

\subsection{Air Worthiness, Safety, Certification, and Infrastructure Related Challenges and Developments}

Safety and reliability are paramount in the aviation sector. Any technological penetration would not happen without a solid track record of testing it. The EP concept introduces many new technologies in the aircraft in addition to the incumbent ones. The procedure for integration of these new elements 
needs validation with an appropriate testbed. There are few developments found in this regard. A sub-scale desktop experimental testbed called Propulsion Simulation Grid Simulator (PEGS) is emulated for a TeDP drivetrain including turbine engine and all the components of electrical drivetrain. NASA Armstrong Flight Research Center (AFRC) laid pilot platform Hybrid Electric Integrated Systems Testbed (HEIST) aims to facilitate hardware integration and pilot simulation for HEDP configuration systems. The platform is designed for testing the control and power management laws for a $200 \mathrm{~kW}$ electrical powertrain system. The architectural layout of the testbed is illustrated in Figure 4.

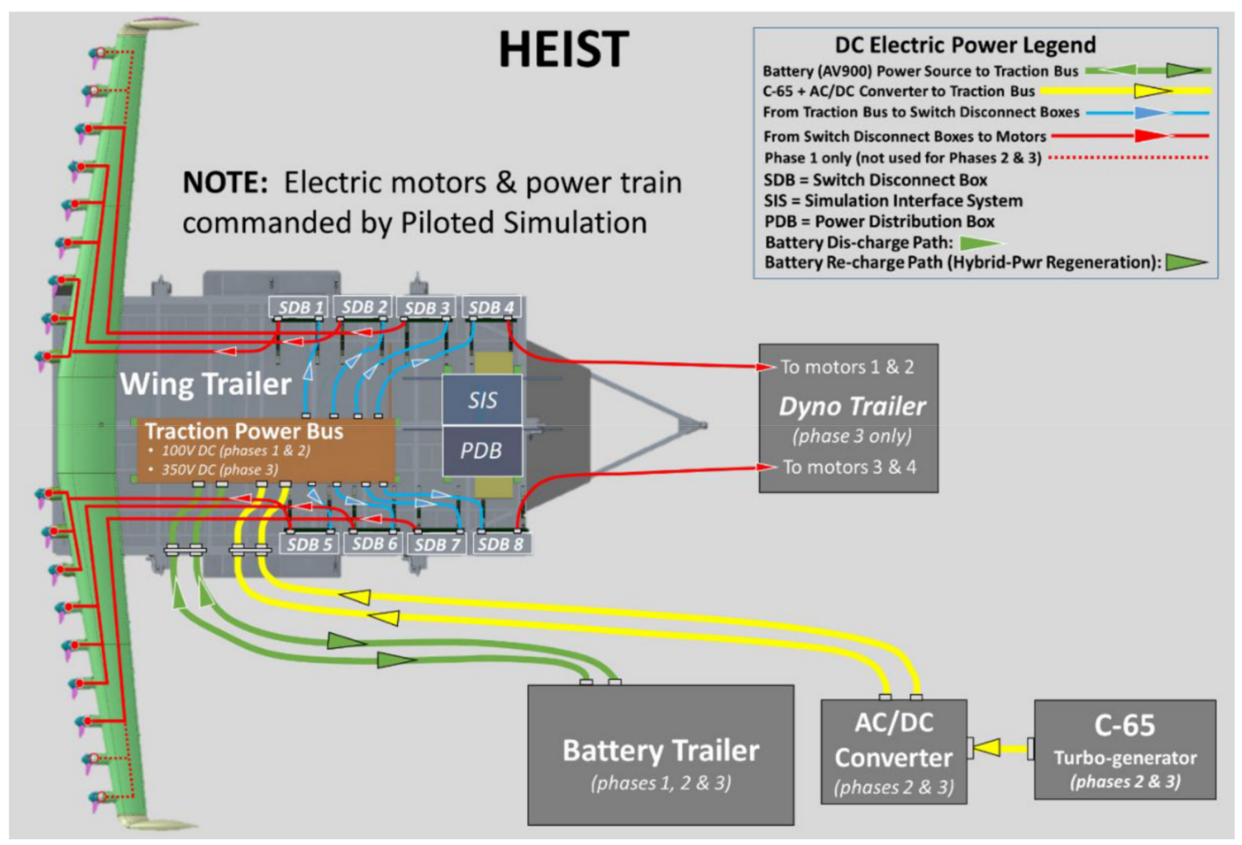

Figure 4. Hybrid Electric Integrated System Testbed (HEIST)—Concepts of operation view. Source: NASA [11].

Furthermore, a full-scale electric aircraft powertrain test capability NASA Electric Aircraft Testbed (NEAT) platform is under-development at GRC. The platform as displayed in Figure 5, is meant to test re-configurable powertrain architectures of different sizes and attributes [246]. The platform aims to test both ambient and cryogenic environment high-power system components in order to prepare them for a TRL-6. It is also intended to support component development and illustration of a large-scale power (up to $24 \mathrm{MW}$ power generator, $2 \mathrm{MW}$ heat dissipation, and environment for 12,000 ft altitude) prior to actual deployment in the aircraft.

Zonal safety analysis (ZSA) as part of safety assessment process is a recommended practice in the design phase of the civil aircrafts. However, for aircrafts with such novel features and new components, conducting it at the preliminary design phase, facilitates a better understanding of the safety criticality, airworthiness condition attached to the system. It also gives opportunity for analyzing the influence of a configuration selection on the system architecture and on the structural designs. In absence of any procedure defined for doing such analysis for preliminary design phase, authors Chen et al. [247] proposed a preliminary ZSA method and subsequently, run a case study on the N3-X notional design. Few recommendations were made with respect to the requisite inputs and towards improvements to the existing standards Those are for considerations in:

- $\quad$ system design and architectural lay-out to be made as focus of the ZSA

- fault tree analysis (FTA)/functional hazard analysis (FHA) are necessary while developing the external system failure modes

- $\quad$ to include inter zonal effect analysis from the external system failure mode as part of ZSA. 


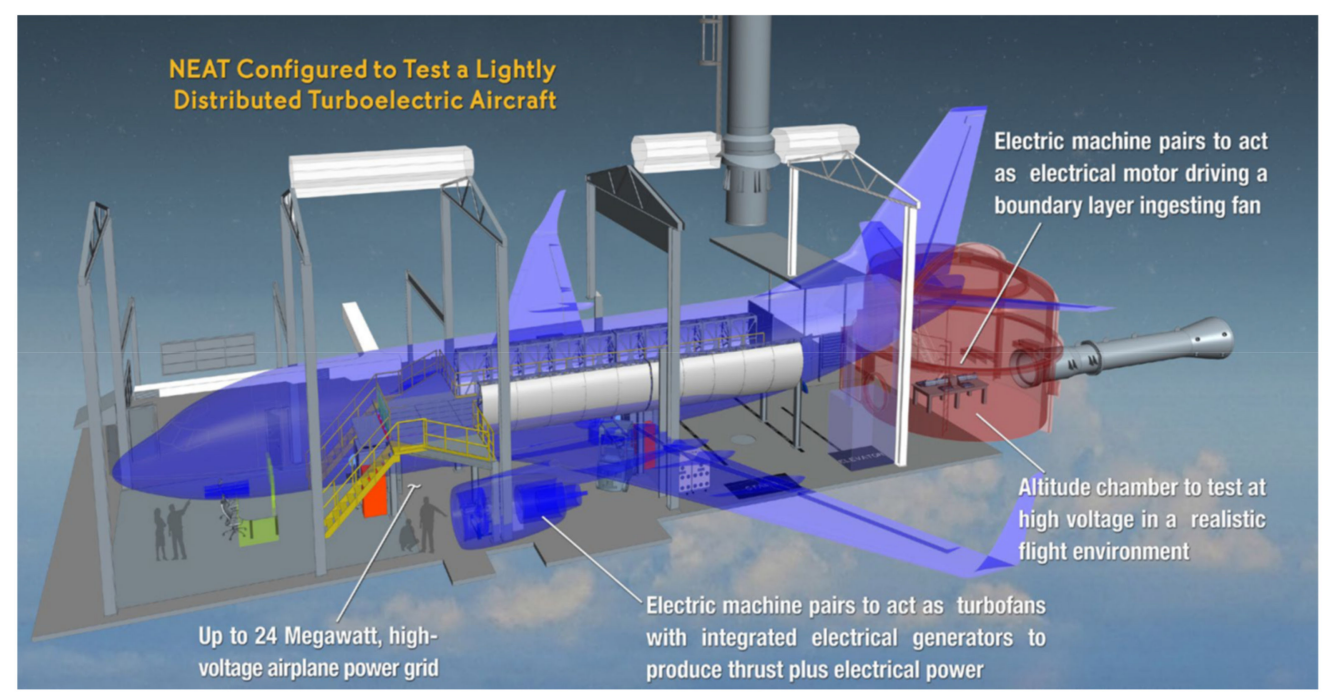

Figure 5. NASA electric aircraft testbed. Source: NASA/MIT/Aurora Flight Sciences.

FTA/FHA based failure analysis studies facilitates understanding of the impacts of the system level failure on the design. Having a view towards that and with consideration of alternate architecture/design, this approach helps in improving the failure rate and thus, enhances the reliability [189]. A Fault management strategy considers many of the design aspects under off-nominal conditions such as for fault response time and facilitates right section of the architecture, redundancy level in the network etc. for maintaining a desired level of reliability [248].

Likewise, uncertainty quantification and risk assessment studies are desired to ensure design robustness and technology sufficiency in the components. A case study of uncertainty quantification with Monte-Carlo and Latin hypercube sampling methods performed on N3-X TeDP architecture and identified a risk of $2 \%$ overloading the transmission system [249].

In the conceptual design phase, the conventional practice of NOx emission prediction is made with use of empirical correlation models and the certification test is made on a static engine test stand, keeping it independent of the airplane related performance. As the hybrid electric/turboelectric operations differ from the conventional ones, this conventional approach of certification may not be suitable for certification measures and hence a modified procedure is needed [52].

\section{Summary}

This section summarizes the present situation and what the future holds on various research and technological fronts in order to make electrical propulsion a reality in the aviation industry. This is divided into four broad dimensions; the research gap for technology progress, developments made on the simulation and performance assessment front, gaps in the aircraft sizing and synthesis tool developmental aspects, and finally the framework that ascertains the airworthiness of the presented technology.

\subsection{Technology Gap}

The success of the electric aircraft is attributed to future technology improvements in the electrical and thermal system components and implementation of disruptive operational and design concepts.

The promise of an efficient, airworthy, light weight, and high performing electric aircraft depends on the success of a multitude of subcomponents that are part of the electric propulsion system. This subsection sheds light on some of the important design consideration of it for successful electric aircraft application. 
1. Energy storage solutions-The industry needs to foster development of high SE and SP modular battery storage solutions. Development of a high cycle life energy solution is paramount for boosting the operational cost. Furthermore, the development needs to be in alignment with the aircraft characteristic operational features and compliant with airworthiness and public safety requirements. Fuel cell technology needs significant boost in SP. Besides, in SOFC technology, significant research investment is needed to improve the reliability and efficiency in the hot recycle blower and steam reformer to achieve the full potential in it. Hydrogen-fueled fuel cell are constrained for higher power application due to low SE, low SP, thermal management techniques and airport infrastructure issues. Both energy storage technologies need development to meet the certification requirements.

2. Power system components-High-efficiency and high SP drivetrain components are all desired metrics to be fulfilled, in varying degrees to be able to fit in with the aircraft weight and volume constraints. The research and prototypical work in the electrical components showed break-through progress for achieving higher SP and efficiency as desired; however, the real challenge would be to make it airworthy, under low ambient pressure and varying operating temperature environment

3. Material improvements-While in a fully electric large passenger aircraft superconducting technology is considered as the only enabler, fully electric regional-jet aircraft or single-aisle hybrid electric aircraft in the short/medium range are still viable, with normal temperature operating electrical components. Technology developments for higher conductivity wires, light weight structural material, material with enhanced magnetic properties, , insulation material with higher thermal capacity and voltage withstanding capacity in the electrical machine component is paramount for developing a high SP and high efficiency product. Likewise, better performing high temperature tolerant $\mathrm{MW}$-class, and $\mathrm{kV}$ class compact power electronics switch developments, innovative topology/modular design is a further need to achieve the scalability in the power converter component.

4. Superconducting technology—Superconducting components are treated as possible efficiency and weight enhancing technology, but this would require additional developments for an efficient and higher power to weight to ratio associated cryocooler system. AC conductor technology development for higher voltage level with lower loss is a perquisite to get the full benefits of a superconducting system. Furthermore, robustness and safety are other major bottleneck that has to be surmounted to make it usable in aircraft service.

5. High voltage power system requirements- Adopting a higher voltage level increases the risk of insulation break down and arcing phenomenon. Hence, a special attention is needed to make the electrical components fault-tolerant, immune to the electromagnetic interference and surge phenomenon. Developments of insulation material with high voltage withstanding capacity, advanced circuit breaker technologies-SSCBs, hybrid CBs, fault current limiter is crucial. A suitable architecture selection has much to do with fail-safe operation for the components and the system during off-nominal conditions, with provisioning for aircraft controllability such as balancing out yaw movement etc.

6. Thermal management-Designing of a light weight radiator, strategic utilization of the waste heat such as with a radiator designed to benefit from Meredith effect, use of different cooling mediums such as fuel with surface cooler, and use of the waste heat for ECS are proposed as some of the means. This kind of research needs further detailed investigation.

Table 8 summarizes the technology enablers, respective developments, and research gaps in current investigations. 
Table 8. Propulsion system technology enablers and research gaps.

\begin{tabular}{|c|c|c|c|c|}
\hline Configuration & Notional Benefits & $\begin{array}{c}\text { Propulsion Technology } \\
\text { Enabler }\end{array}$ & $\begin{array}{l}\text { Electrical and Thermal } \\
\text { Technology Enabler }\end{array}$ & Research Gap \\
\hline Fully Electric & $\begin{array}{l}\text {-Zero inflight } \mathrm{CO}_{2} \text { emission } \\
\text {-Elimination of high-altitude } \\
\text { non- } \mathrm{CO}_{2} \text { emission } \\
\text {-Reduction in the noise }\end{array}$ & $\begin{array}{l}\text {-Boundary layer } \\
\text { ingestion system } \\
\text {-Distributed propulsion system }\end{array}$ & $\begin{array}{l}\text {-Superconducting technology } \\
\text {-Cryo-cooling system } \\
\text {-High specific power, } \\
\text { high efficiency components } \\
\text {-Efficient/light weight } \\
\text { cooling system } \\
\text {-Battery technologies with better } \\
\text { packaging efficiency, cycle life, } \\
\text { specific energy, } \\
\text { charge/discharge rate }\end{array}$ & $\begin{array}{l}\text {-Achieving a battery SE beyond } 600 \mathrm{Wh} / \mathrm{kg} \text { needs } \\
\text { introduction of break-through technology. } \\
\text { Furthermore, challenged with maintaining a high } \\
\text { SP, and cycle life and charge and discharge rate. } \\
\text {-SOFC technology needs research investment in } \\
\text { advanced technologies such as in steam reformer, } \\
\text { hot recycle blower to boost the performance. } \\
-\mathrm{H}_{2} \text { fueled fuel cell technology need significant } \\
\text { technology improvement in the storage techniques, } \\
\text { thermal management system and airport } \\
\text { infrastructure requirements. } \\
\text {-Development of high voltage withstanding } \\
\text { insulation material, advanced SSCBs, } \\
\text { fault current limiter is paramount. }\end{array}$ \\
\hline Turboelectric & $\begin{array}{l}\text {-Improvement in overall } \\
\text { vehicle efficiency } \\
\text {-Noise improvement }\end{array}$ & $\begin{array}{l}\text {-Distributed electric } \\
\text { propulsion system } \\
\text {-Boundary layer } \\
\text { ingestion system } \\
\text {-Low NOx } \\
\text { combustor technology } \\
\text {-New airframe technology to } \\
\text { enable BLI/DEP system and } \\
\text { leverage noise shielding effect } \\
\text {-Improved engine } \\
\text { thermal efficiency }\end{array}$ & $\begin{array}{l}\text {-Superconducting technology } \\
\text {-Cryo-cooling system } \\
\text {-High voltage level architecture } \\
\text {-Superior efficiency in electrical } \\
\text { drivetrain system } \\
\text {-A suitable electrical grid } \\
\text { architecture for ensuring } \\
\text { fail-safe and reliable system } \\
\text { operation during } \\
\text { off-nominal condition }\end{array}$ & $\begin{array}{l}\text {-An architecture selection should not only consider } \\
\text { the technologies in the components, but also } \\
\text { flexibility of using it for aircraft controllability with } \\
\text { well-coordinated fault management strategies. } \\
\text {-The efficiency and safety aspect of cryocooler } \\
\text { system needs improvement. } \\
\text {-DEP integration flight testing/experimental test } \\
\text { bed for scalable sized propulsors is needed to } \\
\text { investigate the impacts for different sized aircrafts. } \\
\text {-Small core development, numerical and } \\
\text { experimental investigation of inlet distortion } \\
\text { impact on the fan efficiency/structural robustness, } \\
\text { distortion tolerant BLI fan designs are necessary. }\end{array}$ \\
\hline Hybrid Electric & $\begin{array}{l}\text {-Optimized engine performance } \\
\text { through load balancing } \\
\text {-Mission level fuel burn } \\
\text { saving opportunity } \\
\text {-NOx emission benefit }\end{array}$ & $\begin{array}{l}\text {-Variable area } \\
\text { core/bypass Nozzle } \\
\text {-A suitable operational strategy }\end{array}$ & $\begin{array}{l}\text {-Efficiency in the electrical } \\
\text { drive train } \\
\text {-Specific Power Density } \\
\text {-Battery Energy density } \\
\text {-Optimized Operation Strategy }\end{array}$ & $\begin{array}{l}\text {-A fully/partially turboelectric system requires } \\
95 \%-98 \% \text { efficient electrical system to } \\
\text { gain overall benefit. } \\
\text {-Superconducting technology developments are } \\
\text { paramount AC superconducting conductor with } \\
\text { low loss for high voltage application development } \\
\text { would be an enabler. }\end{array}$ \\
\hline
\end{tabular}




\subsection{Modeling Framework Gap}

A high-fidelity model quantifies the benefits with better accuracy, while a multidisciplinary optimization framework facilitates the wide design space exploration to suggest an optimized design. A balance in both is desired.

Many compelling and competing alternatives are proposed in this technology frontier with promising avenues. The preliminary studies recommend the vast design space exploration of the DEP and BLI concepts for various possibility improvements. The benefits of BLI should be conferred with the high-fidelity physics-based model to understand the impact on propulsion fan efficiency by flight testing, or wind tunnel methods. Many impacts and considerations of a DEP system remain to be explored, namely, integration, structural robustness of the DEP configurations, and possible noise reduction opportunity. Moreover, there is very little work done on integrating this feature into a multidisciplinary optimization environment. This pertains to optimized aerodynamic integration, formulating an optimized degree of hybridization, and sizing of the aircraft optimized for different performances.

The electrical system model development concerns the prediction of the efficiency and weight and heat loss in the components. The electrical models used for the conceptual design optimization studies are low-fidelity levels, either based on statistical correlation-based methods or assumed for a fixed member in the specific power or in the efficiency parameter. There is a strong design and performance trade-off at the individual component level and at the sub-system level giving an opportunity for selection of the right bus voltage level, for a design architecture based on DC or AC system, etc. A higher-fidelity level electrical sizing framework is desired in order to make an informed decision on such values.

\subsection{Performance Assessment Study Gap}

The electric aircraft benefits are not only intended towards fuel/energy savings, but also for other established performance metrics such as noise and emission reductions, as well as for a favorable operating cost to make it commercially viable.

The conceptual assessment studies made on fuel/energy savings, and emission reduction opportunities. do not account for the life cycle analysis of the battery and other propulsion system components. Likewise, electric aircraft performance is to be assessed in conjunction with the ground based electrical generation system conversion efficiencies. A holistic approach considering the life cycle analysis would show the actual potential for fuel burn and emission savings.

Replacing the gas engine with batteries certainly alleviates the noise problem coming from the core. However, efforts to be made for predicting and modeling noise shielding effects generated through strategical prolusion-airframe integration approaches.

Operating cost parity is an important ingredient for economic sustainability of the electric aircraft operation. The potential for achieving dramatic reductions in operating cost is a motivator for early adoption of electric propulsion system. This gets a further boost due to the ever-increasing volatility in the aviation fuel price and low electricity price from renewable sources, and also from the carbon emission taxes. However, the operating cost models miss out on the battery Llifecycle cost assessment and impacts from the ground infrastructure investments. Furthermore, it lacks analysis concerning uncertainties arising from the fuel price, energy price and the projection in the battery technology. A summary of the performance studies and of the gaps is presented in Table 9. 
Table 9. Performance assessment summary and the gaps.

\begin{tabular}{|c|c|c|c|c|c|}
\hline \multirow{3}{*}{ Configuration } & \multicolumn{5}{|c|}{ Assessment Summary and Gap } \\
\hline & \multicolumn{4}{|c|}{ Potential } & \multirow{2}{*}{ Research Gap } \\
\hline & $\mathrm{CO}_{2}$ Emission & $\mathrm{NO}_{\mathrm{x}}$ Emission & Noise & Operating Cost & \\
\hline Fully Electric & $\begin{array}{l}\text {-It has potential to lower } \\
\text { the equivalent } \mathrm{CO}_{2} \\
\text { emission, if the electrical } \\
\text { grid transits to a } \\
\text { renewable based system. } \\
\text {-Fully electric aircraft in } \\
\text { the large passenger } \\
\text { segment are highly } \\
\text { unlikely to achieve net } \\
\mathrm{CO}_{2} \text { benefit. }\end{array}$ & $\begin{array}{l}\text {-The fully electric aircraft } \\
\text { are free of NOx emission. }\end{array}$ & $\begin{array}{l}\text {-Gives the opportunity for } \\
\text { noise reduction as } \\
\text { electrical motors are } \\
\text { quieter in its operation } \\
\text { compared to jet engines. }\end{array}$ & $\begin{array}{l}\text {-The operating cost benefit } \\
\text { has high reliance on the } \\
\text { future battery technology } \\
\text { development-cycle life, } \\
\text { specific energy, the } \\
\text { electricity/fuel price. }\end{array}$ & \multirow{3}{*}{$\begin{array}{l}\text {-The net } \mathrm{CO}_{2} \text { emission reduction potential needs } \\
\text { to be based on a battery/fuel life cycle emission } \\
\text { analysis with due consideration of emission } \\
\text { during operation, production and transportation } \\
\text { and energy mix in the region. } \\
\text {-Huge infrastructure investment at the airport is } \\
\text { needed for swapping or charging the battery, } \\
\text { hence entails cost impact assessment. } \\
\text {-The economic cost impact of the electric aircraft } \\
\text { operation needs suitable life cycle cost analysis } \\
\text { model, energy replacement strategies in a short } \\
\text { turnaround time, more accurate rate prediction } \\
\text { of the electricity/fuel pricing, etc. } \\
\text {-Turboshaft engine would require low-NOx } \\
\text { combustor technology to minimize the } \\
\text { NOx emission. } \\
\text {-Noise analysis is majorly lacking in the system } \\
\text { studies, which needs future attention. There is } \\
\text { no accurate noise estimation correlation that } \\
\text { exists for motor operation, which makes the } \\
\text { prediction uncertain. -Low cost, high lifecycle, } \\
\text { and high specific energy storage are the key } \\
\text { enablers for operating cost benefits. With the } \\
\text { current limitation of the battery technology, } \\
\text { there is a need for a break-through improvement } \\
\text { to gain operation cost benefit. } \\
\text {-Uncertainity quantification and error esimation } \\
\text { techniques are highly desired for the design } \\
\text { roboustness and in idnetifying the suitable } \\
\text { technology parameter for the components }\end{array}$} \\
\hline Turboelectric & $\begin{array}{l}\text {-It has a little promise for } \\
\mathrm{CO}_{2} \text { emission reduction. }\end{array}$ & $\begin{array}{l}\text {-Advanced engine } \\
\text { technology complies with } \\
\text { the current ICAO } \\
\text { standards and meet the } \\
\text { NOx reduction targets for } \\
\text { the future timeframe. }\end{array}$ & $\begin{array}{l}\text {-Gives impact of noise } \\
\text { shielding if the propulsors } \\
\text { are embedded in the wing. } \\
\text {-Electrical motors are } \\
\text { quieter in operation } \\
\text { compared to fan. } \\
\text {-It enables an effective } \\
\text { high BPR design, without } \\
\text { increasing the fan speed. } \\
\text { Hence benefits from lower } \\
\text { acoustic impacts. }\end{array}$ & $\begin{array}{l}\text {-Impact huge capital cost } \\
\text { to the airliner due to the } \\
\text { additional components. } \\
\text {-The fuel burn cost } \\
\text { reduction to compensate } \\
\text { for the additional } \\
\text { capital cost. }\end{array}$ & \\
\hline Hybrid Electric & $\begin{array}{l}\text {-The ground-based energy } \\
\text { sources should have fewer } \\
\text { emissions to claim for net } \\
\mathrm{CO}_{2} \text { benefits. }\end{array}$ & $\begin{array}{l}\text {-Gives opportunity for } \\
\text { NOx emission reduction, } \\
\text { however it shows a } \\
\text { trade-off with fuel } \\
\text { consumption. }\end{array}$ & $\begin{array}{l}\text {-Gives impact of noise } \\
\text { shielding if the propulsors } \\
\text { are embedded in the wing. } \\
\text {-A commuter aircraft with } \\
\text { electrical motor driven } \\
\text { variable pitch propeller } \\
\text { gives low noise operation } \\
\text { at the take-off, however, } \\
\text { gets penalty for higher } \\
\text { take-off field } \\
\text { length/climb rate. }\end{array}$ & $\begin{array}{l}\text {-The cost parity is } \\
\text { dependent on higher } \\
\text { degree of hybridization } \\
\text { and high specific } \\
\text { energy/cycle life in } \\
\text { the battery. } \\
\text {-Beneficial in shorter } \\
\text { range and for higher } \\
\text { specific energy. }\end{array}$ & \\
\hline
\end{tabular}


The current development in the aviation sector has a potential to revolutionize the existing business model to migrate to an electrified propulsion based operation. With an achievable battery specific energy of $500 \mathrm{Wh} / \mathrm{kg}$, a niche market exists for fully/hybrid electric aircraft that can replace the regional segment turboprop aircraft in the PAX 19-50 segments in short-haul range of 300-600 nm. This is primarily possible due to high operational costs of these turboprop planes and the acceptable technology level of the existing battery technology to cater to this size and range segment. The turboelectric configurations which are majorly targeted for large passenger aircraft need significant improvement in the propulsion technology related to BLI fans, airframe technology, and in the electrical drivetrain efficiency $(95 \%-98 \%)$ to make the concept viable.

The authors' projection for the hybrid electric/fully electric aircraft penetration into the market is presented in Table 10.

Table 10. Payload/range projection for fully/hybrid electric aircraft.

\begin{tabular}{ccc}
\hline Battery SE-Cell Level in Wh/kg & Hybrid Electric (Segment/Range) & Fully Electric (Segment/Range) \\
\hline 250 & 2-3 PAX, 200 nm & 6-10 PAX, 300-600 nm \\
\hline 400 & 19 PAX, 500 nm 30 PAX, 400 nm & 19 PAX, 400 nm 50-70 PAX, 300 nm \\
\hline 500 & $50-70$ PAX, 500 nm & 30 PAX, 500 nm 50-70 PAX, 400 nm \\
\hline
\end{tabular}

\subsection{Safety, Regulatory, Certification Procedure}

Under the assumption that the developments in electrical technology (for battery and power electronics) are likely to mature enough to enable the hybrid electric aircraft or even fully electric aircraft operations feasibly in the foreseeable future, the industry needs to look out for suitable regulation and certification standards. This move would boost the revenue potential and encourage new entrants in the aviation sector. The noticeable and key change made by Federal Aviation Administration (FAA) and European Union Aviation Safety Agency (EASA) allows the use of non-conventional engines in the general aviation sector.

Such forward looking regulations are expected to facilitate commercial implementation of these new concepts. The regulations also should keep abreast with the market and technological evolution, which would act as a further enabler for the overall electric aircraft development.

It is envisioned that the new electric aircraft operation concepts would have significant impacts on the airline operations, existing ground handling procedures, and airport/ electrical grid infrastructure and thus, needs increased attention. The current engine test procedure under ICAO certification standards, safety analysis procedure entails modification to accommodate nuances of electric aircraft operation.

With the exception of few, the assessment reports made so far did not include many of the safety, reliability, and aircraft operating environment constraint considerations. It is envisaged that the small-scale flight demonstrators like X-57 Maxwell, E-Fan X, and LEAPTech would lead the path for the future electrification of the aviation sector with the benchmarking of standards and certification processes.

Sufficient advancement is made in exploring the key technology areas of electric aircraft operation, however, the challenges still remains to make a transition of these technologies to a commercial product. Therefore, a continuous research investment and industry support across the breadth of technology is needed to make it realizable. Such efforts are to be suitably corroborated by working towards eliminating various regulatory and certification barriers. While it is good to assess the scope of energy storage technologies, electrical and thermal components' development for projected future technology, and operational efficiency through improved mission cycles, it is even more important to ascertain the feasibility of an all-electric or hybrid electric aircraft, based on the current technology scenario. To postpone the developments to future and to look for alternatives in 15-30 years' time may not be the best bet, since it would mean many unforeseen challenges to be solved additionally in future (those are 
not imagined currently), when the technology is ready. Close follow up on the market evolution would ensure that the technology and research investments are made in the products whose market potentials are imminent. Philosophically speaking, the technology developments in each individual piece of engineering research are always incremental, except for specific material discoveries that go on to become a game changer in many application areas. Therefore, significant research effort must be devoted to investigating what can be done to the electric propulsion solutions, with the evolutionary technology development. Then only can it satisfy the vision of successful, viable and cleaner future aviation demands, meeting all the safety, reliability, and certification criteria, and in the process, to realize the environmental goals.

Author Contributions: S.S. and K.K. outlined the article, S.S. wrote the manuscript, X.Z. and K.K. reviewed the article. All authors have read and approved the manuscript.

Funding: This work has received funding support from Clean Sky 2 Joint Undertaking under European Union's Horizon 2020 research and innovation programs HECARRUS in grant agreement number 865089 and TRADE in grant agreement number 755458 .

Conflicts of Interest: The authors declare no conflict of interest.

\section{Abbreviations}

\begin{tabular}{|c|c|}
\hline ACARE & Advisory Council for Aeronautical Research in Europe \\
\hline AFRC & Armstrong Flight Research Center \\
\hline ANPC & Active Neutral Point Clamped \\
\hline BHL & Bauhaus Luftfahrt \\
\hline BDFM & Brushless Doubly-Fed Machine \\
\hline BED & Battery Energy Density \\
\hline BL & Boundary layer \\
\hline BLI & Boundary Layer Ingestion \\
\hline BPR & Bypass Ratio \\
\hline BWB & Blended Wing Body \\
\hline CAEP & ICAO Aviation Environmental Protection \\
\hline CAS & Convergent Aeronautics Solution \\
\hline CENTRELINE & Concept Validation Study for Fuselage Wake filling Propulsion Integration \\
\hline CESTOL & Cruise Efficient Short Take-off and Landing \\
\hline CFD & Computational Fluid Dynamic \\
\hline CNT & Carbon Nanotube \\
\hline COSAR & Cost-Specific Air Range \\
\hline CSV & Constant Voltage Level \\
\hline CTOL & Conventional Take-off and Landing \\
\hline DEP & Distributed Electric Propulsion \\
\hline DLR & Deutsches Zentrum fuer Luft- und Raumfahrt/German Aerospace Center \\
\hline DOC & Direct Operating Cost \\
\hline $\mathrm{DP}$ & Distributed propulsion \\
\hline DRAGON & Distributed fans Research Aircraft with electric Generators by ONERA \\
\hline EASA & European Union Aviation Safety Agency \\
\hline ECO-150 & Environmentally Conscious 150 \\
\hline EDF & Electrical Ducted Fan \\
\hline $\mathrm{EP}$ & Electric Propulsion \\
\hline ESAR & Energy Specific Air Range \\
\hline EVA & Environmental Assessment Framework \\
\hline EVE & Electrically Variable Engine \\
\hline EWL & Energy Transformation in Aviation \\
\hline FAA & Federal Aviation Administration \\
\hline FAR & Federal Aviation Regulations \\
\hline FAST & Fixed wing Aircraft Sizing Tool \\
\hline FCMC & Flying Capacitor Multilevel Converter \\
\hline
\end{tabular}




\begin{tabular}{|c|c|}
\hline FET & Field Effect Transistors \\
\hline FLOPS & Flight Optimization System \\
\hline $\mathrm{GaN}$ & Gallium Nitride \\
\hline GRC & Glenn Research Centre \\
\hline GT-HEAT & Georgia Tech Hybrid Electric Analysis \\
\hline $\mathrm{HCB}$ & Hybrid Circuit Breaker \\
\hline HEDP & Hybrid Electric Distributed Propulsion \\
\hline HAPSS & Hybrid Aircraft Propulsion System Synthesis \\
\hline HEIST & Hybrid-Electric Integrated Systems Test Bed \\
\hline HTS & High-Temperature Superconductor \\
\hline IASP & Integrated Aircraft Study Platform \\
\hline IATA & International Air Transport Association \\
\hline $\mathrm{ICAO}$ & International Civil Aviation Organization \\
\hline IGBT & Insulated-Gate Bipolar Transistor \\
\hline IM & Induction Machine \\
\hline IOC & Initial Operational Capability \\
\hline KPP & Key Performance Parameter \\
\hline LEAPTech & Leading Edge Asynchronous Propellers Technology \\
\hline LDI & Lean Direct Injection \\
\hline $\mathrm{Li}$-air/O $\mathrm{O}_{2}$ & Lithium Air/Oxygen \\
\hline Li-Ion & Lithium Ion \\
\hline Li-S & Lithium Sulfur \\
\hline LPP & Lean Premix Pre-Vaporized \\
\hline LTO & Landing and Take-off \\
\hline MDO & Multidisciplinary Optimization \\
\hline $\mathrm{MgB}_{2}$ & Magnesium Diboride \\
\hline MOSFET & Metal oxide semiconductor field effect transistor \\
\hline MPC & Model Predicative Control \\
\hline MTOW/M & Maximum Take-off Weight/Mass \\
\hline MW & Megawatt \\
\hline MYSTIC & Multidisciplinary Sizing Tool for Integrated Concepts \\
\hline NAE & National Academies of Sciences Medicine and Engineering \\
\hline NASA & National Aeronautics and Space Administration \\
\hline $\mathrm{NbTi}$ & Nobium Titanium \\
\hline NEAT & NASA Electric Aircraft Testbed \\
\hline $\mathrm{Ni}-\mathrm{Cd}$ & Nickel Cadmium \\
\hline NPSS & Numerical Propulsion System Simulation \\
\hline NRA & NASA Research Announcement \\
\hline OEI & One Engine Inoperating \\
\hline OPR & Overall Pressure Ratio \\
\hline PANTHER & Propulsion Airframe Integration for Hybrid Electric Research \\
\hline PATI & Propulsion-Airframe-Thermal Integration \\
\hline PAX & Passenger Capacity \\
\hline PEGASUS & Parallel Electric-Gas Architecture with Synergistic Utilization Scheme \\
\hline PMSM & Permanent Magnet Synchronous Machine \\
\hline RCE & Remote Control Environment \\
\hline RQL & Rich-burn Quick quench-lean Burn \\
\hline RRNA & Rolls-Royce North America \\
\hline RTAPS & Research and Technology for Aerospace Propulsion \\
\hline SAR & Specific Air Range \\
\hline SCEPTOR & Scalable Convergent Electric Propulsion Technology Operation Research \\
\hline SE & Specific Energy \\
\hline SFC & Specific Fuel Consumption \\
\hline SFW & Subsonic Fixed Wing \\
\hline SHAPSO & Systematic Hybrid Aircraft Power Schedule Optimizer \\
\hline $\mathrm{Si}-\mathrm{C}$ & Silicon Carbide \\
\hline
\end{tabular}




$\begin{array}{ll}\text { SOA } & \text { State-of-the-Art } \\ \text { SOFC } & \text { Solid Oxide Fuel Cell } \\ \text { SP } & \text { Specific Power } \\ \text { SRM } & \text { Switched-Reluctance Machine } \\ \text { SSCB } & \text { Solid State Circuit Breaker } \\ \text { SUAVE } & \text { Stanford University of Aerospace Vehicle Environment } \\ \text { SUGAR } & \text { Subsonic Ultra Green Aircraft Research } \\ \text { TASOPT } & \text { Transport Aircraft System Optimization } \\ \text { TeDP } & \text { Turboelectric Distributed Propulsion } \\ \text { TMS } & \text { Thermal Management System } \\ \text { TOGW } & \text { Take-off Gross Weight } \\ \text { TRADE } & \text { Turboelectric Aircraft Development Environment } \\ \text { TRL } & \text { Technology Readiness Level } \\ \text { UESA } & \text { Universally Electric Systems Architecture } \\ \text { UTRC } & \text { United Technology Research Center } \\ \text { WFSM } & \text { Wound Field Synchronous Machine } \\ \text { VSC } & \text { Voltage Source Converter } \\ \text { VSV } & \text { Variable System Voltage } \\ \text { VTOL } & \text { Vertical Take-off and Landing } \\ \text { YBaCuO } & \text { Yttrium Barium Copper Oxide } \\ & \end{array}$

\section{References}

1. Airbus. Global Market Forecast: Cities, Airports \& Aircraft 2019-2038, Report 2019. Available online: https://www.airbus.com/aircraft/market/global-market-forecast.html (accessed on 15 January 2020).

2. Boeing. Commercial Market Outlook 2019-2038. 2019. Available online: https://www.boeing.com/ commercial/market/commercial-market-outlook/ (accessed on 15 January 2020).

3. IATA. Aircraft Technology Roadmap to 2050. 2019. Available online: https://www.iata.org/contentassets/ 8d19e716636a47c184e7221c77563c93/technology20roadmap20to20205020no20foreword.pdf (accessed on 20 January 2020).

4. Busquin, P.; Arguelles, P.; Lumsden, J.; Bishoff, M. European Aeronautics: A Vision for 2020; European Community: Bruxelles, Belgium, 2001.

5. European Commission. Flightpath 2050: Europe's Vision for Aviation-Report of the High Level Group on Aviation Research. In Report of the High Level Group on Aviation Research; European Commission: Luxembourg, 2011. Available online: https://ec.europa.eu/transport/sites/transport/files/modes/air/doc/flightpath2050.pdf (accessed on 20 January 2020).

6. NASA. Strategic Implementation Plan 2017 Update, NP-2017-01-2352-HQ. 2017. Available online: https: //www.nasa.gov/sites/default/files/atoms/files/sip-2017-03-23-17-high.pdf (accessed on 15 January 2020).

7. Ashcraft, S.W.; Padron, A.S.; Pascioni, K.A.; Stout, G.W., Jr.; Huff, D.L. Review of Propulsion Technologies for N+ 3 Subsonic Vehicle Concepts; NASANASA/TM-2011-217239; NASA Glenn Research Center: Cleveland, OH, USA, 2011.

8. Hepperle, M. Electric Flight-Potential and Limitations, Presented at the Energy Efficient Technologies and Concepts of Operation, Lisbon, Portugal. 2012. Available online: https://elib.dlr.de/78726/ (accessed on 8 August 2019).

9. Moore, M.D. Misconceptions of Electric Aircraft and their Emerging Aviation Markets. In Proceedings of the 52nd Aerospace Sciences Meeting, National Harbor, MD, USA, 13-17 January 2014; p. 0535.

10. Mavris, D.N.; Pfaender, H.; Jimenez, H.; Garcia, E.; Feron, E.; Bernardo, J. Application of Strategic Planning Process with Fleet Level Analysis Methods; NASA Langley Research Center: Hampton, VA, USA, 2016.

11. Jansen, R.; Bowman, C.; Jankovsky, A.; Dyson, R.; Felder, J. Overview of NASA Electrified Aircraft Propulsion (EAP) Research for Large Subsonic Transports. In Proceedings of the 53rd AIAA/SAE/ASEE Joint Propulsion Conference, Atlanta, GA, USA, 10-12 July 2017; p. 4701. 
12. Bowman, C.L.; Felder, J.L.; Marien, T.V. Turbo-and Hybrid-Electrified Aircraft Propulsion Concepts for Commercial Transport. In Proceedings of the 2018 AIAA/IEEE Electric Aircraft Technologies Symposium (EATS), Cincinnati, OH, USA, 12-14 July 2018; pp. 1-8.

13. Gnadt, A.R.; Speth, R.L.; Sabnis, J.S.; Barrett, S.R. Technical and environmental assessment of all-electric 180-passenger commercial aircraft. Prog. Aerosp. Sci. 2019, 105, 1-30. [CrossRef]

14. Brelje, B.J.; Martins, J.R. Electric, hybrid, and turboelectric fixed-wing aircraft: A review of concepts, models, and design approaches. Prog. Aerosp. Sci. 2019, 104,1-19. [CrossRef]

15. Weimer, J.A. The role of electric machines and drives in the more electric aircraft. In Proceedings of the IEEE International Electric Machines and Drives Conference, 2003. IEMDC'03, Madison, WI, USA, 1-4 June 2003; Volume 1, pp. 11-15.

16. Stückl, S.; van Toor, J.; Lobentanzer, H. VOLTAIR-the all electric propulsion concept platform-a vision for atmospheric friendly flight. In Proceedings of the 28th International Congress of the Aeronautical Sciences (ICAS), Brisbane, Australia, 23-28 September 2012.

17. Vratny, P.C.; Forsbach, P.; Seitz, A.; Hornung, M. Investigation of universally electric propulsion systems for transport aircraft. In Proceedings of the 29th International Congress of the Aeronautical Sciences, St. Petersburg, Russia, 7-12 September 2014.

18. Duffy, K.P.; Jansen, R.H. Turboelectricand Hybrid Electric Aircraft Drive Key Performance Parameters. In Proceedings of the 2018 AIAA/IEEE Electric Aircraft Technologies Symposium (EATS), Cincinnati, OH, USA, 12-14 July 2018; pp. 1-19.

19. NAE. Commercial Aircraft Propulsion and Energy Systems Research: Reducing Global Carbon Emissions; The National Academies Press: Washington, DC, USA, 2016; Available online: https://www.nap.edu/catalog/ 23490/commercial-aircraft-propulsion-and-energy-systems-research-reducing-global-carbon (accessed on 15 October 2019)ISBN 978-0-309-44096-7.

20. Jansen, R.; Brown, G.V.; Felder, J.L.; Duffy, K.P. Turboelectric aircraft drive key performance parameters and functional requirements. In Proceedings of the 51st AIAA/SAE/ASEE Joint Propulsion Conference, Orlando, FL, USA, 27-29 July 2015; p. 3890.

21. Jansen, R.; Duffy, K.P.; Brown, G. Partially turboelectric aircraft drive key performance parameters. In Proceedings of the 53rd AIAA/SAE/ASEE Joint Propulsion Conference, Atlanta, GA, USA, 10-12 July 2017; p. 4702.

22. Felder, J.; Tong, M.; Chu, J. Sensitivity of mission energy consumption to turboelectric distributed propulsion design assumptions on the N3-X hybrid wing body aircraft. In Proceedings of the 48th AIAA/ASME/SAE/ASEE Joint Propulsion Conference \& Exhibit, Atlanta, GA, USA, 30 July-1 August 2012; p. 3701.

23. Kim, H.D.; Felder, J.L.; Tong, M.T.; Berton, J.J.; Haller, W.J. Turboelectric distributed propulsion benefits on the N3-X vehicle. Aircr. Eng. Aerosp. Technol. Int. J. 2014, 86, 558-561. [CrossRef]

24. Felder, J.L.; Brown, G.V.; DaeKim, H.; Chu, J. Turboelectric Distributed Propulsion in a Hybrid Wing Body Aircraft. Proceedings of 20th International Society for Airbreathing Engines (ISABE 2011), Gothenburg, Sweden, 12-16 September 2011.

25. Welstead, J.; Felder, J.; Guynn, M.; Haller, B.; Tong, M.; Jones, S.; Ordaz, I.; Quinlan, J.; Mason, B. Overview of the NASA STARC-ABL (Rev. B) Advanced Concept. In Proceedings of the Boeing NASA Electric Aircraft Workshop, Washington, DC, USA, 22 March 2017.

26. Welstead, J.; Felder, J.L. Conceptual design of a single-aisle turboelectric commercial transport with fuselage boundary layer ingestion. In Proceedings of the 54th AIAA Aerospace Sciences Meeting, San Diego, CA, USA, 4-8 January 2016; p. 1027.

27. Bradley, M.; Droney, C. Subsonic Ultra Green Aircraft Research Phase II: $n+4$ Advanced Concept Development; CR-2012-2175562012; NASA: Washington, DC, USA, 2012.

28. Schiltgen, B.T.; Freeman, J. Aeropropulsive interaction and thermal system integration within the ECO-150: A turboelectric distributed propulsion airliner with conventional electric machines. In Proceedings of the 16th AIAA Aviation Technology, Integration, and Operations Conference, Washington, DC, USA, 13-17 June 2016; p. 4064.

29. Bradley, M.K.; Droney, C.K. Subsonic Ultra Green Aircraft Research: Phase 2. Volume 2; Hybrid Electric Design Exploration; NASA Langley Research Center: Hampton, VA, USA, 2015. 
30. Perullo, C.; Mavris, D.N. Assessment of Vehicle Performance Using Integrated NPSS Hybrid Electric Propulsion Models. In Proceedings of the 50th AIAA/ASME/SAE/ASEE Joint Propulsion Conference, Cleveland, OH, USA, 28-30 July 2014; p. 3489.

31. Lents, C.E.; Hardin, L.W.; Rheaume, J.; Kohlman, L. Parallel Hybrid Gas-Electric Geared Turbofan Engine Conceptual Design and Benefits Analysis. In Proceedings of the 52nd AIAA/SAE/ASEE Joint Propulsion Conference, Washington, DC, USA, 13-17 June 2016; p. 4610.

32. Zhao, X.; Sahoo, S.; Kyprianidis, K.; Rantzer, J.; Sielemann, M. Off-design performance analysis of hybridised aircraft gas turbine. Aeronaut. J. 2019, 123, 1999-2018. [CrossRef]

33. Sahoo, S.; Zhao, X.; Kyprianidis, K.G.; Kalfas, A. Performance Assessment of an Integrated Parallel Hybrid-Electric Propulsion System Aircraft. In Proceedings of the ASME Turbo Expo 2019: Turbomachinery Technical Conference and Exposition, Phoenix, AZ, USA, 17-21 June 2019.

34. Hoelzen, J.; Liu, Y.; Bensmann, B.; Winnfeld, C.; Elham, A.; Friedrichs, J.; Rauschenbach, R.H. Conceptual Design of Operation Strategies for Hybrid Electric Aircraft. Energies 2018, 11, 217. [CrossRef]

35. Lents, C.E.; Hardin, L.W. Fuel Burn and Energy Consumption Reductions of a Single-Aisle Class Parallel Hybrid Propulsion System. In Proceedings of the AIAA Propulsion and Energy 2019 Forum, Indianapolis, IN, USA, 19-22 August 2019; p. 4396.

36. Rheaume, J.M.; MacDonald, M.; Lents, C.E. Commercial Hybrid Electric Aircraft Thermal Management System Design, Simulation, and Operation Improvements. In Proceedings of the AIAA Propulsion and Energy 2019 Forum, Indianapolis, IN, USA, 19-22 August 2019; p. 4492.

37. Trawick, D.; Perullo, C.; Armstrong, M.; Tai, J.; Mavris, D. Development and Application of GT-HEAT to the design of the Electrically Variable Engine. In Proceedings of the 55th AIAA Aerospace Sciences Meeting, Grapevine, TX, USA, 9-13 January 2017.

38. Gladin, J.C.; Trawick, D.; Mavris, D.N.; Armstrong, M.J.; Bevis, D.; Klein, K. Fundamentals of Parallel Hybrid Turbofan Mission Analysis with Application to the Electrically Variable Engine. In Proceedings of the 2018 AIAA/IEEE Electric Aircraft Technologies Symposium, Cincinnati, Ohio, USA, 9-11 July 2018; p. 5024.

39. Perullo, C.; Trawick, D.; Armstrong, M.; Tai, J.C.; Mavris, D.N. Cycle Selection and Sizing of a Single-Aisle Transport with the Electrically Variable Engine (TM) (EVE) for Fleet Level Fuel Optimization. In Proceedings of the 55th AIAA Aerospace Sciences Meeting, Grapevine, TX, USA, 9-13 January 2017; p. 1923.

40. Pornet, C.; Kaiser, S.; Isikveren, A.T.; Hornung, M. Integrated fuel-battery hybrid for a narrow-body sized transport aircraft. Aircr. Eng. Aerosp. Technol. Int. J. 2014, 86, 568-574. [CrossRef]

41. Zhao, X.; Sahoo, S.; Kyprianidis, K.; Sumsurooah, S.; Valente, G.; Rashed, M.; Vakil, M.; Hill, C.; Jacob, C.; Gobbin, A.; et al. A framework for optimization of hybrid aircraft. In Proceedings of the ASME Turbo Expo 2019: Turbomachinery Technical Conference and Exposition, GT 2019, 17-21 June 2019.

42. Antcliff, K.R.; Guynn, M.D.; Marien, T.; Wells, D.P.; Schneider, S.J.; Tong, M.J. Mission Analysis and Aircraft Sizing of a Hybrid-Electric Regional Aircraft. In Proceedings of the 54th AIAA Aerospace Sciences Meeting, San Diego, CA, USA, 4-8 January 2016; p. 1028.

43. Antcliff, K.R.; Capristan, F.M. Conceptual Design of the Parallel Electric-Gas Architecture with Synergistic Utilization Scheme (PEGASUS) Concept. In Proceedings of the 18th AIAA/ISSMO Multidisciplinary Analysis and Optimization Conference, Denver, CO, USA, 5-9 June 2017; p. 4001.

44. Pornet, C.; Isikveren, A. Conceptual design of hybrid-electric transport aircraft. Prog. Aerosp. Sci. 2015, 79, 114-135. [CrossRef]

45. Strack, M.; Chiozzotto, G.P.; Iwanizki, M.; Plohr, M.; Kuhn, M. Conceptual Design Assessment of Advanced Hybrid Electric Turboprop Aircraft Configurations. In Proceedings of the 17th AIAA Aviation Technology, Integration, and Operations Conference, Denver, CO, USA, 5-9 June 2017; p. 3068.

46. Epstein, A.H.; O'Flarity, S.M. Considerations for Reducing Aviation's $\mathrm{CO}_{2}$ with Aircraft Electric Propulsion. J. Propuls. 2019, 35, 572-582. [CrossRef]

47. Wick, A.T.; Hooker, J.R.; Zeune, C.H. Integrated aerodynamic benefits of distributed propulsion. In Proceedings of the 53rd AIAA Aerospace Sciences Meeting, Kissimmee, FL, USA, 5-9 January 2015; p. 1500.

48. Rolt, A.; Whurr, J. Optimizing Propulsive Efficiency in Aircraft with Boundary Layer Ingesting Distributed Propulsion. In Proceedings of the 22nd International Symposium on Air Breathing Engines, Phoenix, AZ, USA, 25-30 October 2015; pp. 25-30. 
49. Kim, H.; Berton, J.; Jones, S. Low noise cruise efficient short take-off and landing transport vehicle study. In Proceedings of the 6th AIAA Aviation Technology, Integration and Operations Conference (ATIO), Wichita, KS, 25-27 September 2006; p. 7738.

50. Kim, H.D.; Perry, A.T.; Ansell, P.J. A review of distributed electric propulsion concepts for air vehicle technology. In Proceedings of the 2018 AIAA/IEEE Electric Aircraft Technologies Symposium (EATS), Cincinnati, OH, USA, 12-14 July 2018; pp. 1-21.

51. Armstrong, M.J.; Ross, C.A.; Blackwelder, M.J.; Rajashekara, K. Trade studies for NASA N3-X turboelectric distributed propulsion system electrical power system architecture. SAE Int. J. Aerosp. 2012, 5, 325-336. [CrossRef]

52. Berton, J.J.; Haller, W.J. A noise and Emissions Assessment of the N3-X Transport. In Proceedings of the 52nd Aerospace Sciences Meeting, National Harbor, MD, USA, 13-17 January 2014; p. 0594.

53. Hornung, M.; Isikveren, A.T.; Cole, M.; Sizmann, A. Ce-Liner-Case Study for eMobility in Air Transportation. In Proceedings of the 2013 Aviation Technology, Integration, and Operations Conference, Los Angeles, CA, USA, 12-14 August 2013; p. 4302.

54. Hoogreef, M.; Vos, R.; de Vries, R.; Veldhuis, L.L. Conceptual Assessment of Hybrid Electric Aircraft with Distributed Propulsion and Boosted Turbofans. In Proceedings of the AIAA Scitech 2019 Forum, San Diego, CA, USA, 7-11 January 2019; p. 1807.

55. De Vries, R.; Brown, M.; Vos, R. Preliminary Sizing Method for Hybrid-Electric Distributed-Propulsion Aircraft. J. Aircr. 2019, 56, 2172-2188. [CrossRef]

56. Hermetz, J.; Ridel, M.; Doll, C. Distributed electric propulsion for small business aircraft a concept-plane for key-technologies investigations. In Proceedings of the International Council of Aeronautical Sciences (ICAS) 2016, Daejeon, South Korea, 25-30 Sep 2016.

57. Patterson, M.D.; Derlaga, J.M.; Borer, N.K. High-Lift Propeller System Configuration Selection for NASA's SCEPTOR Distributed Electric Propulsion Flight Demonstrator. In Proceedings of the 16th AIAA Aviation Technology, Integration, and Operations Conference, Washington, DC, USA, 13-17 June 2016; p. 3922.

58. Müller, L.; Heinze, W.; Kožulović, D.; Hepperle, M.; Radespiel, R. Aerodynamic installation effects of an over-the-wing propeller on a high-lift configuration. J. Aircr. 2014, 51, 249-258. [CrossRef]

59. Hoogreef, M.; de Vries, R.; Sinnige, T.; Vos, R. Synthesis of Aero-Propulsive Interaction Studies Applied to Conceptual Hybrid-Electric Aircraft Design. In Proceedings of the AIAA Scitech 2020 Forum, Orlando, FL, USA, 6-10 January 2020; p. 0503.

60. Marcus, E.A.; de Vries, R.; Kulkarni, A.R.; Veldhuis, L.L. Aerodynamic Investigation of an over-the-Wing Propeller for Distributed Propulsion. In Proceedings of the 2018 AIAA Aerospace Sciences Meeting, Kissimmee, FL, USA, 8-12 January 2018; p. 2053.

61. Schmollgruber, P.; Atinault, O.; Cafarelli, I.; Döll, C.; Francois, C.; Hermetz, J.; Liaboeuf, R.; Paluch, B.; Ridel, M. Multidisciplinary Exploration of DRAGON: An ONERA Hybrid Electric Distributed Propulsion Concept. In Proceedings of the AIAA Scitech 2019 Forum, San Diego, CA, USA, 7-11 January 2019; p. 1585.

62. Patterson, J.C., Jr.; Bartlett, G.R. Evaluation of Installed Performance of a Wing-Tip-Mounted Pusher Turboprop on a Semispan Wing; NASA Langley Research Center: Hampton, VA, USA, 1987.

63. Bijewitz, J.; Seitz, A.; Hornung, M.; Isikveren, A.T. Progress in optimizing the propulsive fuselage aircraft concept. J. Aircr. 2017, 54, 1979-1989. [CrossRef]

64. Stoll, A.M. Comparison of CFD and experimental results of the LEAPTech distributed electric propulsion blown wing. In Proceedings of the15th AIAA Aviation Technology, Integration, and Operations Conference, Dallas, TX, USA, 22-26 June 2015; p. 3188.

65. Borer, N.K.; Patterson, M.D.; Viken, J.K.; Moore, M.K.; Bevirt, J.; Stoll, A.M.; Gibson, A.R. Design and performance of the NASA SCEPTOR distributed electric propulsion flight demonstrator. In Proceedings of the16th AIAA Aviation Technology, Integration, and Operations Conference, Washington, DC, USA, 13-17 June 2016; p. 3920.

66. Thauvin, J.; Barraud, G.; Budinger, M.; Roboam, X.; Leray, D.; Sareni, B. Hybrid regional aircraft: A comparative review of new potentials enabled by electric power. In Proceedings of the 52nd AIAA/SAE/ASEE Joint Propulsion Conference, Salt Lake City, UT, USA, 25-27 July 2016; p. 4612.

67. Steiner, H.J.; Vratny, P.C.; Gologan, C.; Wieczorek, K.; Isikveren, A.T.; Hornung, M. Optimum number of engines for transport aircraft employing electrically powered distributed propulsion. CEAS Aeronaut. J. 2014, 5, 157-170. [CrossRef] 
68. Klunk, G.T.; Freeman, J.L. Vertical Tail Area Reduction for Aircraft with Spanwise Distributed Electric Propulsion. In Proceedings of the 2018 AIAA/IEEE Electric Aircraft Technologies Symposium, Cincinnati, OH, USA, 9-11 July 2018; p. 5022.

69. Gohardani, A.S.; Doulgeris, G.; Singh, R. Challenges of future aircraft propulsion: A review of distributed propulsion technology and its potential application for the all electric commercial aircraft. Prog. Aerosp. Sci. 2011, 47, 369-391. [CrossRef]

70. Borer, N.K.; Moore, M.D. Integrated propeller-wing design exploration for distributed propulsion concepts. In Proceedings of the 53rd AIAA Aerospace Sciences Meeting, Kissimmee, FL, USA, 5-9 January 2015; p. 1672.

71. Berton, J.J.; Nark, D.M. Low-Noise Operating Mode for Propeller-Driven Electric Airplanes. J. Aircr. 2019, 56, 1708-1714. [CrossRef]

72. Huff, D.L.; Henderson, B.S.; Envia, E. Motor noise for electric powered aircraft. In Proceedings of the 22nd AIAA/CEAS Aeroacoustics Conference, Lyon, France, 30 May-1 June 2016; p. 2882.

73. Bijewitz, J.; Seitz, A.; Isikveren, A.T.; Hornung, M. Multi-disciplinary design investigation of propulsive fuselage aircraft concepts. Aircr. Eng. Aerosp. Technol. Int. J. 2016, 88, 257-267. [CrossRef]

74. Hardin, L.; Tillman, G.; Sharma, O.; Berton, J.; Arend, D. Aircraft system study of boundary layer ingesting propulsion. In Proceedings of the 48th AIAA/ASME/SAE/ASEE Joint Propulsion Conference \& Exhibit, Atlanta, GA, USA, 30 July-1 August 2012; p. 3993.

75. Seitz, A.; Peter, F.; Bijewitz, J.; Habermann, A.; Goraj, Z.; Kowalski, M.; Pardo, A.J.; Hall, C.; Meller, F. Concept validation study for fuselage wake-filling propulsion integration. In Proceedings of the 31st Congress of the International Council of the Aeronautical Sciences, Belo Horizonte, Brazil, 9-14 September 2018; pp. 9-14.

76. Hileman, J.; Spakovszky, Z.; Drela, M.; Sargeant, M.; Jones, A. Airframe design for silent fuel-efficient aircraft. J. Aircr. 2010, 47, 956-969. [CrossRef]

77. Hall, D.K.; Huang, A.C.; Uranga, A.; Greitzer, E.M.; Drela, M.; Sato, S. Boundary Layer Ingestion Propulsion Benefit for Transport Aircraft. J. Propuls. Power 2017, 33, 1118-1129. [CrossRef]

78. Uranga, A.; Drela, M.; Greitzer, E.M.; Titchener, N.A.; Lieu, M.K.; Siu, N.M.; Huang, A.C.; Gatlin, G.M. Preliminary experimental assessment of the boundary layer ingestion benefit for the D8 aircraft. In Proceedings of the 52nd Aerospace Sciences Meeting, Hannon, National Harbor, MD, USA, 13-17 January 2014; p. 0906.

79. Plas, A.; Sargeant, M.A.; Madani, V.; Crichton, D.; Greitzer, E.M.; Hynes, T.P.; Hall, C.A. Performance of a boundary layer ingesting (BLI) propulsion system. In Proceedings of the 45th AIAA Aerospace Sciences Meeting and Exhibit, Reno, NV, USA, 8-11 January 2007; p. 450.

80. Kawai, R.T.; Friedman, D.M.; Serrano, L. Blended Wing Body (BWB) Boundary Layer Ingestion (BLI) Inlet Configuration and System Studies, NASA/CR-2006-214534. 2006. Available online: https://ntrs.nasa.gov/ archive/nasa/casi.ntrs.nasa.gov/20070006754.pdf (accessed on 15 October 2019).

81. Smith, L.H. Wake ingestion propulsion benefit. J. Propuls. Power 1993, 9, 74-82. [CrossRef]

82. Bijewitz, J.; Seitz, A.; Hornung, M.; eV, B.L. A review of recent aircraft concepts employing synergistic propulsion-airframe integration. In Proceedings of the 30th Congress of the International Council of the Aeronautical Sciences, ICAS, Daejeon, Korea, 25-30 September 2016.

83. Gray, J.S.; Martins, J.R. Coupled aeropropulsive design optimisation of a boundary-layer ingestion propulsor. Aeronaut. J. 2019, 123, 121-137. [CrossRef]

84. Gladin, J.C.; Trawick, D.; Perullo, C.; Tai, J.C.; Mavris, D.N. Modeling and design of a Partially electric distributed aircraft propulsion system with GT-HEAT. In Proceedings of the 55th AIAA Aerospace Sciences Meeting, Grapevine, TX, USA, 9-13 January 2017; p. 1924.

85. Florea, R.V.; Voytovych, D.; Tillman, T.G.; Stucky, M.; Shabbir, A.; Sharma, O.P.; Arend, D.J. Aerodynamic analysis of a boundary-layer-ingesting distortion-tolerant fan. In Proceedings of the ASME Turbo Expo 2013: Turbine Technical Conference and Exposition, San Antonio, TX, USA, 3-7 June 2013.

86. NASA Glenn Research Center: Boundary Layer Ingestion Propulsion Concept Undergoing High-Speed Testing in the NASA Glenn $8^{\prime} \times 6^{\prime}$ Wind Tunnel. Available online: https://www1.grc.nasa.gov/aeronautics/bli/ (accessed on 22 January 2020). 
87. Ang, A.; Rao, A.G.; Kanakis, T.; Lammen, W. Performance analysis of an electrically assisted propulsion system for a short-range civil aircraft. Proc. Inst. Mech. Eng. Part G J. Aerosp. Eng. 2019, 233, 1490-1502. [CrossRef]

88. Airbus. E-Thrust: A Concept for Future E-Aircraft Propulsion. Available online: https://www.airbus.com/ innovation/future-technology/electric-flight.html (accessed on 15 January 2020).

89. Danis, R.A.; Freeman, J.L.; Schiltgcn, B.T. Applications for Hybrid Electric Power and Energy Supplementation on a Single-Aisle Airliner. In Proceedings of the 2018 AIAA/IEEE Electric Aircraft Technologies Symposium (EATS), Cincinnaati, OH, USA, 9-11 July 2018; pp. 1-19.

90. Trawick, D.R. A Methodology for the Determination of Optimal Operational Schedules of Hybrid Electric Architectures. Ph. D. Thesis, Georgia Institute of Technology, Atlanta, GA, USA, 2018.

91. Zhu, Q.; Forsyth, A.; Todd, R. Investigation of Hybrid Electric Aircraft Operation on Battery Degradation. In Proceedings of the 2018 IEEE International Conference on Electrical Systems for Aircraft, Railway, Ship Propulsion and Road Vehicles \& International Transportation Electrification Conference (ESARS-ITEC), Nottingham, UK, 7-9 November 2018; pp. 1-6.

92. Kyprianidis, K.G.; Dahlquist, E. On the trade-off between aviation NOx and energy efficiency. Appl. Energy 2017, 185, 1506-1516. [CrossRef]

93. Ommi, F.; Azimi, M. Most effective combustion technologies for reducing Nox emissions in aero gas turbines. Int. J. Multiphys. 2016, 6, 417-424. [CrossRef]

94. Graham, W.R.; Hall, C.A.; Morales, M.V. The potential of future aircraft technology for noise and pollutant emissions reduction. Transp. Policy 2014, 34, 36-51. [CrossRef]

95. International Energy Agency. World Energy Statistics 2016; 9264261478; OECD: Paris, France, 2016.

96. Hassan, M.; Pfaender, H.; Mavris, D.N. Feasibility Analysis of Aviation CO2 Emission Goals under Uncertainty. In Proceedings of the 17th AIAA Aviation Technology, Integration, and Operations Conference, Denver, CO, USA, 5-9 June 2017; p. 3267.

97. Marien, T.V.; Antcliff, K.R.; Guynn, M.D.; Wells, D.P.; Schneider, S.J.; Tong, M.; Trani, A.A.; Hinze, N.K.; Dollyhigh, S.M. Short-Haul Revitalization Study Final Report; NASA/TM-2018-219833; NASA Langley Research Center: Hampton, VA, USA, 2018.

98. Harish, A.; Perron, C.; Bavaro, D.; Ahuja, J.; Ozcan, M.; Justin, C.Y.; Briceno, S.; German, B.J.; Mavris, D.N. Economics of advanced thin-haul concepts and operations. In Proceedings of the 16th AIAA Aviation Technology, Integration, and Operations Conference, Washington, DC, USA, 13-17 June 2016; p. 3767.

99. Seitz, A.; Schmitz, O.; Isikveren, A.T.; Hornung, M. Electrically Powered Propulsion: Comparison and Contrast to Gas Turbines; Deutsche Gesellschaft für Luft-und Raumfahrt-Lilienthal-Oberth eV: Bonn, Germany, 2012.

100. Pornet, C.; Kaiser, S.; Gologan, C. Cost-based flight technique optimization for hybrid energy aircraft. Aircr. Eng. Aerosp. Technol. Int. J. 2014, 86, 591-598. [CrossRef]

101. Lorenz, L.; Seitz, A.; Kuhn, H.; Sizmann, A. Hybrid Power Trains for Future Mobility; Deutsche Gesellschaft für Luft-und Raumfahrt-Lilienthal-Oberth eV: Bonn, Germany, 2014.

102. Isikveren, A.T.; Kaiser, S.; Pornet, C.; Vratny, P.C. Pre-design strategies and sizing techniques for dual-energy aircraft. Aircr. Eng. Aerosp. Technol. Int. J. 2014, 86, 525-542. [CrossRef]

103. Isikveren, A.T.; Pornet, C.; Vratny, P.C.; Schmidt, M. Optimization of Commercial Aircraft Using Battery-Based Voltaic-Joule/Brayton Propulsion. J. Aircr. 2016, 246-261. [CrossRef]

104. Isikveren, A.T.; Seitz, A.; Vratny, P.C.; Pornet, C.; Plötner, K.O.; Hornung, M. Conceptual studies of universally-electric systems architectures suitable for transport aircraft. In Deutscher Luft-Und Raumfahrt Kongress; DLRK: Berlin, Germany, 2012.

105. Dever, T.P.; Duffy, K.P.; Provenza, A.J.; Loyselle, P.L.; Choi, B.B.; Morrison, C.R.; Lowe, A.M. Assessment of Technologies for Noncryogenic Hybrid Electric Propulsion; NASA Glenn Research Center: Cleveland, OH, USA, 2015.

106. Bradley, M.K.; Droney, C.K. Subsonic Ultra Green Aircraft Research: Phase I Final Report; National Aeronautics and Space Administration, Langley Research Center: Hampton, VA, USA, 2011.

107. Loder, D.C.; Bollman, A.; Armstrong, M.J. Turbo-electric Distributed Aircraft Propulsion: Microgrid Architecture and Evaluation for ECO-150. In Proceedings of the 2018 IEEE Transportation Electrification Conference and Expo (ITEC), Long Beach, CA, USA, 13-15 June 2018; pp. 550-557.

108. Goldberg, C.; Nalianda, D.; Pilidis, P.; Singh, R. Economic Viability Assessment of NASA's Blended Wing Body N3-X Aircraft. In Proceedings of the 53rd AIAA/SAE/ASEE Joint Propulsion Conference, Atlanta, GA, USA, 10-12 July 2017; p. 4604. 
109. Dubois, A.; van der Geest, M.; Bevirt, J.; Clarke, S.; Christie, R.J.; Borer, N.K. Design of an Electric Propulsion System for SCEPTOR's Outboard Nacelle. In Proceedings of the 16th AIAA Aviation Technology, Integration, and Operations Conference, Washington, DC, USA, 13-17 June 2016.

110. Schnulo, S.L.; Chin, J.; Smith, A.; Paul-Dubois-Taine, A. Steady State Thermal Analyses of SCEPTOR X-57 Wingtip Propulsion. In Proceedings of the 17th AIAA Aviation Technology, Integration, and Operations Conference, Denver, CO, USA, 5-9 June 2017; p. 3783.

111. Iwanizki, M.; Arzberger, M.; Plohr, M.; Silberhorn, D.; Hecken, T. Conceptual Design Studies of Short Range Aircraft Configurations with Hybrid Electric Propulsion. In Proceedings of the AIAA Aviation 2019 Forum, Dallas, TX, USA, 17-21 June 2019; p. 3680.

112. Liu, Y.; Elham, A.; Horst, P.; Hepperle, M. Exploring vehicle level benefits of revolutionary technology progress via aircraft design and optimization. Energies 2018, 11, 166. [CrossRef]

113. Lammen, W.; Vankan, J. Energy Optimization of Single Aisle Aircraft with Hybrid Electric Propulsion. In Proceedings of the AIAA Scitech 2020 Forum, Orlando, FL, USA, 6-10 January2020; p. 0505.

114. Lammen, W.; Vankan, W. Electrification studies of single aisle aircraft: A 'retrofit'investigation including parallel hybrid electric propulsion. In Proceedings of the International Symposium on Sustainable Aviation, Budapest, Hungary, 26-29 May 2019; pp. 26-29.

115. Vankan, W.; Lammen, W. Parallel hybrid electric propulsion architecture for single aisle aircraft-powertrain investigation. Proceedings of 9th the EASN conference, Athens, Greece, 3-6 September 2019.

116. Voskuijl, M.; van Bogaert, J.; Rao, A.G. Analysis and design of hybrid electric regional turboprop aircraft. CEAS Aeronaut. J. 2018, 9, 15-25. [CrossRef]

117. Zamboni, J.; Vos, R.; Emeneth, M.; Schneegans, A. A method for the conceptual design of hybrid electric aircraft. In Proceedings of the AIAA Scitech 2019 Forum, San Diego, CA, USA, 7-11 January 2019; p. 1587.

118. Hecken, T.; Zhao, X.; Iwanizki, M.; Arzberger, M.J.; Silbergorn, D.; Plohr, M.; Kyprianidis, K.; Sahoo, S.; Sumsurooah, S.; Valente, G.; et al. Conceptual Design Studies of "Boosted Turbofan" Configuration for short range. In Proceedings of the AIAA Scitech 2020 Forum, Orlando, FL, USA, 6-10 January 2020; p. 0506.

119. Felder, J.; Kim, H.; Brown, G. Turboelectric distributed propulsion engine cycle analysis for hybrid-wing-body aircraft. In Proceedings of the 47th AIAA Aerospace Sciences Meeting Including the New Horizons Forum and Aerospace Exposition, Orlando, FL, USA, 5-9 January 2009; p. 1132.

120. Williamson, M. Air power the rise of electric aircraft. Eng. Technol. 2014, 9, 77-79. [CrossRef]

121. Pornet, C.; Gologan, C.; Vratny, P.C.; Seitz, A.; Schimtz, O.; Isikveren, A.T.; Hornung, M. Methodology for sizing and performance assessment of hybrid energy aircraft. J. Aircr. 2014, 52, 341-352. [CrossRef]

122. Vratny, P.C.; Hornung, M. Sizing Considerations of an Electric Ducted Fan for Hybrid Energy Aircraft. Transp. Res. Procedia 2018, 29, 410-426. [CrossRef]

123. Gladin, J.C.; Perullo, C.; Tai, J.C.; Mavris, D.N. A Parametric Study of Hybrid Electric Gas Turbine Propulsion as a Function of Aircraft Size Class and Technology Level. In Proceedings of the 55th AIAA Aerospace Sciences Meeting, Grapevine, TX, USA, 9-13 January 2017; p. 0338.

124. Bertrand, P.; Spierling, T.; Lents, C.E. Parallel Hybrid Propulsion System for a Regional Turboprop: Conceptual Design and Benefits Analysis. In Proceedings of the AIAA Propulsion and Energy 2019 Forum, Indianapolis, IN, USA, 19-22 August 2019; p. 4466.

125. De Vries, M.H.R.; Vos, R. Aero-Propulsive Efficiency Requirements for Turboelectric Transport Aircraft. In Proceedings of the AIAA Scitech 2020 Forum, AIAA Scitech 2020 Forum, Orlando, FL, USA, 6-10 January 2020.

126. Isikveren, A.T.; Fefermann, Y.; Maury, C.; Level, C.; Zarati, K.; Salane, J.P.; Pornet, C.; Thoraval, B. Pre-design of a commuter transport utilising Voltaic-Joule/Brayton motive power systems. Aeronaut. J. 2018, 122, $205-237$. [CrossRef]

127. Gesell, H.; Wolters, F.; Plohr, M. System analysis of turbo-electric and hybrid-electric propulsion systems on a regional aircraft. Aeronaut. J. 2019, 123, 1602-1617. [CrossRef]

128. Gemin, P.; Kupiszewski, T.; Radun, A. Architecture, Voltage, and Components for a Turboelectric Distributed Propulsion Electric Grid (AVC-TeDP); NASA/CR-2015-218713; NASA Glenn Research Center: Cleveland, OH, USA, 2015.

129. Kyprianidis, K. An Approach to Multi-Disciplinary Aero Engine Conceptual Design. In Proceedings of the International Symposium on Air Breathing Engines, ISABE 2017, Manchester, UK, 3-7 September 2017; Paper No. ISABE-2017-22661. 
130. Smith, J.; Batish, P.; Brandt, S.; Morton, S. A student developed sizing methodology for electric powered aircraft applied to small UAVs. In Proceedings of the 2000 World Aviation Conference, San Diego, CA, USA, 10-12 October 2000; p. 5536.

131. Lückhof, J.; Stumpf, E. Performance Estimation of Different UAV-Configurations in Preliminary Design. In Proceedings of the 66. Deutscher Luft- und Raumfahrtkongress, Munich, Germany, DLRK, 5-7 September 2017.

132. Choi, T.; Soban, D.; Mavris, D. Creation of a design framework for all-electric aircraft propulsion architectures. In Proceedings of the 3rd International Energy Conversion Engineering Conference, San Francisco, CA, 15-18 August 2005; p. 5549.

133. Reynold, K. Trajectory optimization of a battery-powered competition aircraft. In Proceedings of the 51 st Aerospace Sciences Meeting, Dallas, TX, USA, 7-10 January 2013; AIAA-2013-1155.

134. Riboldi, C.E.; Gualdoni, F. An integrated approach to the preliminary weight sizing of small electric aircraft. Aerosp. Sci. Technol. 2016, 58, 134-149. [CrossRef]

135. Nam, T.; Soban, D.; Mavris, D. A generalized aircraft sizing method and application to electric aircraft. In Proceedings of the 3rd International Energy Conversion Engineering Conference, San Francisco, CA, USA, 15-18 August 2005; p. 5574.

136. Cinar, G.; Emeneth, M.; Mavris, D.N. A Methodology for Sizing and Analysis of Electric Propulsion Subsystems for Unmanned Aerial Vehicles. In Proceedings of the 54th AIAA Aerospace Sciences Meeting, San Diego, CA, USA, 4-8 January 2016; p. 0216.

137. Cinar, G.; Mavris, D.N.; Emeneth, M.; Schneegans, A.; Fefermann, Y. Development of parametric power generation and distribution subsystem models at the conceptual aircraft design stage. In Proceedings of the 55th AIAA Aerospace Sciences Meeting, Grapevine, TX, USA, 9-13 January 2017; p. 1182.

138. Cinar, G.; Mavris, D.N.; Emeneth, M.; Schneegans, A.; Riediger, C.; Fefermann, Y.; Isikveren, A. Sizing, integration and performance evaluation of hybrid electric propulsion subsystem architectures. In Proceedings of the 55th AIAA Aerospace Sciences Meeting, Grapevine, TX, USA, 9-13 January 2017; p. 1183.

139. Isikveren, A.T. Method of Quadrant-Based Algorithmic Nomographs for Hybrid/Electric Aircraft Predesign. J. Aircr. 2017, 55, 396-405. [CrossRef]

140. Riboldi, C.E.; Gualdoni, F.; Trainelli, L. Preliminary weight sizing of light pure-electric and hybrid-electric aircraft. Transp. Res. Procedia 2018, 29, 376-389. [CrossRef]

141. Finger, D.F.; Braun, C.; Bil, C. An initial sizing methodology for hybrid-electric light aircraft. In Proceedings of the 2018 Aviation Technology, Integration, and Operations Conference, Atlanta, GA, USA, 25-29 June 2018; p. 4229.

142. Finger, D.; Götten, F.; Braun, C.; Bil, C. Initial Sizing for a Family of Hybrid-Electric VTOL General Aviation Aircraft. Dtsch. Luft-Und Raumfahrtkongress DLRK 2018, 2018, 480102.

143. Finger, D.F.; Braun, C.; Bil, C. Comparative Assessment of Parallel-Hybrid-Electric Propulsion Systems for Four Different Aircraft. In Proceedings of the AIAA Scitech 2020 Forum, Orlando, FL, USA, 6-10 January 2020; p. 1502.

144. De Vries, R.; Brown, M.T.; Vos, R. A Preliminary Sizing Method for Hybrid-Electric Aircraft Including Aero-Propulsive Interaction Effects. In Proceedings of the 2018 Aviation Technology, Integration, and Operations Conference, Atlanta, GA, 25-26 June 2018; p. 4228.

145. Orefice, F.; della Vecchia, P.; Ciliberti, D.; Nicolosi, F. Aircraft Conceptual Design Including Powertrain System Architecture and Distributed Propulsion. In Proceedings of the AIAA Propulsion and Energy 2019 Forum, Indianapolis, IN, USA, 19-22 August 2019; p. 4465.

146. De Vries, R.; Hoogreef, M.; Vos, R. Preliminary Sizing of a Hybrid-Electric Passenger Aircraft Featuring over-the-Wing Distributed-Propulsion. In Proceedings of the AIAA Scitech 2019 Forum, San Diego, CA, USA, 7-11 January 2019; p. 1811.

147. Finger, D.F.; de Vries, R.; Vos, R.; Braun, C.; Bil, C. A Comparison of Hybrid-Electric Aircraft Sizing Methods. In Proceedings of the AIAA Scitech 2020 Forum, Orlando, FL, USA, 6-10 January 2020; p. 1006.

148. Perullo, C.A.; Trawick, D.R.; Mavris, D.N. Assessment of engine and vehicle performance using integrated hybrid-electric propulsion models. J. Propuls. Power 2016, 32, 1305-1314. [CrossRef]

149. Schnell, R.; Zhao, X.; Rallis, E.; Kavvalos, M.; Sahoo, S.; Schnoes, M.; Kyprianidis, K. Assessment of a Turbo-Electric Aircraft Configuration with Aft-Propulsion Using Boundary Layer Ingestion. Aerospace 2019, 6, 134. [CrossRef] 
150. Kyprianidis, K.G.; Quintero, R.F.C.; Pascovici, D.S.; Ogaji, S.O.; Pilidis, P.; Kalfas, A.I. EVA: A tool for environmental assessment of novel propulsion cycles. In Proceedings of the ASME Turbo Expo 2008: Power for Land, Sea, and Air, Berlin, Germany, 9-13 June 2008; pp. 547-556.

151. Perullo, C.; Mavris, D. A review of hybrid-electric energy management and its inclusion in vehicle sizing. Aircr. Eng. Aerosp. Technol. Int. J. 2014, 86, 550-557. [CrossRef]

152. Martins, J.R.; Lambe, A.B. Multidisciplinary design optimization: A survey of architectures. AIAA J. 2013, 51, 2049-2075. [CrossRef]

153. Brombach, J.; Lücken, A.; Nya, B.; Johannsen, M.; Schulz, D. Comparison of different electrical HVDC-architectures for aircraft application. In Proceedings of the Electrical Systems for Aircraft, Railway and Ship Propulsion (ESARS), Bologna, Italy, 16-18 October 2012; pp. 1-6.

154. Silva, H.L.; Guimarães, T.A. Conceptual Design of a Thin-Haul Aircraft by Energy Sizing Optimization Including Aero-Propulsive Interactions. In Proceedings of the AIAA Scitech 2020 Forum, Orlando, FL, USA, 6-10 January 2020; p. 1503.

155. Liu, C.; Doulgeris, G.; Laskaridis, P.; Singh, R. Thermal cycle analysis of turboelectric distributed propulsion system with boundary layer ingestion. Aerosp. Sci. Technol. 2013, 27, 163-170. [CrossRef]

156. Gray, J.; Moore, K.; Naylor, B. OpenMDAO: An open source framework for multidisciplinary analysis and optimization. In Proceedings of the 13th AIAA/ISSMO Multidisciplinary Analysis Optimization Conference, Fort Worth, TX, USA, 13-15 September 2010; p. 9101.

157. Falck, R.D.; Chin, J.; Schnulo, S.L.; Burt, J.M.; Gray, J.S. Trajectory optimization of electric aircraft subject to subsystem thermal constraints. In Proceedings of the 18th AIAA/ISSMO Multidisciplinary Analysis and Optimization Conference, Denver, CO, USA, 5-9 June 2017; p. 4002.

158. Falck, R.D.; Gray, J.S.; Naylor, B. Parallel aircraft trajectory optimization with analytic derivatives. In Proceedings of the 17th AIAA/ISSMO Multidisciplinary Analysis and Optimization Conference, Washington, DC, USA, 13-17 June 2016; p. 3207.

159. Hendricks, E.S.; Falck, R.D.; Gray, J.S. Simultaneous propulsion system and trajectory optimization. In Proceedings of the 18th AIAA/ISSMO Multidisciplinary Analysis and Optimization Conference, Denver, CO, USA, 5-9 June 2017; p. 4435.

160. Hendricks, E.S.; Gray, J.S. pyCycle: A Tool for Efficient Optimization of Gas Turbine Engine Cycles. Aerospace 2019, 6, 87. [CrossRef]

161. Sgueglia, A.; Schmollgruber, P.; Bartoli, N.; Morlier, J.; Benard, E.; Jasa, J.; Martins, J.R.R.A.; Hwang, J.T.; Gray, J.S. Multidisciplinary Design Optimization Framework with Coupled Derivative Computation for Hybrid Aircraft. J. Aircr. 2020. to be published.

162. Kruger, M.; Uranga, A. The Feasibility of Electric Propulsion for Commuter Aircraft. In Proceedings of the AIAA Scitech 2020 Forum, Orlando, FL, USA, 6-10 January 2020; p. 1499.

163. Brelje, B.J.; Martins, J.R. Development of a conceptual design model for aircraft electric propulsion with efficient gradients. In Proceedings of the 2018 AIAA/IEEE Electric Aircraft Technologies Symposium, Cincinnati, OH, USA, 9-11 July 2018; p. 4979.

164. Sgueglia, A.; Schmollgruber, P.; Bartoli, N.; Atinault, O.; Benard, E.; Morlier, J. Exploration and Sizing of a Large Passenger Aircraft with Distributed Ducted Electric Fans. In Proceedings of the 2018 AIAA Aerospace Sciences Meeting, Kissimmee, FL, USA, 8-12 January 2018; p. 1745.

165. Vegh, J.M.; Alonso, J.J.; Orra, T.H.; da Silva, C.I. Flight path and wing optimization of lithium-air battery powered passenger aircraft. In Proceedings of the 53rd AIAA Aerospace Sciences Meeting, Kissimmee, FL, USA, 5-9 January 2015; p. 1674.

166. Centracchio, F.; Rossetti, M.; Iemma, U. Approach to the Weight Estimation in the Conceptual Design of Hybrid-Electric-Powered Unconventional Regional Aircraft. J. Adv. Transp. 2018, 2018, 6320197. [CrossRef]

167. Ganesh, R.V. Design Optimization of a Regional Transport Aircraft with Hybrid Electric Distributed Propulsion Systems. Master's Thesis, Virginia Tech Electronic Theses and Dissertations (ETDs), Virginia Polytechnic Institute and State University, Blacsburg, VA, USA, 3 August 2018.

168. Drela, M. Design Drivers of energy-efficient transport aircraft. SAE Int. J. Aerosp. 2011, 4, 602-608. [CrossRef]

169. Armstrong, M.J.; Blackwelder, M.; Bollman, A.; Ross, C.; Campbell, A.; Jones, C.; Norman, P. Architecture, Voltage, and Components for a Turboelectric Distributed Propulsion Electric Grid-Final Report; NASA/CR-2015-218440; NASA Glenn Research Center: Cleveland, OH, USA, 2015. 
170. Masson, P.J.; Soban, D.S.; Upton, E.; Pienkos, J.E.; Luongo, C.A. HTS motors in aircraft propulsion: Design considerations. IEEE Trans. Appl. Supercond. 2005, 15, 2218-2221. [CrossRef]

171. Schiltgen, B.; Green, M.; Gibson, A.; Hall, D.; Cummings, D.; Hange, C. Benefits and concerns of hybrid electric distributed propulsion with conventional electric machines. In Proceedings of the 48th AIAA/ASME/SAE/ASEE Joint Propulsion Conference \& Exhibit, Atlanta, GA, USA, 30 July-1 August 2012; p. 3769.

172. Raimondi, G.; Sawata, T.; Holme, M.; Barton, A. Aircraft embedded generation systems. In Proceedings of the 2002 International Conference on Power Electronics, Machines and Drives, Sante Fe, NM, USA, 4-7 June 2002; Conf. Publ. No. 487; pp. 217-222.

173. Avery, C.; Burrow, S.; Mellor, P. Electrical generation and distribution for the more electric aircraft. In Proceedings of the 42nd International Universities Power Engineering Conference, Brighton, UK, 4-6 September 2007; pp. 1007-1012.

174. Nya, B.; Brombach, J.; Schulz, D. Benefits of higher voltage levels in aircraft electrical power systems. In Proceedings of the Electrical Systems for Aircraft, Railway and Ship Propulsion (ESARS), Bologna, Italy, 16-18 October 2012; pp. 1-5.

175. Zhao, X.; Guerrero, J.M.; Wu, X. Review of aircraft electric power systems and architectures. In Proceedings of the 2014 IEEE International Energy Conference (ENERGYCON), Cavtat, Croatia, 13-16 May 2014; pp. 949-953.

176. Jansen, R.; Bowman, C.; Jankovsky, A. Sizing power components of an electrically driven tail cone thruster and a range extender. In Proceedings of the 16th AIAA Aviation Technology, Integration, and Operations Conference, Washington, DC, USA, 13-17 June 2016; p. 3766.

177. Sadey, D.J.; Taylor, L.; Beach, R. Proposal and development of a high voltage variable frequency alternating current power system for hybrid electric aircraft. In Proceedings of the 14th International Energy Conversion Engineering Conference, Salt Lake City, UT, USA, 25-27 July 2016; p. 4928.

178. Armstrong, M.J.; Blackwelder, M.; Ross, C. Sensitivity of TeDP Microgrid System Weight and Efficiency to Operating Voltage. In Proceedings of the 50th AIAA/ASME/SAE/ASEE Joint Propulsion Conference, Cleveland, OH, USA, 28-30 July 2014; p. 3492.

179. Perullo, C.A.; Trawick, D.; Clifton, W.; Tai, J.C.; Mavris, D.N. Development of a suite of hybrid electric propulsion modeling elements using NPSS. In Proceedings of the ASME Turbo Expo 2014: Turbine Technical Conference and Exposition, Düsseldorf, Germany, 16-20 June 2014; p. 01AT01A042.

180. Vratny, P.C.; Kuhn, H.; Hornung, M. Influences of voltage variations on electric power architectures for hybrid electric aircraft. CEAS Aeronaut. J. 2017, 8, 31-43. [CrossRef]

181. Schweickart, D.L.; Horwath, J.C.; Hatfield, L.L.; Krompholz, H.; Walko, L.C. The relevancy of environmental parameter space for electrical insulation design in aerospace vehicles. In Proceedings of the Conference Record of the Twenty-Sixth International Power Modulator Symposium, 2004 and 2004 High-Voltage Workshop, San Francisco, CA, USA, 23-26 May 2004; pp. 30-33.

182. Cotton, I.; Nelms, A.; Husband, M. Higher voltage aircraft power systems. IEEE Aerosp. Electron. Syst. Mag. 2008, 23, 25-32. [CrossRef]

183. Jones, C.E.; Norman, P.J.; Galloway, S.J.; Armstrong, M.J.; Bollman, A.M. Comparison of candidate architectures for future distributed propulsion aircraft. IEEE Trans. Appl. Supercond. 2016, 26, 1-9. [CrossRef]

184. Duffy, K.P. Electric Motors for Non-Cryogenic Hybrid Electric Propulsion. In Proceedings of the 51st AIAA/SAE/ASEE Joint Propulsion Conference, Orlando, FL, USA, 27-29 July 2015; p. 3891.

185. Green, M.; Schiltgen, B.; Gibson, A. Analysis of a distributed hybrid propulsion system with conventional electric machines. In Proceedings of the 48th AIAA/ASME/SAE/ASEE Joint Propulsion Conference \& Exhibit, Atlanta, GA, USA, 30 July-1 August 2012; p. 3768.

186. Biser, S.; Wortmann, G.; Ruppert, S.; Filipenko, M.; Noe, M.; Boll, M. Predesign Considerations for the DC Link Voltage Level of the CENTRELINE Fuselage Fan Drive Unit. Aerospace 2019, 6, 126. [CrossRef]

187. Kempkes, M.; Roth, I.; Gaudreau, M. Solid-state circuit breakers for medium voltage DC power. In Proceedings of the 2011 IEEE Electric Ship Technologies Symposium, Alexandria, VA, USA, 10-13 April 2011; pp. $254-257$.

188. Armstrong, M.; Ross, C.; Phillips, D.; Blackwelder, M. Stability, Transient Response, Control, and Safety of a High-Power Electric Grid for Turboelectric Propulsion of Aircraft; Rolls-Royce North American Technologies, Inc.-Liberty Works: Indianapolis, IN, USA, 2013. 
189. Shaw, J.C.; Fletcher, S.; Norman, P.; Galloway, S.; Burt, G. Failure Analysis of a Turboelectric Distributed Propulsion Aircraft Electrical Network: A Case Study; SAE Technical Paper0148-7191; SAE International in United States: Warrendale, PA, USA, 2015.

190. Armstrong, M.J.; Ross, C.A.; Blackwelder, M.J.; Rajashekara, K. Propulsion system component considerations for NASA N3-X turboelectric distributed propulsion system. SAE Int. J. Aerosp. 2012, 5, 344-353. [CrossRef]

191. Haran, K.S.; Kalsi, S.; Arndt, T.; Karmaker, H.; Badcock, R.; Buckley, B.; Haugan, T.; Izumi, M.; Loder, D.; Bray, J.W. High power density superconducting rotating machines-Development status and technology roadmap. Supercond. Sci. Technol. 2017, 30, 123002. [CrossRef]

192. Ganev, E. High-performance electric drives for aerospace more electric architectures part I-Electric machines. In Proceedings of the 2007 IEEE Power Engineering Society General Meeting, Tampa, FL, USA, 24-28 June 2007; pp. 1-8.

193. Ganev, E. Selecting the Best Electric Machines for Electrical Power-Generation Systems: High-performance solutions for aerospace More electric architectures. IEEE Electrif. Mag. 2014, 2, 13-22. [CrossRef]

194. Jansen, R.; Jesus-Arce, Y.D.; Kascak, P.; Dyson, R.W.; Woodworth, A.; Scheidler, J.J.; Edwards, R.; Stalcup, E.J.; Wilhite, J.; Duffy, K.P.; et al. High Efficiency Megawatt Motor Conceptual Design. In Proceedings of the 2018 Joint Propulsion Conference, Cincinnati, OH, USA, 9-11 July 2018; p. 4699.

195. Masson, P.J.; Brown, G.V.; Soban, D.S.; Luongo, C.A. HTS machines as enabling technology for all-electric airborne vehicles. Supercond. Sci. Technol. 2007, 20, 748. [CrossRef]

196. Luongo, C.A.; Masson, P.J.; Nam, T.; Mavris, D.; Kim, H.D.; Brown, G.V.; Waters, M.; Hall, D. Next generation more-electric aircraft: A potential application for HTS superconductors. IEEE Trans. Appl. Supercond. 2009, 19, 1055-1068. [CrossRef]

197. Brown, G. Weights and efficiencies of electric components of a turboelectric aircraft propulsion system. In Proceedings of the 49th AIAA aerospace sciences meeting including the new horizons forum and aerospace exposition, Orlando, FL, USA, 4-7 January 2011; p. 225.

198. Nick, W.; Nerowski, G.; Neumuller, H.W.; Frank, M.; Hasselt, P.V.; Frauenhofer, J.; Steinmeyer, F. 380 kW synchronous machine with HTS rotor windings-Development at Siemens and first test results. Phys. C Supercond. Appl. 2002, 372, 1506-1512. [CrossRef]

199. Scheidler, J.J.; Tallerico, T.; Miller, W.A.; Torres, W. Progress Toward the Critical Design of the Superconducting Rotor for NASA's 1.4 MW High-Efficiency Electric Machine. In Proceedings of the AIAA Propulsion and Energy 2019 Forum, Indianapolis, IN, USA, 19-22 August 2019; p. 4496.

200. Yoon, A.; Yi, X.; Martin, J.; Chen, Y.; Haran, K. A high-speed, high-frequency, air-core PM machine for aircraft application. In Proceedings of the 2016 IEEE Power and Energy Conference at Illinois (PECI), Urbana, IL, USA, 19-20 February 2016; pp. 1-4.

201. Zhang, X.; Haran, K.S. High-specific-power electric machines for electrified transportation applications-technology options. In Proceedings of the 2016 IEEE Energy Conversion Congress and Exposition (ECCE), Milwaukee, WI, USA, 18-22 September 2016; pp. 1-8.

202. Zhang, X.; Bowman, C.L.; O'Connell, T.C.; Haran, K.S. Large electric machines for aircraft electric propulsion. IET Electr. Power Appl. 2018, 12, 767-779. [CrossRef]

203. Van der Geest, M.; Polinder, H.; Ferreira, J.A.; Christmann, M. Power density limits and design trends of high-speed permanent magnet synchronous machines. IEEE Trans. Transp. Electrif. 2015, 1, $266-276$. [CrossRef]

204. Anderson, A.D.; Renner, N.J.; Wang, Y.; Agrawal, S.; Sirimanna, S.; Lee, D.; Banerjee, A.; Haran, K.; Starr, M.J.; Felder, J.L. System weight comparison of electric machine topologies for electric aircraft propulsion. In Proceedings of the 2018 AIAA/IEEE Electric Aircraft Technologies Symposium (EATS), Cincinnati, OH, USA, 12-14 July 2018; pp. 1-16.

205. Rucker, J.E.; Kirtley, J.L.; McCoy, T.J. Design and analysis of a permanent magnet generator for naval applications. In Proceedings of the IEEE Electric Ship Technologies Symposium, Philadelphia, PA, USA, 27-27 July 2005; pp. 451-458.

206. Anton, D.F. eAircraft: Hybrid-Elektrische Antriebe für Luftfahrzeuge, 14th ed.; Tag der Deutschen Luft-und Raumfahrtregionen: Potsdam, Germany; Siemens AG: Berlin, Germany, 2019.

207. Baik, S.; Kwon, Y.; Kim, H.M.; Sangjin, K.; Lee, J.D.; Kim, Y.C.; Park, H.J.; Kwon, W.S.; Park, G.S. Electrical parameter evaluation of a 1 MW HTS motor via analysis and experiments. Cryogenics 2009, 49, 271-276. [CrossRef] 
208. Dyson, R.W.; Passe, P.; Duffy, K.P.; Jansen, R. High Efficiency Megawatt Motor Rotating Cryocooler Conceptual Design. In Proceedings of the AIAA Propulsion and Energy 2019 Forum, Indianapolis, IN, USA, 19-22 August 2019; p. 4515.

209. Gieras, J.F. Multimegawatt synchronous generators for airborne applications: A review. In Proceedings of the 2013 International Electric Machines \& Drives Conference, Chicago, IL, USA, 12-15 May 2013; pp. 626-633.

210. Sanchez, R.; Yoon, A.; Yi, X.; Chen, Y.; Zheng, L.; Haran, K. Mechanical validation of a high power density external cantilevered rotor. IEEE Trans. Ind. Appl. 2018, 54, 3208-3216. [CrossRef]

211. Pyrhonen, J.; Nerg, J.; Kurronen, P.; Lauber, U. High-speed, 8 MW, solid-rotor induction motor for gas compression. In Proceedings of the 2008 18th International Conference on Electrical Machines, Vilamoura, Portugal, 6-9 September 2008; pp. 1-6.

212. Pyrhonen, J.; Nerg, J.; Kurronen, P.; Lauber, U. High-speed high-output solid-rotor induction-motor technology for gas compression. IEEE Trans. Ind. Electron. 2009, 57, 272-280. [CrossRef]

213. Hennessy, M.J. Lightweight, Efficient Power Converters for Advanced Turboelectric Aircraft Propulsion Systems; MTECH Laboratories: LLC, Ballston Lake, NY, USA, 2014.

214. Han, D.; Noppakunkajorn, J.; Sarlioglu, B. Analysis of a SiC three-phase voltage source inverter under various current and power factor operations. In Proceedings of the IECON 2013-39th Annual Conference of the IEEE Industrial Electronics Society, Vienna, Austria, 10-13 November 2013; pp. 447-452.

215. Han, D.; Noppakunkajorn, J.; Sarlioglu, B. Comprehensive efficiency, weight, and volume comparison of $\mathrm{SiC}$-and Si-based bidirectional DC-DC converters for hybrid electric vehicles. IEEE Trans. Veh. Technol. 2014, 63, 3001-3010. [CrossRef]

216. Kicin, S.; Traub, F.; Hartmann, S.; Bianda, E.; Bernhard, C.; Skibin, S.; Canales, F. A new concept of a high-current power module allowing paralleling of many $\mathrm{SiC}$ devices assembled exploiting conventional packaging technologies. In Proceedings of the 2016 28th International Symposium on Power Semiconductor Devices and ICs (ISPSD), Prague, Czech, 12-16 June 2016; pp. 467-470.

217. Han, D.; Ogale, A.; Li, S.; Li, Y.; Sarlioglu, B. Efficiency characterization and thermal study of GaN based $1 \mathrm{~kW}$ inverter. In Proceedings of the 2014 IEEE Applied Power Electronics Conference and Exposition-APEC 2014, Fort Worth, TX, USA, 16-20 March 2014; pp. 2344-2350.

218. Gammeter, C.; Krismer, F.; Kolar, J.W. Weight and efficiency analysis of switched circuit topologies for modular power electronics in MEA. In Proceedings of the IECON 2016-42nd Annual Conference of the IEEE Industrial Electronics Society, Florence, Italy, 23-26 October 2016; pp. 3640-3647.

219. Zhang, D.; He, J.; Pan, D. A Megawatt-Scale Medium-Voltage High-Efficiency High Power Density "SiC $+\mathrm{Si}$ " Hybrid Three-Level ANPC Inverter for Aircraft Hybrid-Electric Propulsion Systems. IEEE Trans. Ind. Appl. 2019, 55, 5971-5980. [CrossRef]

220. A Guide to Understanding Battery Specifications; MIT Electric Vehicle Team: December 2008. Available online: https://web.mit.edu/evt/summary_battery_specifications.pdf (accessed on 15 January 2020).

221. Rheaume, J.M.; Lents, C. Energy Storage for Commercial Hybrid Electric Aircraft; SAE Technical Paper 2016-01-2014; SAE International in United States: Warrendale, PA, USA, 2016.

222. Stoia, T.; Balan, C.; Atreya, S.; O'Neil, P. Solid Oxide Fuel Cell-Steam Reformation Power System Configuration Options for an All-Electric Commuter Airplane Flight Demonstrator. In Proceedings of the 2018 Aviation Technology, Integration, and Operations Conference, Atlanta, GA, USA, 25-29 June 2018; p. 3358.

223. Papathakis, K.V.; Schnarr, O.C.; Lavelle, T.M.; Borer, N.K.; Stoia, T.; Atreya, S. Integration Concept for a Hybrid-Electric Solid-Oxide Fuel Cell Power System into the X-57 Maxwell. In Proceedings of the 2018 Aviation Technology, Integration, and Operations Conference, Atlanta, GA, USA, 25-29 June 2018; p. 3359.

224. Van Wensveen, J.; Peter, F.; Rau, T.; Hornung, M. Assessment of a Fuel Cell Powered Full Electric Subsystem Architecture for the Avacon Research Baseline Aircraft. In Proceedings of the German Aerospace Congress 2019, Darmstad, Germany, 30 September-2 October 2019.

225. Dean, T.; Wroblewski, G.E.; Ansell, P.J. Mission Analysis and Component-Level Sensitivity Study of Hybrid-Electric General Aviation Propulsion Systems. In Proceedings of the 2018 AIAA Aerospace Sciences Meeting, Kissimmee, FL, USA, 8-12 January 2018; p. 1749.

226. Christen, T.; Carlen, M.W. Theory of Ragone plots. J. Power Sources 2000, 91, 210-216. [CrossRef]

227. Misra, A. Summary of 2017 NASA Workshop on Assessment of Advanced Battery Technologies for Aerospace Applications. In Proceedings of the 2018 SciTech Forum, Kissimmee, FL, USA, 8-12 January 2018. 
228. Kuhn, H.; Seitz, A.; Lorenz, L.; Isikveren, A.T.; Sizmann, A. Progress and perspectives of electric air transport. In Proceedings of the 28th International Congress of the International Council of the Aeronautical Sciences ICAS, Brisbane, Australia, 23-28 September 2012; Volume 6.

229. Misra, A. Energy Storage for Electrified Aircraft: The Need for Better Batteries, Fuel Cells, and Supercapacitors. IEEE Electrif. Mag. 2018, 6, 54-61. [CrossRef]

230. Song, M.-K.; Zhang, Y.; Cairns, E.J. A long-life, high-rate lithium/sulfur cell: A multifaceted approach to enhancing cell performance. Nano Lett. 2013, 13, 5891-5899. [CrossRef]

231. Bruce, P.G.; Freunberger, S.A.; Hardwick, L.J. Li-O $\mathrm{O}_{2}$ and Li-S batteries with high energy storage. Nat. Mater. 2012, 11, 19-29. [CrossRef]

232. Gerssen-Gondelach, S.J.; Faaij, A.P. Performance of batteries for electric vehicles on short and longer term. J. Power Sources 2012, 212, 111-129. [CrossRef]

233. Nagata, H.; Chikusa, Y. All-Solid-State Lithium-Sulfur Battery with High Energy and Power Densities at the Cell Level. Energy Technol. 2016, 4, 484-489. [CrossRef]

234. Johnson, L. The viability of high specific energy lithium air batteries. In Proceedings of the Symposium on Research Opportunities in Electrochemical Energy Storage-Beyond Lithium Ion: Materials Perspectives, Oak Ridge National Laboratory, TN, USA, 7-8 October 2010.

235. Wild, M.; Neill, L.O.; Zhang, T.; Purkayastha, R.; Minton, G.; Marinescu, M.; Offer, G.J. Lithium sulfur batteries, a mechanistic review. Energy Environ. Sci. 2015, 8, 3477-3494. [CrossRef]

236. Kraytsberg, A.; Ein-Eli, Y. Review on Li-air batteries-Opportunities, limitations and perspective. J. Power Sources 2011, 196, 886-893. [CrossRef]

237. Kellermann, H.; Habermann, A.; Vratny, P.; Hornung, M. Assessment of fuel as alternative heat sink for future aircraft. Appl. Therm. Eng. 2020, 170, 114985. [CrossRef]

238. Newman, R.W.; Dooley, M.; Lui, C. Efficient propulsion, power, and thermal management integration. In Proceedings of the 49th AIAA/ASME/SAE/ASEE Joint Propulsion Conference, San Jose, CA, USA, 14-17 July 2013; p. 3681.

239. Northcutt, B.; Mudawar, I. Enhanced design of cross-flow microchannel heat exchanger module for high-performance aircraft gas turbine engines. J. Heat Transf. 2012, 134, 061801. [CrossRef]

240. Liu, J.; Peck, J.; Yazawa, K.; Fisher, T.S.; Shih, T.I. Bypass, Loss, and Heat Transfer in Aircraft Surface Coolers. Front. Mech. Eng. 2019, 5, 46. [CrossRef]

241. Freeman, J.; Osterkamp, P.; Green, M.; Gibson, A.; Schiltgen, B. Challenges and opportunities for electric aircraft thermal management. Aircr. Eng. Aerosp. Technol. Int. J. 2014, 86, 519-524. [CrossRef]

242. Brelje, B.J.; Jasa, J.P.; Martins, J.R.; Gray, J.S. Development of a Conceptual-Level Thermal Management System Design Capability in OpenConcept. NATO, RTO-EN-AVT-195, vol. 1001, p. 48109. Available online: http://openmdao.org/pubs/NATO_AVT-323-22_Brelje.pdf (accessed on 10 March 2020).

243. Van Heerden, A.S.; Judt, D.M.; Lawson, C.P.; Jafari, S.; Nikolaidis, T.; Bosak, D. Framework for integrated dynamic thermal simulation of future civil transport aircraft. In Proceedings of the AIAA SciTech 2020 Forum, Orlando, FL, USA, 6-10 January 2020; p. 1942.

244. Annapragada, S.R.; Macdonald, M.; Sur, A.; Mahmoudi, R.; Lents, C. Hybrid Electric Aircraft Battery Heat Acquisition System. In Proceedings of the 2018 AIAA/IEEE Electric Aircraft Technologies Symposium (EATS), Cincinnati, OH, USA, 12-14 July 2018; pp. 1-13.

245. Dyson, R.W. Novel Thermal Energy Conversion Technologies for Advanced Electric Air Vehicles. In Proceedings of the 2018 AIAA/IEEE Electric Aircraft Technologies Symposium (EATS), Cincinnati, OH, USA, 12-14 July 2018; pp. 1-14.

246. Dyson, R. NASA Electric Aircraft Test bed (NEAT) Development Plan-Design, Fabrication, Installation; NASA/TM-2016-219085, 2016; NASA Glenn Research Center, Cleveland, OH, USA, July 2016. Available online: https://ntrs.nasa.gov/archive/nasa/casi.ntrs.nasa.gov/20160010440.pdf (accessed on 15 January 2020).

247. Chen, Z.; Fielding, J.P. A zonal safety analysis methodology for preliminary aircraft systems and structural design. Aeronaut. J. 2018, 122, 1330-1351. [CrossRef] 
248. Flynn, M.-C.; Jones, C.; Norman, P.; Galloway, S. Fault management strategies and architecture design for turboelectric distributed propulsion. In Proceedings of the 2016 International Conference on Electrical Systems for Aircraft, Railway, Ship Propulsion and Road Vehicles \& International Transportation Electrification Conference (ESARS-ITEC), Toulouse, France, 2-4 November 2016; pp. 1-6.

249. Alrashed, M.; Nikolaidis, T.; Pilidis, P.; Jafari, S. Turboelectric Uncertainty Quantification and Error Estimation in Numerical Modelling. Appl. Sci. 2020, 10, 1805. [CrossRef]

(C) 2020 by the authors. Licensee MDPI, Basel, Switzerland. This article is an open access article distributed under the terms and conditions of the Creative Commons Attribution (CC BY) license (http://creativecommons.org/licenses/by/4.0/). 